\title{
EFEITO DO N, P e K NA DISPONIBILIDADE DO $Z n$ NO SOLO E NA SUA CONCENTRAÇÃO NA PARTE AÉREA DO FEIJOEIRO
}

\author{
SALATIÉR BUZETTI
}

Orientador: Dr. TAKASHI MURAOKA

\footnotetext{
Dissertação apresentada à Escola

Superior de Agricultura "Luiz de Queiroz", da Universidade de São Paulo, para obtenção do título de Mestre em Agronomia. Área de Concentração: Solos $\theta$ Nutrição de Plantas,
}

PIRACICABA

Estado de São Paulo - Brasil

Novembro - 1984 
A minha familia:

Egydio (in memorian)

Diolina, Laerte, Adelaide, Ana Angélica,

Selma, Marco, Damião, Märio, Benedita,

Damiana, AZexandre e Ana Paula

ofereço

$\bar{\AA}$

Wilma e Bruno

Dedico 


\section{AGRADECIMENTOS}

- O autor agradece a todos que colaboraram para a realização deste trabalho e em especial às seguintes pessoas e instituições:

- Ao orientador e amigo Dr. Takashi Muraoka pelo bom convivio, apoio e orientação segura ao longo deste trabalho.

- Aos Srs. José Roberto Martins, João Odemir Salvador, Dacir Bortoletto, Marileuza Aparecida Bassi, Sandra T.P. dos San tos, Aparecida Calegaro, Lurdes Aparecida Dário, lolanda A. Ruffini, Fátima Patreze, Lenita M.C. Pacheco e Sandra Genaro Nicolleti, pelos auxilios na parte técnica.

- Aos Professores Dr. Dilermando Perecin, Gener Tadeu Perei ra, Walter Veriano Valério Filho, Marco Eustáquio de Sá, Mário Luiz Teixeira de Moraes, Antonio Orlando Mauro e Shi zuo Senô, pela contribuição na parte estatística.

- Ao Dr. Júlio Nakagawa pelo incentivo constante.

- A Universidade Estadual Paulista Jülio de Mesquita Filho UNESP - Campus de Ilha Solteira e Escola Superior de Agricultura "Luiz de Queiroz" - USP - Piracicaba, pela oportunidade de realização do Curso de Pós-Graduação. 
- A Secção de Fertilidade do Solo pelo desenvolvimento do presente trabalho.

- A Seç̧ão de Radioquímica do CENA e ao Departamento de Química da ESALQ pela realização de parte das anālises químicas.

- A CAPES/PICD pela bolsa de estudo concedida.

- A Maria Clara Espíndola e Sandra Aparecida Batista Perez pela dedicação constante junto a secretaria do Departamento de Agricultura da UNESP - Ilha Solteira.

A Grafite pelos serviços de composição da dissertação.

- Aos colegas do CEnA: Paula Pinheiro Padovesi, Raffaella Ros setto, Paulo F.S. Martins, Celi Daghlian, Maria Aparecida Schiavuzo e Brigitte P. Eduardo e,da Pös-Graduação em Solos e Nutrição de Plantas pelo convívio e amizade.

E finalmente a todos que de alguma forma. contribuiram para o bom andamento deste trabalho. 
1. Introdução $\ldots \ldots \ldots \ldots \ldots \ldots \ldots \ldots \ldots \ldots \ldots \ldots \ldots \ldots \ldots \ldots \ldots \ldots$

2. Revisão de Literatura $\ldots \ldots \ldots \ldots \ldots \ldots \ldots \ldots \ldots$

2.1. Nitrogêneio $\times \mathrm{Zinco} \ldots \ldots \ldots \ldots \ldots \ldots \ldots$

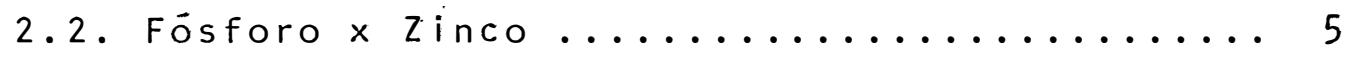

2.3. Potássio $\times$ Zinco $\ldots \ldots \ldots \ldots \ldots \ldots \ldots \ldots \ldots$

3. Material e Métodos .................... 13

4. Resultados e Discussão .................... 21

4.1. Fatores que afetam a disponibilidade de - $-Z n$

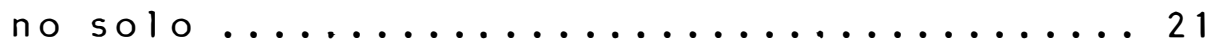

4.1.1. Efeito de doses de $N$ e PKCaMg na disponibilidade de $Z$ n no solo ........ 21

4.1.2. Efeito de doses de P e NKCaMg na disponibilidade de $Z$ n no solo ........ 28

4.1.3. Efeito de doses de K e NPCaMg na disponibilidade de $Z$ n no solo ....... 38

4.2. Fatores que afetam a concentração de $\mathrm{Zn}$ na

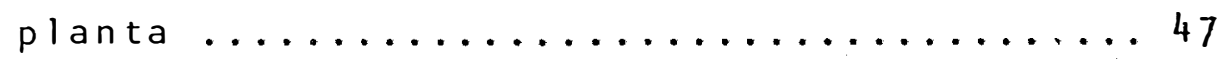

4.2.1. Efeito de doses de $N$ e PKCaMg na concentração de $Z n$ na planta ...... 47 
4.2.2. Efeito de doses de $P$ e NKCaMg na con centração de Zn na planta .........

4.2.3. Efeito de doses de $K$ e NPCaMG na con

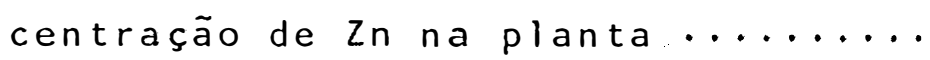

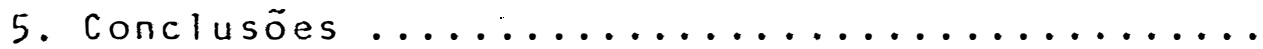

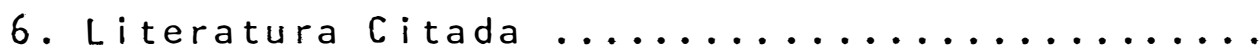


EFEITO DO N,P E K NA DISPONIBILIDADE DO Zn NO SOLO E NA SUA CONCENTRAÇ̃̃O NA PARTE AÉREA

DO FEIJOEIRO 。

Autor: Salatiër Buzetti. Orientador: Takashi Muraoka.

RESUMO

O presente trabalho foi conduzido em casa de ve-. getação pertencente ao CENA - Centro de Energia Nuclear na Agri cultura, localizado em Piracicaba, SP. Utilizou-se a cultura do feijoeiro (Phaseolus vulgaris L. ) cv. 'Carioca' cultivada em um Latossolo Vermelho Escuro, textura média, do Município de Pi racicaba e um Podzölico Vermelho Amarelo, variação Laras, do Mu nicípio de São Carlos, em vasos de barro com $2,5 l$ de solo. 0 delineamento experimental utilizado foi o interiamente casualizado em um esquema fatorial $3 \times 3, \operatorname{com} 3$ experimentos em cada solo. Os experimentos foram: $I-3$ doses de $\mathrm{N} x 3$. doses PKCaMg; II- 3 doses de $P$ x 3 doses de NKCaMg; III- 3 doses de K $x$ doses de NPCaMg; procurou verificar: a) - o efeito dos eleméntos N, P e K, aplicados ao solo e o pH, no teor de $Z n$ disponível no so 10 e, b) - o efeito da concentração dos elementos N, P, k, Ca e Mg na planta, do péso de matēria seca, do teor de Zn disponível no solo, do pH e das doses aplicadas de $N$, P ou K, na concentra ção de Zn na planta. 
. vi i i.

Como resultados verificou-se que o teor de $\mathrm{Zn}$ disponível no solo pode variar de acordo com o solo em estudo, com as doses aplicadas de N, P ou K, a lëm da aplicação de outros elementos. Para a concentração de Zn na planta, houve vari ação com as doses de $N$ aplicadas nos dois solos e em todas as combinações com a mistura PKCaMg. Com as doses de P a concentração de Zn na planta variou quando essas doses foram testadas isoladamente, ou seja, sem a aplicação de outros elementos, ou quando em combinação com a dose dois da mistura NKCaMg, para am bos os solos. As doses de $K$ exerceram efeito na concentraçã de Zn na planta, mesmo quando aplicada com ou sem a presença de ou tros elementos, nos dois solos em estudo. 
EFFECT OF $N$, P AND $K$ ON THE SOIL Zn AVAILABILITY AND ON THE Zn CONTENT IN THE BEAN PLANTS

Author: Salatiēr Buzetti. Adviser: Takashi Muraoka.

SUMMARY

This research was carried out in green-house, at CENA (Centro de Energia Nuclear na Agricultura), Piracica ba, sP, Brasil. Feijão bean (Phaseolus vulgaris L.) Carioca cultivar was grown in pots containing $2.5 l$ of medium textu re Dark Red Latosol Soil, from Piracicaba and Red Yellow Podzolic soil Laras variation, from são Carlos. The experi mental design utilized was a interely randomized $3 \times 3$ facto rial, with three experiments in each soil: I) 3 dosis of $N$ $\mathrm{x} 3$ dosis of $\mathrm{P}, \mathrm{K}, \mathrm{Ca}$ and $\mathrm{Mg}$; II) 3 dosis of $\mathrm{P} \times \mathrm{x}$ dosis of $\mathrm{N}, \mathrm{K}, \mathrm{Ca}$ and $\mathrm{Mg}$; III) 3 dosis of $\mathrm{K}$ and 3 dosis of $\mathrm{N}, \mathrm{P}, \mathrm{Ca}$ and $\mathrm{Mg}$. The objectives were to verify: a) the effect of elements applied to the soils and of the pH on the soil availa ble zinc and, b) the effects of concentration of elements in the plants, dry matter yield, soil available zinc, soil $\mathrm{pH}$, and dosis of applied $N, P$ and $K$ on the plant zinc con tent. 
The results showed that the soil available zinc may vary according to the soil studied, with the dosis of applied N, P or K, besides the application of other elements. For the content of zinc in the plants, the effect varied with dosis of applied $N$ in both soils and in all combination of $\mathrm{P}, \mathrm{K}, \mathrm{Ca}, \mathrm{Mg}$ mixture, The content of $\mathrm{Zn}$ in the plant varied, for both soils, when the P dosis were tes ted isolately, that is, without application of other elements, and when in combination with the second dosis of the $\mathrm{N}, \mathrm{K}, \mathrm{Ca}$ e Mg mixture. The $\mathrm{K}$ dosis affected zinc content in the plant, even when applied with or without the presence of other elements, in both soils studied. 
1. INTRODUÇÄO

o feijão $\vec{e}$ um dos alimentos bäsicos para a nossa população, representando para o País além do caráter econômico, um elemento de alto significado social. Cons. titui-se na maior fonte de proteína ćonsumida pelos brasileiros, ocupando em 1983, entre as culturas exploradas, o quarto lugar em ärea cultivada (Anuārio estatístico do Brasil, 1984).

Segundo RAMOS (1973), a produção de uma planta está em geral relacionada com uma sẻrie de características agro nômicas. Vários fatores dentre os quais, a nutrição mineral, podem influenciar estas características agronômicas e consequentemente a produção, sendo portanto a fertilidade do solo, um dos fatores mais proeminentes da baixa produtividade da cultura.

Vários trabalhos mostrando o incremento na produ tividade mediante o uso dos macronutrientes, tem sido relatados, entretanto a mesma importância não tem sido dada aos micronutrientes. Destes, o zinco parece ser elemento que mais 1 imita 
a produtividade do feijoeiro nos nossos solos, sendo este fato mais agravante quando se utiliza de adubações omitindo tal elemento, que è o que normalmente ocorre.

Existem värias citações comentando sobre a corre 1 ação direta em nutrição de plantas, entre a concentração de nutrientes disponíveis no meio e a soma deles acumulados nos tecidos das plantas. Entretanto, este relacionamento em certas condições, pode ser modificado durante o processo de absorçao e translocação, devido às interações entre os nutrientes, o mesmo ocorrendo com a sua disponibilidade no solo. Tal modifi cação pode afetar a produção mäxima de cada cultura, havendo pa ra isto a necessidade de um perfeito equilíbrio entre os nutrientes fornecidos. Corroborando a importância das interações de nutrientes, OLSEN (1972) relata que a função fisiológica de um nutriente e o seu mecanismo de absorção no solo não pode ser estudado e interpretado isoladamente dos outros nutrientes.

Em ass $1 m$ sendo, o presente trabalho teve como ob jetivo, verificar o efeito do $N, P$ e $K$, dentro de 3 níveis de fertilidade, na disponibilidade do $Z n$ em dois solos e na sua concentração em plantas de feijão. 


\section{REVISÃO DE LITERATURA}

2.1. Nitrogênio x Zinco

Os resultados obtidos em experimentos conduzidos com o objetivo de se verificar o efeito do nitrogênio sobre a disponibilidade do zinco no solo e a sua absorção pelas plantas, são contraditórios, variando dentre outros, com o tipo de solo, doses e fontes de nitrogênio aplicadas, além da cultura utiliza $\mathrm{d}$ a .

Com relação à disponibilidade de zinco no solo, háa autores que verificaram diminuição nesta disponibilidade, tais como BOAWN et alii (1960) os quais citam que essa diminuição era devida ao aumento do $\mathrm{pH}$, provocado pelos fertilizantes nitrogenados, embora tal efeito variasse com a cultura utilizada; também. VIETS et a zii (1957) citam o efeito do pH e TANAKA e ISHIZUKA (1969) reportam que essabaixa disponibilidade é devidà aplicação de uréia e cloreto de amônio. 
Quanto ao aumento na disponibilidade, GIORDANo et alii (1966), STANTON e BURGER (1970) e CHAUDHRY et ali (1974) citam o efeito do pH, devido à aplicação de fertilizantes nitrogenados àcidos.

Para a absorção de zinco pelas plantas, REUTHER e SMITH (1950) e VIETS et alii (1957) concluiram que o nitrogê nio pode induzir ou acentuar a deficiência de zinco em plantas, devido ao seu maior desenvolvimento; OZANNE (1955) cita que o zinco absorvido pode ficar retido nas raízes como complexo Zn proteína, dificultando assim, a translocação do mesmo para a parte aérea; CHAUdHRY e LONERAGAN (1970) relatam que o nitrogê nio diminuiu drasticamente a concentração de cobre e zinco na parte aërea e raiz de plantas de trigo, devido ao seu maior desenvolvimento tanto da parte aérea como do sistema radicular, havendo portanto maior absorção de cobre e zinco, mas a concentração foi diminuída devido ao efeito diluição. Estes ülti mos autores verificaram posteriormente que o nitrogênio aplicado na forma de nitrato de cálcio, diminuiu a absorção de zinco pelas plantas de trigo, e tal fato não ocorria quando o nitrato era substituído pelo cloro (CHAUDHRY e LONERAGAN, 1972). OLSEN (1972) citando vários autores, relata que a aplicação de nitrogênio tem sido mostrada como a possível causa da deficiência de zinco em plantas cítricas.

Por outro lado, SINGH e SINGH(1981) verificaram que a aplicação de 80 ppm de nitrogênio aumentou a concentração 
de zinco em plantas de arroz, entretanto, a aplicação de 160 ppm não aumentou ou tendeu a diminuí-1a quando comparada com a ap $1 \underline{i}$ cação de 80 ppm; como explicação citam tambēm o efeito diluição. THOMPSON (1962) cita que a fertilização nitrogenada tendeu a aumentar os teores de zinco em plantas de milho; STANTON e BURGER (1970) verificaram aumentos significativos na absorção do zinco pelo painço mediante a aplicação de $\mathrm{NH}_{4} \mathrm{NO}_{3}$ e TERMAN e ALLEN (1974) também verificaram aumentos na concentração de zin co em plantas de milho devido a aplicação de nitrogênio. SINGH e FRANKLIN (1974) citam que o fertilizante nitrogenado $\mathrm{NH}_{4} \mathrm{NO}_{3}$ quando aplicado juntamente com o zinco proporcionou alta absorção deste elemento pelas plantas de milho; o $\mathrm{NaNO}_{3}$ aplicado se parado ou juntamente com o zinco e o $\left(\mathrm{NH}_{4}\right)_{2} \mathrm{SO}_{4}$ aplicado separado, teve apenas um pequeno efeito na absorção do zinco. Também SOLTANPOUR (1969) verificou aumento na absorção do zinco pela cultura da batata, utilizando o nitrogênio, o mesmo ocorrendo com PARKER (1962) e PUMPREY et alii (1963) com a cultura do mi 1ho, CHAUDHRY et alii (1977) com plantas de arroz cultivada em dois solos calcários, inundados e MURAOKA (1981) com a cultura do feijoeiro.

$$
\text { 2.2. Fósforo } \times \text { Zinco }
$$

Existe uma vasta 1 iteratura comentando sobre as relações fósforo e zinco, e as conclusões são as mais variadas possiveis, tanto no que tange à disponibilidade do zinco no so- 
1o e na sua absorção pelas plantas, como na explicação dos meca nismos envolvidos.

Com respeito à disponibilidade de zinco, vários autores citam uma diminuição quando se testam doses de fósforo. Assim Misra e Misra (1969), Singh e Dartigues (1969), citados por KALYANASUNDARAM e MEHTA (1970) e MANDAL e HALDAR (1980) con cluiram que a aplicação de fósforo causa efeito depressivo no conteūdo de zinco disponível no solo, sendo este efeito mais proeminente no zinco nativo do solo do que o aplicado; PRASAD et alii (1968), ELLIS et alii (1964), BADANUR e VENKATA RAO (1980), HULAGUR et alii (1980) e KHAN (1969), relataram também a menor disponibilidade de zinco no solo devido ao fósforo; SEATZ e JURINAK (1957) dá como explicação a formação de $\mathrm{Zn}_{3}\left(\mathrm{PO}_{4}\right)_{2} \cdot 4 \mathrm{H}_{2} \mathrm{O}$ como a causa da redução na disponibilidade; SHUKLA (1971) concluiu que as reações $P$ - Zn são influenciadas pelas fontes de fósforo. Já BINGHAN e GARBER (1960), BOAWN et alii (1970), LINDSAY (1972) e REDDY et alii (1973) citam que a precipitação do zinco pelo fósforo, não é provavelmente devido ao fósforo induzindo a defi ciência de zinco nas plantas, e sugere que o efeito do fósforo está na absorção do zinco do solo pelas raízes, mas por outrome canismo e não pela precipitação de fosfato de zinco insolüvel. SPENCER (1960) concluiu que o zinco foi imobilizado no solo pe1o fosfato; SANTos (1971) relata também a formação de compostos de fosfatos de zinco, reduzindo assim a disponibilidade, o mesmo concluindo THORNE (1957), BINGHAN et a $i$ i (1958) e BINGHAN 
(1963). Também MALAvolta (1980) relata que o fósforo causa: inibição não competitiva na absorção do $\mathrm{Zn}^{2+}$, precipitação do zinco na superfície das raízes dependendo do pH do meio, além da diminuição no transporte de zinco para a parte aérea e dilui ção na concentração do zinco na matéria seca.

Por outro 1 ado, a 1 guns autores verificaram efeito positivo do fósforo na absorção do Zn. Assim, LAKER (1967) observou que a aplicação de 60 ppm de p proporcionou aumentos no conteúdo de zinco extraído do solo; PAULI et alii (1968) relatam que a alta concentração de fósforo aumentou o zinco extraído por àgua, sugerindo que o problema do fósforo induzindo a deficiência de zinco deve ser devido a reações que ocorre na planta e näo no solo; ELSOKKARY et alii (1981) verificaram um significativo aumento nos teores de $\left(\mathrm{NH}_{4}\right)_{2} \mathrm{CO}_{3}$ EDTA extraindo zinco, quando se aplicou o zinco somente ou com o fósforo. MARINHO e IGUE (1972) também verificaram que a aplicação de P aumentou a quantidade de $Z n$ extraída pelo método do EDT, embora esse aumento não ficou bem definido quando se utilizou o método do HCl ; KEEFER e SINGH (1968) concluiram que a aplicação de fósforo aumentou o conteúdo do zinco do solo, solúvel em àgua e BROWN et alii (1970) verificaram pouca variação no teor de zinco do solo, com a aplicação de fósforo.

Com relação a interação $P$ e $Z n$ na absorção pé las plantas, hả inümeros trabalhos mostrando que o fósforo induz a deficiência de zinco, como os de-BURLESON e PAGE (1967), 
STUKENHOLTZ et a $i$ i (1966), WARNOCK (1970), SHARMA et a $i i$ (1968 a, b) e PAULSEN e ROTIMI (1968), os quais verificaram au mentos ou não da variação do teor de zinco das raízes, em detri mento ao das folhas, sugerindo assim um problema de mobilidade do elemento da raiz para a parte aérea. KHAN (1969), MARINHO e IGUE (1972) e LOPEZ GOROSTIAGA e MALAVOLTA (1974), relatamo efeito de diluição mediante a aplicação de $P$, em que a taxa de absorção de $\mathrm{Zn}$ não acompanha o desenvolvimento das plantas. BAHIA e BRAGA (1974), BOAWN e LEGGET (1964) e MILLIKAN (1963) citam um distürbio metabölico nas células da planta, provocado pelo desequilíbrio entre o $P$ e $Z n$, ou que, concentrações excessivas de fósforo interferem na função metabólica do zinco. Outros autores citam que a interação $P-Z n$, pode ocorrer na superfície das raízes, tais como STUKENHOLTZ et alii (1966), ELLIS et alii (1964) e MOTSARA (1974). CHAUDHRY e LONERAGAN (1972) e KEEFER e SINGH (1968) citam o efeito do fósforo na mudança da capacidade fisiológica da planta em absorver zinco. LOPEZ GOROSTIAGA e MALAVOLTA (1974) relatam o efeito do fósforo na trans locação do zinco, além do efeito de diluição, já citado.

o fósforo causando diminuição na concentração de zinco nos tecidos das plantas. encontra respaldos nos trabalhos de BURLESON et alii (1961); BROWN e TIFFIN (1962); LANGIN et a $i$ i (1962); THOMPSON (1962); ELLIS et a $i$ i (1964); JACKSON et ali $i$ 1967); LO e REISENAUER (1968); SHARMA et a $i i$ (1968a); BROWN et alii (1970); RUDGERS et alii (1970); CHAUDHRY e SHARIF (1974); 
TERMAN e ALLEN (1974); FAGERIA e ZIMMERMANN (1979); CHRISTENSEN e JACKSON (1982) e PATIL e SOMAWANShi(1982). Já OLSEN (1972) cita que o fósforo inativando o zinco no solo pode näo ser uma explicação satisfatória para a interação. Um efeito do fósforo na absorção do zinco pelas plantas no qual o fósforo atua no sítio de absorção ou, limitando a translocação ou mesmo a utili zação do zinco pelas plantas, parece ser uma hipótese mais satisfatória. Soltanpour (1969) cita a diminuição dos teores de zinco em batata somente quando o fósforo foi aplicado junto com o zinco, o mesmo não ocorrendo quando aplicados separadamente; SAFAYA e SINGH (1977) conduzindo experimentos com duas variedades de cawpi, verificaram diferente susceptibilidade à indução de deficiência de zinco, com a aplicação de fösforo; GANIRON et alii (1969) citam a deficiência de zinco induzida pelo fósfo ro em "seedlings" de milho e o efeito da temperatura.

Por outro lado, alguns trabalhos mostram que o fósforo pode até mesmo aumentar a absorção de zinco pelas plantas, como os de WALLACE et ali $i$ (1974), os quais verificaram que a interação era negativa somente em condições de alta concentração de fósforo no meio e baixa concentração de zinco, o mesmo não ocorrendo quando se aumentava o nível de zinco. pois neste caso e, com altas doses de fósforo a planta absorvia mais zinco.

Outros autores não verificaram efeito do fósforo na nutrição mineral da planta em relação ao zinco, como: BOAWN et alii 
(1954), REHM et alii (1980), SEATZ et alii (1959). Já, PAULI et alii (1968), relatam o efeito positivo do fósforo na absorção do zinco pelas plantas de feijoeiro; ORABI et alii (1981) verificaram aumento na absorção e conteúdo de zinco em plantas de milho com a aplicação de fósforo; BASAK et alii (1982) obtiveram os mesmos resultados com a cultura do arroz e, WALLACE et alii (1978) conduzindo experimento em solução nutritiva com cinco cultivares de soja em diferentes nïveis de fósforo e pH, verificaram que em $\mathrm{pH}$ alto, aumentando a concentração de fósforo, havia uma diminuição na concentração de zinco nas raízes, caules e folhas. Em contraste, quando o pH era baixo, aumen tando-se a concentração de fósforo, resultou em maior concentra ção de zinco, nas partes analisadas. YADAV e SHUKLA (1982) citam que a utilização e translocação de zinco pelas plantas foi aumentada consideravelmente com a aplicação de 25 ppm de $P$, o mesmo não ocorrendo com a aplicação de 250 ppm de P. ORABI et alii (1982) verificaram aumento de absorção de zinco pelas plantas de tomate, com a aplicação de fósforo em solo aluvial, quando não se aplicou o zinco. Em solo calcäreo a absorção de zinco foi aumentada com a aplicação de fósforo, mesmo o zinco sendo ou não aplicado no solo. EKSOKKARY et alii (1981), testando quatro doses de fósforo e três de zinco, verificaram que no tratamento sem a aplicação de zinco, a adição de fósforo aumentou a absorção de zinco pelas plantas de milho, entretanto com a aplicação de zinco a adição de fósforo diminuiu a absorção de zinco. LONERAGAN et alii (1979) verificaram que a apli 
cação de um nível médio de fósforo em um solo podzölico, resultou em um aumento na absorção de zinco pelo trevo na ordem de 25 a $70 \%$. SHARMA et alii (1968a) verificaram que a aplicação de 25 ppm de $P$ aumentava a absorção de zinco em duas variedades de trigo mexicana, o mesmo não ocorrendo quando a dose de fósforo era aumentada para 100 ppm.

2.3. Potássio x Zinco

Com relação à aplicação de potássio na absorção de zinco pelas plantas, STUKENHOLTZ et a $i$ i (1966) citam que altas proporções de potássio diminuiram os efeitos adversos da absorção de fósforo ou zinco pelo milho; olson et alii (1965) relatam que altas concentrações de potássio trocável no solo diminuiu igualmente o efeito antagônico da absorção de fósforo. ou zinco; WARD et alii (1963) conduzindo experimento em casa de vegetação com a cultura do milho, verificaram que numa alta porcentagem de saturação de potássio no solo, sem a aplicação de fósforo, havia uma redução na utilização de zinco pelas plan tas e TERMAN e ALLEN (1974) verificaram que para a cultura do milho a aplicação de potássio diminuiu a concentração de zinco nas plantas. SHUKLA e MUKHI (1979) relatam uma relação triangular entre sódio, potássio e zinco, em plantas de milho, sendo que cada nutriente testado diminuiu a eficiência do "outro no desenvolvimento e concentração no tecido. 
Outros autores verificaram efeito sinërgico do potássio na absorção do zinco, tais como WeAR e PATTERSON (1965), os quais atribuiram essa causa ao efeito indireto do potássio na relação fósforo-zinco e GALLo et alii (1975) verificaram um aumento na concentração de zinco nas diferentes partes da planta de milho com a aplicação de potássio. TIWARI et alii (1982) conduzindo um experimento em campo com o objetivo de se verificar o efeito da aplicação de potássio e zinco em batata, concluiram que quando se aumentou o suprimento de potásio, hou ve efeito benéfico na absorção e translocação de zinco, indican do aî uma maior utilização do fertilizante contendo zinco. THOMPSON (1962) verificou aumento na concentração de zinco em folhas de milho mediante a aplicação de doses de até $30 \mathrm{~kg} / \mathrm{ha}$ de $K_{2} \mathrm{O}$, mas essa concentração foi reduzida quando se aplicou doses mais elevadas de potássio. Por outro 1ado, MURAOKA (1981) não verificou efeito do potássio na absorção de zinco em plantas de feijão. 
3. MATERIAL E METODOS'

o presente trabalho foi conduzido no ano de 1983 , em casa de vegetação, pertencente ao Centro de Energia Nuclear na Agricultura - CENA, localizado em Piracicaba, SP. Para ta1, utilizou-se vasos de barro com capacidade para 31 , impermeab $\underline{i}$ lizados internamente com neutrol. Fez-se uso de dois solos, provenientes de um Latossolo Vermelho Escuro, textura média, do Município de Piracicaba (LE) e de um Podzölico Vermelho Amarelo, Variação Laras, do Município de São Carlos (PV), ambos retirados a uma profundi dade de 0 a $20 \mathrm{~cm}$ e com as caracteristicas quimicas como constam na Tabela 01 . Os solos foram secos ao ar e peneirados em peneira com malhas de $5 \mathrm{~mm}$ de abertura, sendo posteriormente in cubados em sacos de polietileno, com os corretivos. As doses dos corretivos foram baseadas em incubaçöes feitas anteriormen* te, necessäria para atingir um pH em torno de 6,0, isto nos tratamentos em que foi utilizado os corretivos, nos outros tratamentos a incubação constou apenas de solo e āgua. Após trinta dias de incubação, o solo foi colocado para secar ao ar 
e peneirado novamente. Cada vaso recebeu 2,5 1 de um dos dois solos, os quais receberam ou não corretivo, de acordo com o trat amento.

0 trabalho constou de 3 ensaios, nos dois tipos de solos, sendo que cada ensaio teve 9 tratamentos, utilizandose o delineamento inteiramente casualizado e um esquema fatorial $3 \times 3, \operatorname{com} 4$ repetições e os seguintes tratamentos: Expe rimento I : 3 doses de $\mathrm{N} \times 3$ doses de PKCaMg; Experimento II: 3 doses de $\mathrm{P} \times 3$ doses de NKCaMg; Experimento III: 3 doses de K 3 doses de NPCaMg; como constam na Tabela 02 .

As doses 0,1 e 2 se referem respectivamente a $0-50-100 \mathrm{ppm}$ de $N$ (uréia) e $\mathrm{K}$ (cloreto de potássio) e 0 - 100 - 200 ppm de P (ácidofosförico). Com relação ao Ca e Mg, as doses correspondentes são: $0-865-865$ ppm de Ca e $0-280-280$ ppm de Mg, para o solo LE e, $0-165-165$ ppm de Ca e $0-55-55$ ppm de Mg, para o PV. A dose 1 de Ca e Mg teve como fonte o óxido de cálcio e óxido de magnêsio, com doses para elevar o pH do solo a redor de 6,0. Para a dose 2, utilizou-se, o cloreto de cálcio e o cloreto de magnésio na mesma proporção de Ca ou Mg contido nos corretivos. Apỏs a adição do N, P, K (doses 1 e 2) e; Ca e $M g$ (dose 2), o solo foi mistura do, posteriormente umedecido e semeadas cinco sementes de feijão (Phaseolus vulgaris L.) cv. 'Carioca', por vaso. 
Tabela 01 . Características químicas dos solos utilizados*.

\begin{tabular}{|c|c|c|c|c|c|c|c|c|c|}
\hline \multirow{2}{*}{ Solo } & \multirow{2}{*}{$\begin{array}{c}\mathrm{pH} \\
\left(\mathrm{H}_{2} \mathrm{O}\right)\end{array}$} & \multirow{2}{*}{$\begin{array}{c}\text { C org. } \\
(\%)\end{array}$} & \multicolumn{6}{|c|}{ meq./100 g. de TFSA } & \multirow{2}{*}{$\begin{array}{c}\mathrm{ppm} * * \\
\mathrm{Zn}\end{array}$} \\
\hline & & & $\mathrm{PO}_{4}^{3-}$ & $\mathrm{K}^{+}$ & $\mathrm{Ca}^{2+}$ & $\mathrm{Mg}^{2+}$ & $\mathrm{Al}^{3+}$ & $\mathrm{H}^{+}$ & \\
\hline $\mathrm{LE}$ & 5,0 & 0,86 & 0,023 & 0,07 & 0,15 & 0,08 & 0,76 & 4,86 & 1,95 \\
\hline P V & 4,8 & 0,22 & 0,031 & 0.08 & 0,26 & 0,13 & 0,75 & 0,82 & 1,60 \\
\hline
\end{tabular}

* segundo métodos descritos em CATANI e JACintho (1974)

** extrator utilizado: DTPA

Tabela 02. Experimentos utilizados no trabalho "Efeito do N, $P$ e $K$ na disponibilidade do $Z n$ no solo e na sua concentração na parte aérea do feijoeiro... ...

E XPER I MENTOS

I

I I

I I I

\begin{tabular}{|c|c|c|c|c|c|c|c|c|c|c|c|c|c|c|}
\hline $\mathrm{N}_{\mathrm{O}}$ & $\mathrm{P}_{0}$ & $\mathrm{~K}_{\mathrm{O}}$ & $\mathrm{Ca}_{\mathrm{o}}$ & $\mathrm{Mg}_{\mathrm{O}}$ & $\mathrm{N}_{\mathrm{O}}$ & $\mathrm{P}_{0}$ & $\mathrm{~K}_{\mathrm{o}}$ & $\mathrm{Ca}_{\mathrm{o}}$ & $\mathrm{Mg}_{\mathrm{o}}$ & $\mathrm{N}_{\mathrm{O}}$ & $\mathrm{P}_{0}$ & $\mathrm{~K}_{\mathrm{O}}$ & $\mathrm{Ca}_{0}$ & $\mathrm{Mg}_{\mathrm{o}}$ \\
\hline $\mathrm{N}_{1}$ & $\mathrm{P}_{\mathrm{O}}$ & $\mathrm{K}_{\mathrm{O}}$ & $\mathrm{Ca}_{\mathrm{o}}$ & $\mathrm{Mg}_{\mathrm{O}}$ & $\mathrm{N}_{\mathrm{O}}$ & $\mathrm{P}_{1}$ & $\mathrm{~K}_{\mathrm{O}}$ & $\mathrm{Ca}_{\mathrm{o}}$ & $\mathrm{Mg}_{\mathrm{O}}$ & $\mathrm{N}_{\mathrm{O}}$ & $\mathrm{P}_{0}$ & $\mathrm{~K}_{1}$ & $\mathrm{Ca}_{\mathrm{O}}$ & $\mathrm{Mg}_{\mathrm{o}}$ \\
\hline $\mathrm{N}_{2}$ & $\mathrm{P}_{\mathrm{O}}$ & $\mathrm{K}_{\mathrm{o}}$ & $\mathrm{Ca}_{\mathrm{o}}$ & $\mathrm{Mg}_{\mathrm{O}}$ & $\mathrm{N}_{\mathrm{O}}$ & $\mathrm{P}_{2}$ & $\mathrm{~K}_{\mathrm{O}}$ & $\mathrm{Ca}_{\mathrm{O}}$ & $\mathrm{Mg}_{\mathrm{O}}$ & $\mathrm{N}_{\mathrm{O}}$ & $\mathrm{P}_{0}$ & $\mathrm{~K}_{2}$ & $\mathrm{Ca}_{0}$ & $\mathrm{Mg}_{\mathrm{o}}$ \\
\hline $\mathrm{N}_{0}$ & $\mathrm{P}_{1}$ & $\mathrm{~K}_{1}$ & $\mathrm{Ca}_{1}$ & $\mathrm{Mg}_{1}$ & $\mathrm{~N}_{1}$ & $\mathrm{P}_{0}$ & $\mathrm{~K}_{1}$ & $\mathrm{Ca}_{1}$ & $\mathrm{Mg}_{1}$ & $\mathrm{~N}_{1}$ & $\mathrm{P}_{1}$ & $\mathrm{~K}_{\mathrm{O}}$ & $\mathrm{Ca}_{1}$ & $\mathrm{Mg}_{1}$ \\
\hline $\mathrm{N}_{1}$ & $\mathrm{P}_{1}$ & $\mathrm{~K}_{1}$ & $\mathrm{Ca}_{1}$ & $\mathrm{Mg}_{1}$ & $\mathrm{~N}_{1}$ & $\mathrm{P}_{1}$ & $\mathrm{~K}_{1}$ & $\mathrm{C} \mathrm{a}_{1}$ & $\mathrm{Mg}_{1}$ & $\mathrm{~N}_{1}$ & $\mathrm{P}_{1}$ & $\mathrm{~K}_{1}$ & $\mathrm{Ca}_{1}$ & $\mathrm{Mg}_{1}$ \\
\hline $\mathrm{N}_{2}$ & $\mathrm{P}_{1}$ & $\mathrm{~K}_{1}$ & $\mathrm{Ca}_{1}$ & $\mathrm{Mg}_{1}$ & $\mathrm{~N}_{1}$ & $\mathrm{P}_{2}$ & $\mathrm{~K}_{1}$ & $\mathrm{Ca}_{1}$ & $\mathrm{Mg}_{1}$ & $\mathrm{~N}_{1}$ & $P_{1}$ & $\mathrm{~K}_{2}$ & $\mathrm{Ca}_{1}$ & $\mathrm{Mg}_{1}$ \\
\hline $\mathrm{N}_{\mathrm{O}}$ & $\mathrm{P}_{2}$ & $\mathrm{~K}_{2}$ & $\mathrm{Ca}_{2}$ & $\mathrm{Mg}_{2}$ & $\mathrm{~N}_{2}$ & $\mathrm{P}_{0}$ & $\mathrm{~K}_{2}$ & $\mathrm{Ca}_{2}$ & $\mathrm{Mg}_{2}$ & $\mathrm{~N}_{2}$ & $\mathrm{P}_{2}$ & $\mathrm{~K}_{\mathrm{o}}$ & $\mathrm{Ca}_{2}$ & $\mathrm{Mg}_{2}$ \\
\hline $\mathrm{N}_{1}$ & $\mathrm{P}_{2}$ & $\mathrm{~K}_{2}$ & $\mathrm{Ca}_{2}$ & $\mathrm{Mg}_{2}$ & $\mathrm{~N}_{2}$ & $\mathrm{P}_{1}$ & $\mathrm{~K}_{2}$ & $\mathrm{C} \mathrm{a}_{2}$ & $\mathrm{Mg}_{2}$ & $\mathrm{~N}_{2}$ & $\mathrm{P}_{2}$ & $\mathrm{~K}_{1}$ & $\mathrm{Ca}_{2}$ & $\mathrm{Mg}_{2}$ \\
\hline $\mathrm{N}_{2}$ & $\mathrm{P}_{2}$ & $\mathrm{~K}_{2}$ & $\mathrm{Ca}_{2}$ & $\mathrm{Mg}_{2}$ & $\mathrm{~N}_{2}$ & $\mathrm{P}_{2}$ & $\mathrm{~K}_{2}$ & $\mathrm{Ca}_{2}$ & $\mathrm{Mg}_{2}$ & $\mathrm{~N}_{2}$ & $\mathrm{P}_{2}$ & $\mathrm{~K}_{2}$ & $\mathrm{Ca}_{2}$ & $\mathrm{Mg}_{2}$ \\
\hline
\end{tabular}


Uma semana após a emergência foi realizado o des baste, deixando-se duas plantas por vaso: Foram efetuadas irrigações diärias, não havendo necessidade de tratamentos fitossanitärios. Os experimentos foram colhidos aos 30 dias apös a emergência, sendo que a parte aẻrea do vegetal foi lavada, seca em estufa com circulação forçada de ar a uma temperatura de 60 a $70^{\circ} \mathrm{C}$ : até peso constante e ava1iado esse parâmétro, após o que, o material foi moido em moinho tipo Willey passando em peneira de 20 mesh.

Após a moagem, 0,1 g do material foi utilizado para a determinação do $N$ (método semi microkjeldah1) e 1,0 g para a digestão nitrica-perclórica, determinando-se P, K, Ca, Mge Zn, segundo os métodos descritos em SARRUGE e HAAg (1974).

Com relação ao solo, foram amostrados cada vaso e colocado o solo para secar ao ar, passando posteriormente em peneira de $2 \mathrm{~mm}$ de abertura. Determinou-se o $\mathrm{pH}^{\mathrm{d} o}$ solo (relação água : solo $=2,5: 1)$ e o $Z n$ disponíve1, segundo o método descrito em LINDSAY e NORVELL (1969).

Para a anälise estatística, quando se analisou o Zn na planta, utilizou-se do mëtodo "Path Coefficients", propos to por WRIGHT (1921), onçe os coeficientes de correlação simples entre a porcentagem de $\mathrm{Zn} n a$ planta e as doses aplicadas de $N$ ou $P$ ou $K$, foram desdobrados em componentes de efeitos diretos e indiretos. Foram considerados além desses dois fato res, a porcentagem na planta de $\mathrm{N}, \mathrm{P}, \mathrm{K}, \mathrm{Ca}, \mathrm{Mg}, \mathrm{o}$ teor de 
matéria seca da parte aērea, o Zn disponível no solo e o pH. 0s "Path Coefficients" foram obtidos através das equações, como constam na Tabela 03. A obtenção dos efeitos dire tos (P) foi feita através da expressão $Y=X \beta$, conforme a Tabe1a 04. Nas equações, os valores de P quantificam os efeitos diretos e representam os coeficientes de regressão parcial, e os efeitos indiretos são representados pelos efeitos diretos multi plicados pelo respectivo coeficiente de correlação simples. Através de equação abaixo obteve-se. o coeficiente de determinação e a variância residual:

$$
\begin{aligned}
& 1=\left(P_{w g}\right)^{2}+\left(P_{1} 10\right)^{2}+\left(P_{2} 10^{2}+\left(P_{3} 10\right)^{2}+\left(P_{4} 10^{2}+\left(P_{5} 10^{2}+\right.\right.\right. \\
& +\left(P_{6} 10^{2}+\left(P_{7} 10\right)^{2}+\left(P_{8} 10\right)^{2}+\left(P_{9} 10^{2}+2 r_{12} \cdot P_{1} 10 .\right.\right. \\
& \mathrm{P}_{210}+2 \mathrm{r}_{13} \cdot \mathrm{P}_{1} 10 \cdot \mathrm{P}_{3} 10+2 \mathrm{r}_{1-4} \cdot \mathrm{P}_{1}{ }_{10} \cdot \mathrm{P}_{4} 10+2 \mathrm{r}_{15} \cdot \mathrm{P}_{1} 10 \cdot \\
& \mathrm{P}_{5} 10+2 \mathrm{r}_{16} \cdot \mathrm{P}_{1} 10 \cdot \mathrm{P}_{6} 10+2 \mathrm{r}_{17} \cdot \mathrm{P}_{1}{ }_{10} \cdot \mathrm{P}_{7}{ }_{10}+2 \mathrm{r}_{1}{ } \cdot \mathrm{P}_{1} 10 \cdot \\
& \mathrm{P}_{8} 10+2 \mathrm{r}_{1}{ }_{9} \cdot \mathrm{P}_{1} 10 \cdot \mathrm{P}_{9} 10+2 \mathrm{r}_{2} 3 \cdot \mathrm{P}_{2} 10 \cdot \mathrm{P}_{3} 10+2 \mathrm{r}_{2}{ }_{4} \cdot \mathrm{P}_{2} 10 \text {. } \\
& \mathrm{P}_{4} 10+2 \mathrm{r}_{25} \cdot \mathrm{P}_{2} 10 \cdot \mathrm{P}_{5} 10+2 \mathrm{r}_{26} \cdot \mathrm{P}_{2} 10 \cdot \mathrm{P}_{6} 10+2 \mathrm{r}_{2} \cdot \mathrm{P}_{2} 10 . \\
& \mathrm{P}_{7} 10+2 \mathrm{r}_{2} \cdot{ }^{\mathrm{P}_{2}} 10 \cdot \mathrm{P}_{8} 10+2 \mathrm{r}_{2} 9 \cdot \mathrm{P}_{2} 10 \cdot \mathrm{P}_{9} 10+2 \mathrm{r}_{3} \cdot{ }^{\mathrm{P}_{3}} 10 \text {. } \\
& \mathrm{P}_{4} 10+2 \mathrm{r}_{35} \cdot \mathrm{P}_{3} \mathrm{P}_{10} \cdot \mathrm{P}_{5} 10+2 \mathrm{r}_{36} \cdot \mathrm{P}_{3} 10 \cdot \mathrm{P}_{6} 10+2 \mathrm{r}_{37} \cdot \mathrm{P}_{3} 10 . \\
& P_{710}+2 r_{3} \cdot P_{3} 10 \cdot P_{8} 10+2 r_{3} 9 \cdot P_{3} 10 \cdot P_{9} 10+2 r_{45} \cdot P_{410} . \\
& \mathrm{P}_{5} 10+2 \mathrm{r}_{46} \cdot \mathrm{P}_{4} 10 \cdot \mathrm{P}_{6} 10+2 \mathrm{r}_{4} \cdot \mathrm{P}_{4} 10 \cdot \mathrm{P}_{7} 10+2 \mathrm{r}_{4 \cdot 8} \cdot \mathrm{P}_{4} 10 \cdot \\
& \mathrm{P}_{8} 10+2 \mathrm{r}_{4} \cdot \mathrm{P}_{4} 10 \cdot \mathrm{P}_{9} 10+2 \mathrm{r}_{56} \cdot \mathrm{P}_{5} 10 \cdot \mathrm{P}_{6} 10+2 \mathrm{r}_{5 \cdot 7} \cdot \mathrm{P}_{5} 10 \text {. }
\end{aligned}
$$




$$
\begin{aligned}
& P_{7} 10+2 r_{5} \cdot P_{5} 10 \cdot P_{8} 10+2 r_{5} \cdot P_{5} 10 \cdot P_{9} 10+2 r_{6} \cdot P_{6} 10 \cdot P_{7} 10+ \\
& 2 r_{6} \cdot{ }^{P_{6}} 10 \cdot{ }_{8} 10+2 r_{6} \cdot{ }_{6} P_{6} 10 \cdot P_{9} 10+2 r_{7} \cdot P_{7} 10 \cdot P_{8} 10 \\
& 2 r_{7}{ } P_{7} 10 \cdot P_{9} 10+2 r_{8} \cdot{ }_{8} P_{8} 10 \cdot P_{9} 10
\end{aligned}
$$

$$
\text { Onde, }(\mathrm{PWg})^{2}=\mathrm{R}^{2}=\text { coeficiente de: determinação }
$$
parcial de concentração de Zn na planta por W (variável residua1) e $1-R^{2}=W=$ efeito residual da concentração de $\mathrm{Zn}$ por $1,2, \ldots$ e 9 ; sendo $1,2,3,4$ e 5 , respectivamente, à con centração de N, P, K, Ca e Mg na planta; 6: o teor de matéria se ca; 7: o teor de Zn disponível no solo; 8: opH; 9 as doses de N, P ou K e 10: a concentração de Zn na planta.

Com relação ao Zn disponível no solo, fez-se in ferēncias apenas às doses aplicadas de $N$, $P$ ou K e da mistura de elementos NPKCaMg, omitindorse o $N$ ou $P$ ou K, de acordo com o experimento; além do pH do solo. Procurour-se correlacionar a-. penas o efeito da reaça do solo com o Zn disponível no solo, através da correlação simples, conforme descrito em PIMENTEL GO MES, 1982 . 


\begin{tabular}{|c|c|c|c|c|c|c|c|c|}
\hline$\stackrel{2}{=}$ & 으 & 으 & 으 & 음 & 으 & 으 & 음 & 으 \\
\hline $\begin{array}{l}\text { की } \\
\text { की }\end{array}$ & $\begin{array}{l}\text { a } \\
\text { a }\end{array}$ & $\begin{array}{c}\Omega \\
0 . \\
\sigma\end{array}$ & $\begin{array}{l}\text { की } \\
\text { or }\end{array}$ & $\begin{array}{l}\text { की } \\
\text { की }\end{array}$ & $\begin{array}{l}\text { की } \\
\text { कू }\end{array}$ & $\begin{array}{l}\text { की } \\
\text { की }\end{array}$ & $\begin{array}{l}\text { की } \\
\text { की }\end{array}$ & م' \\
\hline 45 & $x^{N}$ & 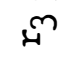 & S्ञ & $\stackrel{\sim n}{n}$ & (6) & $\hat{s}$ & $\mathscr{\omega}^{\infty}$ & 으 \\
\hline+ & + & + & + & + & + & + & + & $م_{\infty}^{\infty}$ \\
\hline $\begin{array}{l}\infty \\
\infty \\
\infty\end{array}$ & م. & $\begin{array}{l}\infty \\
\infty \\
\infty\end{array}$ & ف & م & $\begin{array}{c}\infty \\
\infty \\
\infty\end{array}$ & $\begin{array}{c}\infty \\
\infty_{\infty}^{\infty}\end{array}$ & $n_{1}^{\infty}$ & o \\
\hline 45 & NN & 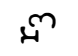 & $L^{+}$ & $\stackrel{n}{n}$ & ماب & $\hat{n}$ & 으 & 응 \\
\hline+ & + & + & + & + & + & + & م & م \\
\hline r & R & $\stackrel{n}{n}$ & $\stackrel{n}{n}$ & R & م) & م. & $\infty$ & or \\
\hline $4^{-}$ & $\mathcal{N}$ & ஸ্ণ & ${ }_{4}^{4}$ & in & 'مי & 응 & 응 & +으 \\
\hline+ & + & + & + & + & + & مَ & ما & مَّم \\
\hline من & مق: & مَ' & $\begin{array}{l}0 \\
0 \\
0\end{array}$ & $\begin{array}{l}0 \\
0 \\
0\end{array}$ & or & & & \\
\hline 4 & L्र & m & $\mathscr{Q}^{\Delta}$ & L & 으 & 으 & 으 & 음 \\
\hline+ & + & + & + & + & in & in & ?n & in \\
\hline $\begin{array}{c}p^{\text {nn }} \\
\text { in }\end{array}$ & $\begin{array}{l}\text { in } \\
\text { in }\end{array}$ & in & in & مी & 0 & & $\dot{\varphi}^{\infty}$ & $n^{a}$ \\
\hline $4^{-}$ & $L^{N}$ & m & st & 음 & 으 & 으 & 으 & 으 \\
\hline${ }^{+} \circ$ & + & + & + & S4 & 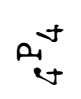 & $\mathrm{R}_{4}^{\checkmark}$ & $a_{t}^{t}$ & $\alpha_{v}^{v}$ \\
\hline$\sim^{*}$ & : & 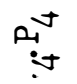 & $\alpha_{1}^{G}$ & $i^{n}$ & $4^{0}$ & s. & & $4^{\sigma}$ \\
\hline 45 & $\mathscr{L}^{N}$ & m & 음 & 으 & 으 & 으 & 으 & 웅 \\
\hline+ & $+\circ$ & + & $E_{i=}^{m}$ & $n_{m}^{m}$ & $n_{m}^{m}$ & $n_{m}^{m}$ & $n_{m}^{m}$ & $p_{m}^{m}$ \\
\hline m & im & n & & $\operatorname{lin}^{\text {Ln }}$ & قن & $i^{n}$ & $\mu^{\infty}$ & $r^{a}$ \\
\hline $4^{-}$ & s. N & +음 & + & $\stackrel{+}{+} \circ$ & $+{ }^{+} \circ$ & $\stackrel{+}{\circ}$ & + & + \\
\hline$+{ }^{+}$으 & + & N & $\begin{array}{l}\text { CV } \\
\alpha^{C V}\end{array}$ & $\stackrel{N}{N}$ & $n_{N}^{N}$ & مN & $n_{\sim}^{N}$ & $a_{N}^{N}$ \\
\hline$a^{4}$ & $a^{N}$ & $\dot{s}^{m}$ & $4^{S}$ & $i^{n}$ & $4^{6}$ & s. & $\mu^{\infty}$ & $\mu^{a}$ \\
\hline $4-$ & + & + & + & $+\circ$ & $+\circ$ & + & + & + \\
\hline+ & - & 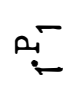 & - & $\stackrel{-}{-}$ & : & $R_{-}^{-}$ & in & - \\
\hline$L^{-}$ & $\mu^{N}$ & $\mu^{m}$ & $\mathscr{t}^{t}$ & $H^{\text {nn }}$ & $4^{0}$ & $\omega^{-1}$ & $\mu^{\infty}$ & ${ }^{a}$ \\
\hline & & & & 11 & & & & \\
\hline 음 & 으 & 음 & 으 & 으 & 으 & 으 & 으 & $\circ 7$ \\
\hline$s^{-}$ & $x^{N}$ & $r^{m}$ & 40 & $H^{\text {in }}$ & $4^{0}$ & s &,$^{\infty}$ & $4^{\infty}$ \\
\hline
\end{tabular}


20

Tabela 04. Expressão para obtenção dos efeitos diretos (P)

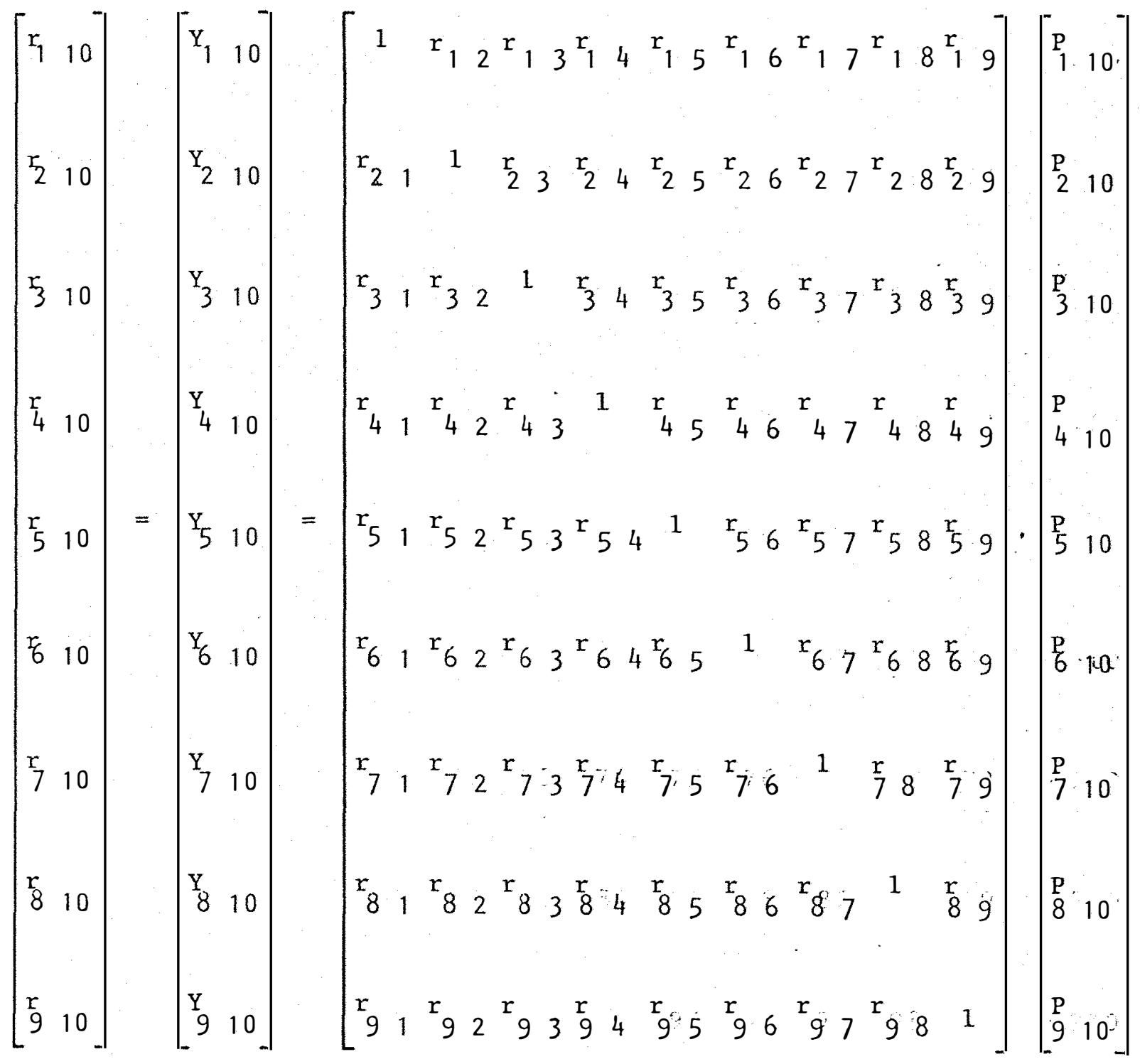


4. RESULTADOS E DISCUSSÃO

4.1. Fatores que afetam a disponibilidade de $Z n$ no solo

4.1.1. Efeito de doses de $N$ e PKCaMg na disponibili dade de Zn no solo

As anāises de variância e coeficientes de varia ção, referentes à concentração de $Z n$ disponível nos solos LE e PV, encontram-se na Tabela 05. Nas Tabelas 06,07 e 08 estão apresentados os desdobramentos da anālise de variância, em regressão linear e quadrática. Os coeficientes de correlação entre a concentração de $\mathrm{Zn}$ disponível e o $\mathrm{pH}$ do solo, estão in seridos na Tabela 09 e, na Figura 01 estão as curvas, equações de regressão e ponto de mäximo, para a concentração de Zn disponível em relação a doses de $N$. 
Tabela 05. Anālises de variância e coeficientes de variação para doses de $N$ e PKCaMg, referentes à concentração de Zn disponível (ppm) nos solos LE e PV.

\begin{tabular}{cccc}
\hline & & \multicolumn{2}{c}{ Q M } \\
\cline { 3 - 4 } Causas de variação & G.L & LE & PV \\
\hline N & 2 & $0,0439^{*}$ & 0,0288 \\
PKCaMg & 2 & $1,4902^{* *}$ & $4,9214 * *$ \\
N x PKCaMg & 4 & $0,1197^{* *}$ & $0,06345^{*}$ \\
Tratamento & $(8)$ & $0,4434^{* *}$ & $1,2693^{* *}$ \\
Resíduo & 27 & 0,0130 & 0,0170 \\
\hline Coeficiente de variação & & 6,35 & 10,82 \\
\hline
\end{tabular}

* - Significativo ao nível de $5 \%$ de probabilidade ** - Significativo ao nível de $1 \%$ de probabilidade

Tabela 06. Desdobramento das análises de variância em regres são 1 inear e quadrática, para a concentração de $\mathrm{Zn}$ nos solos LE e PV, referente a doses de $N$ den tro de PKCaig na dose zero.

\begin{tabular}{lccc}
\hline & & \multicolumn{2}{c}{ Q M } \\
\cline { 3 - 4 } Causas de variação & G.L & LE & PV \\
\hline Regressão linear & 1 & 0,0128 & $0,2048^{*}$ \\
Regressão quadrätica & 1 & 0,0011 & 0,0193 \\
Tratamento & $(2)$ & 0,0070 & $0,1120^{*}$ \\
Resíduo & 9 & 0,013 & 0,0170 \\
\hline
\end{tabular}

* - Significativo ao nível de $5 \%$ de probabilidade 
Tabela 07. Desdobramento das anälises de variância em regressão linear e quadrática, para a concentração de $Z$ n nos solos LE e PV, referente a doses de $N$ dentro de PKCaMg na dose um.

\begin{tabular}{lccc}
\hline & & \multicolumn{3}{c}{ Q M } \\
\cline { 3 - 4 } Causas de variação & G.L & LE & PV \\
\hline Regressão linear & 1 & $0,1922^{* *}$ & 0,0480 \\
Regressão quadrätica & 1 & 0,0054 & 0,0104 \\
Tratamento & $(2)$ & $0,0988^{*}$ & 0,0292 \\
Resíduo & 9 & 0,0130 & 0,0170 \\
\hline
\end{tabular}

* - Significativo ao nível de $5 \%$ de probabilidade ** - Significativo ao nível de $1 \%$ de probabilidade

Tabela 08. Desdobramento das anālises de variância em regressão linear e quadrática, para a concentração de $Z$ n nos solos LE e PV, referente a doses de $N$ dentro de PKCaMg na dose dois.

\begin{tabular}{lcccc}
\hline & & \multicolumn{2}{c}{$Q$ M } \\
\cline { 3 - 5 } Causas de variação & G.L & LE & PV \\
\hline Regressão linear & 1 & $0,1985^{*}$ & 0,0072 \\
Regressão quadrätica & 1 & $0,1568^{*}$ & 0,0216 \\
Tratamento & $(2)$ & $0,1776^{*}$ & 0,0144 \\
Resíduo & 9 & 0,0130 & 0,0170 \\
\hline$* \quad-$ Significativo ao nível de $5 \%$ de probabilidade \\
$* *$ - Significativo ao nível de $1 \%$ de probabilidade
\end{tabular}


Tabela 09. Coeficientes de correlação entre a concen tração de Zn disponível nos solos LE e PV, $x$ pH do solo

\begin{tabular}{lcc}
\hline & & Coeficiente de correlação \\
\cline { 2 - 2 } Tratamentos & LE & PV \\
\hline Doses de N dentro de & $-0,44$ & $-0,57$ \\
PKCaMg na dose zero & & \\
Doses de N dentro de & $-0,76 * *$ & 0,24 \\
PKCaMg na dose um & & \\
Doses de N dentro de & $-0,34$ & $-0,18$ \\
PKCaMg na dose dois & & \\
\hline
\end{tabular}

** - Significativo ao nível de $1 \%$ de probabilidade 


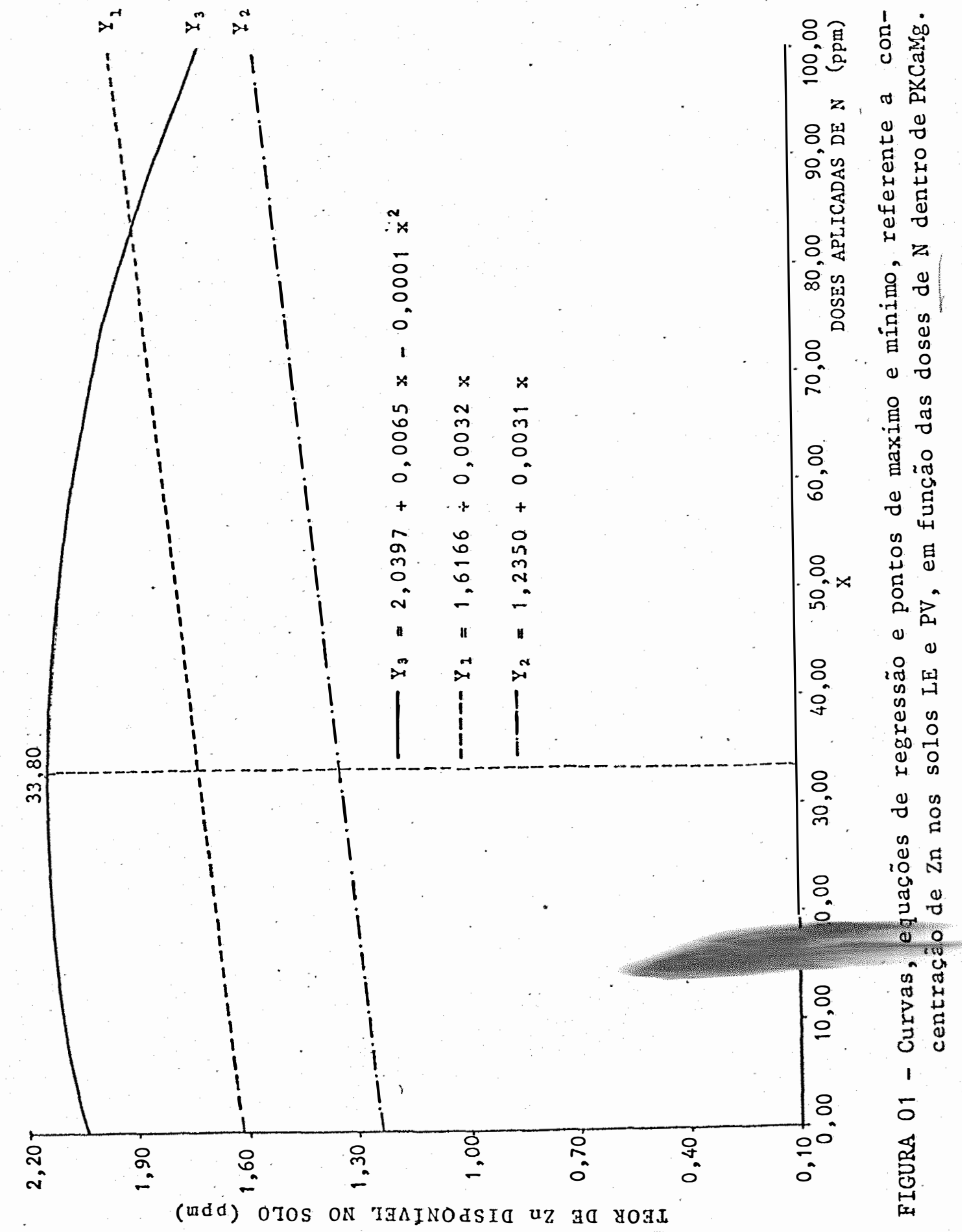


Para o solo LE, conforme a Tabela 05 , verifica se que houve efeito significativo das doses de $\mathrm{N}$ e PKCaMg, assim como da interação $N \times P K C a M g$, ou seja, as doses de $N$ influenciaram as doses de PKCaMg, quanto a concentração de Zn disponíve1 no solo. No desdobramento (Tabela 06), observa-se que as doses de $N$ dentro de PKCaMg na dose zero, não diferiram entre si quanto ao parâmetro analisado. Para as doses de $N$ dentro de PKCaMg na dose um (Tabela 07) houve diferença significativa entre as doses de $N$ testadas, com os dadọs se ajustan do a equação de regressão 1 inear, em relação à concentração de Zn disponível no solo, como se verifica pela figura 01 ( $\left.\mathrm{Y}_{2}\right)$.

Houve portanto, um aumento na concentração de $Z n$ no solo à medida que se aumentou a dose de $N$, na razão de $31.10^{-4}$ ppm de Zn a cada ppm de $N$ aplicado. Para doses de $N$ dentro de PKCaMg na dose dois (Tabela 08), também houve diferença signi ficativa entre as doses de $N$, sendo que os dados se ajustaram à equação do 29 grau. Este efeito é ilustrado na Figura 01 ( $\left.Y_{3}\right)$, onde se verifica aumento na concentração de $Z n$ disponível no solo à medida que se aumentou a dose de $N$ de 0 para 33,80 ppm e diminuída quando se aplicou doses mais elevadas deste elemento. Quanto ao solo PV (Tabela 05), não houve efeito significativo quando se isolou doses de $N$, o mesmo não ocorren do para doses de PKCaMg, e para a interação $N \times$ PKCaMg. No desdobramento houve apenas efeito significativo das doses de $N$ dentro da dose zero de PKCaMg (Tabela 06), com um efeito 1 inear 
crescente de $32 \cdot 10^{-4} \mathrm{ppm}$ de $\mathrm{Zn}$ para cada ppm aplicado de $N$, conforme ilustrado na Figura $01\left(Y_{1}\right)$. As doses de $N$ dentro de PKCaMg nas doses um e dois não foram significativas, ou se$j a$, não influenciaram a disponibilidade de $Z n$ no solo.

Por outro lado, hầ de se frisar que, as respos tas à disponibilidade de Zn nos solos LE e PV são distintas, quando se testam doses de $N$ e PKCaMg. No solo LE foram significativas as doses de $N$ dentro de PKCaMg nas doses um e dois, mas não na dose zero; ao passo que para o solo PV, somente foi significativo o efeito das doses de $N$ dentro de PKCaMg na dose zero, não o sendo em relaçãoàs doses de $N$ dentro de PKCaMg nas doses um e dois.

Esses resultados mostram que as doses de $N$, além de afetar diferentemente a disponibilidade de $\mathrm{Zn}$ nos solos LE e PV, esse efeito tambëm pode variar, quando se variam outros elementos. Em assim sendo, as doses de $N$ podem não afetar a disponibilidade de $Z$ n no solo, quando a aplicação for feita iso ladamente, no solo LE, isto é, não havendo aplicação de PKCaMg nesses tratamentos, o mesmo ocorrendo quando se testou doses de N dentro de PKCaMg nas doses um e dois, no solo PV.

Por outro lado, as doses de $N$ podem diminuir ou aumentar a disponibilidade de $Z n$ no solo, como se verifica na Figura $01\left(Y_{3}\right)$ com um ponto de mäximo de 33,80 ppm de N. Essa variação na disponibilidade de $Z n$ no solo foi devida ao efeito da reação do solo, tendo o $\mathrm{Zn}$ disponível se correlacionado com o $\mathrm{pH}$ 
$(-0,76 * *)$, como se verifica na Tabela 09. Tal resultado corrobora os obtidos por THORNE (1957), onde è citado que altas doses de N provocam diminuição na concentração de $\mathrm{Zn}$ disponível no solo.

Com relação ao aumento na disponibilidade de $\mathrm{Zn}$ no solo, tal fato pode ser verificado na Figura $01\left(_{1}, Y_{2}\right.$ e $\mathrm{Y}_{3}$ até a aplicação de $33,80 \mathrm{ppm}$ de $\mathrm{N}$ ). Esse aumento para os tratamentos das doses de $N$ dentro de PKCaMg na dose zero (Y ${ }_{1}$ ) no solo PV e doses de $\mathrm{N}$ dentro de PKCaMg na dose um $\left(\mathrm{Y}_{2}\right)$, no solo LE, foi devido ao $N$ aplicado e não à reação do sólo, uma vez que o pH não se correlacionou com o $\mathrm{Zn}$ disponível do solo (Tabela 09). Esses resultados concordam com os obtidos por CHAUDHRY e KAUSAR (1977), no que tange ao aumento de disponibiIidade, mas não com a explicação, onde é citado que uma das provāveis causas desse aumento, e o aumento de solubilidade do Zn no solo; tambēm CHAUdHRY e LONERAGAN (1970) têm o mesmo argumento para tal justificativa.

4.1.2. Efeito de doses de $P$ e NKCaMg na disponibilidade de $\mathrm{Zn}$ no solo

Na Tabela 10 encontram-se as anālises de variância e coeficientes de variação, referentes a concentração de Zn disponível nos solos LE e PV. Nas Tabelas 11,12 e 13 , constam-se os desdobramentos das anälises de variäncia, em re- 
Tabela 10. Anālises de variância e coeficientes de variação para doses de $\mathrm{P}$ e NKCaMg, referente à concentra ção de Zn disponível (ppm), nos solos LE e PV.

\begin{tabular}{|c|c|c|c|}
\hline \multirow[b]{2}{*}{ Causas de variação } & \multirow[b]{2}{*}{ G.L. } & \multicolumn{2}{|c|}{ Q M } \\
\hline & & LE & $\mathrm{PV}$ \\
\hline $\mathrm{P}$ & 2 & $0,2594^{* *}$ & 0,0071 \\
\hline $\mathrm{NKC}$ aMg & 2 & $0,4392 * *$ & $4,0160 * *$ \\
\hline $\mathrm{P} \times \mathrm{x}$ NKCaMg & 4 & $0,2073 * *$ & 0,0185 \\
\hline Tratamento & ( 8 ) & $0,2783^{* *}$ & $1,0150 * *$ \\
\hline Resíduo & 27 & 0,0208 & 0,0125 \\
\hline Coeficiente de variação & & $8,7.8$ & 8,67 \\
\hline
\end{tabular}

Tabela 11. Desdobramento da anālise de variância em regressão linear e quadrätica, para a concentração de $\mathrm{Zn}$ no solo LE, referente a doses de $P$ dentro de NKC aMg na dose zero.

\begin{tabular}{lcc}
\hline Causas de variação & G.L. & Q.M. \\
\hline Regressão 1inear & 1 & $0,2415^{* *}$ \\
Regressao quadrätica & 1 & 0,0007 \\
Tratamento & $(2)$ & $0,1211^{*}$ \\
Resíduo & 9 & 0,0208 \\
\hline
\end{tabular}

* - Significativo ao nível de $5 \%$ de probabilidade ** - Significativo ao nível de $1 \%$ de probabilidade 
Tabeila 12. Desdobramento da análise de variância em re gressão linear e quadrática, para a concentração de $Z n$ no solo LE, referente a doses de P dentro de NKCaMg na dose um.

\begin{tabular}{lcc}
\hline Causas de variação & G.L. & Q.M. \\
\hline Regressão linear & 1 & 0,0325 \\
Regressão quadrätica & 1 & 0,0009 \\
Tratamento & $(2)$ & 0,0167 \\
Resíduo & 9 & 0,0208 \\
\hline
\end{tabular}

Tabela 13. Desdobramento da análise de variância em re gressão linear e quadrática, para a concen traçäo de $Z n$ no solo LE, referente a doses de P dentro de NKCaMg na dose dois.

\begin{tabular}{lcc}
\hline Causas de variação & G.L. & Q.M. \\
\hline Regressão linear & 1 & $0,1984^{* *}$ \\
Regressão quadrätica & 1 & $0,8740^{* *}$ \\
Tratamento & $(2)$ & $0,5362^{* *}$ \\
Resíduo & 9 & 0,0208 \\
\hline
\end{tabular}

** - Significativo ao níve 1 de $1 \%$ de probabilidade 
gressão linear e quadrätica. Os coeficientes de correlação entre a concentração de $\mathrm{Zn}$ disponível e o pH do solo estão apre sentados na Tabela 14 e, na Figura 02 são ilustradas as curvas, equações de regressão e ponto de mínimo, para a concentração de Zn disponíve1 $x$ doses de $P$.

Para o solo LE (Tabela 10), verifica-se que houve efeito significativo das doses de $P$ e NKCaMg, havendo também, efeito significativo da interação $P$ x NKCaMg, ou seja, as doses de $P$ influenciaram as doses de NKCaMg quanto ao parâmetro analisado. Com o desdobramento (Tabela 11), detectou-se efeito significativo das doses de $P$ dentro de NKCaMg na dose zero, com um efeito 1 inear, de maneira que, aumentando-se a dose de $P$, diminuiu-se a concentração de $Z n$ disponível na razão de $17 \cdot 10^{-4}$ ppm de $Z n$ a cada ppm de $P$ aplicado (Fig. 02, $Y_{1}$ ). Para doses de $P$ dentro de NKCaMg na dose um, não houve efeito. significativo na disponibilidade de $Z n \quad(T a b e 1 a 12)$. Com rela ção às doses de $P$ dentro de NKCaMg na dose dois, houve um efeito quadrático na concentração de $Z$ n disponível (Tabela 13) com o ponto de mínimo sendo atingido na concentração de 113,84 ppm de $P$, conforme se visualiza na Figura $02\left(Y_{2}\right)$.

Quanto ao solo PV (Tabela 10), não observou-se efeito significativo das doses de $P$, tanto isoladamente como em interação com NKCaMg, mesmo feito o desdobramento (Tabela 15). Para doses da mistura NKCaMg houve efeito significativo, ou seja, hă um comportamento diferente entre essas doses, no que se 
Tabela 14. Coeficientes de correlação entre a concen tração de Zn disponível nos solos LE e PV, $x$ pH do solo.

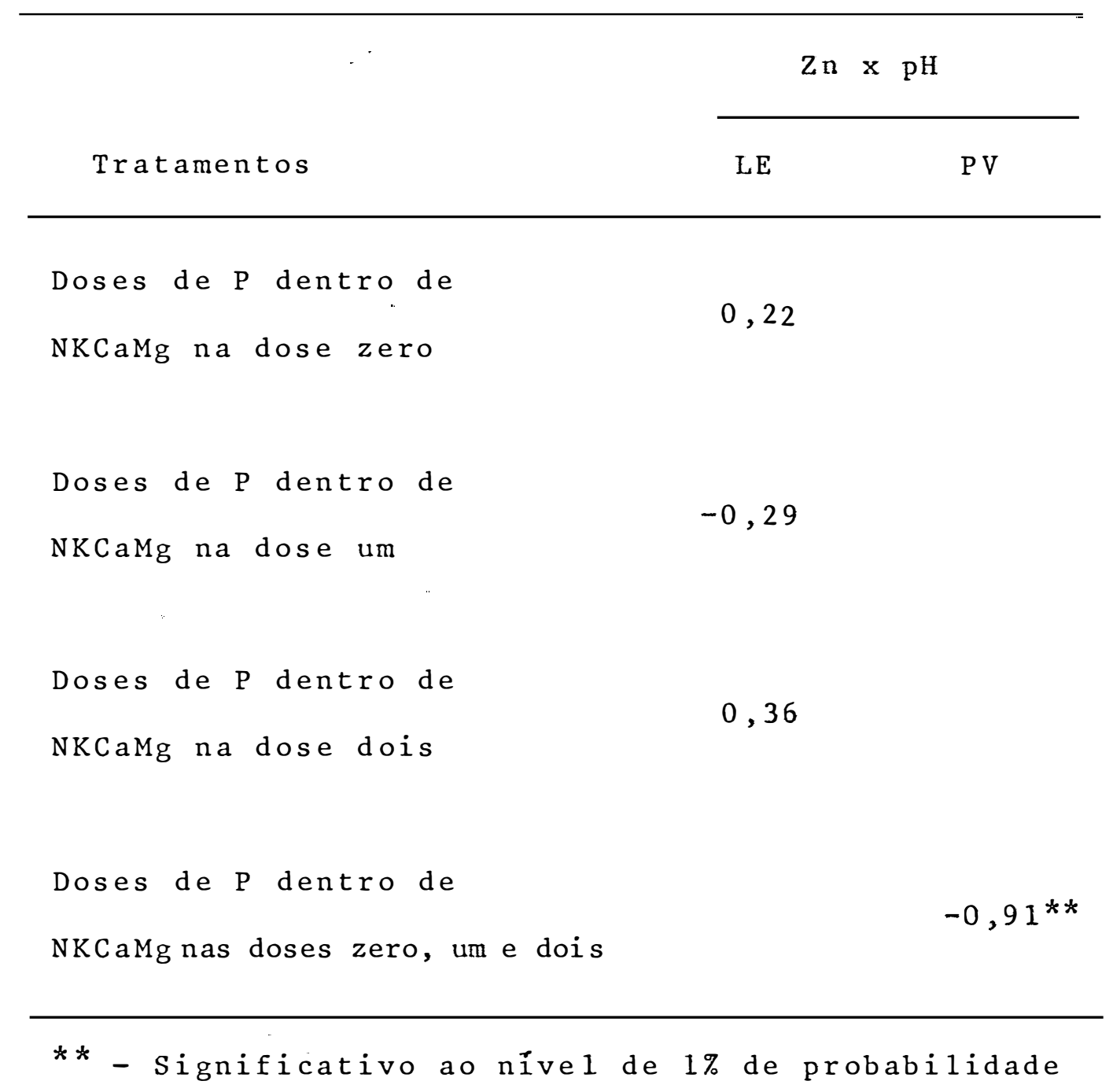




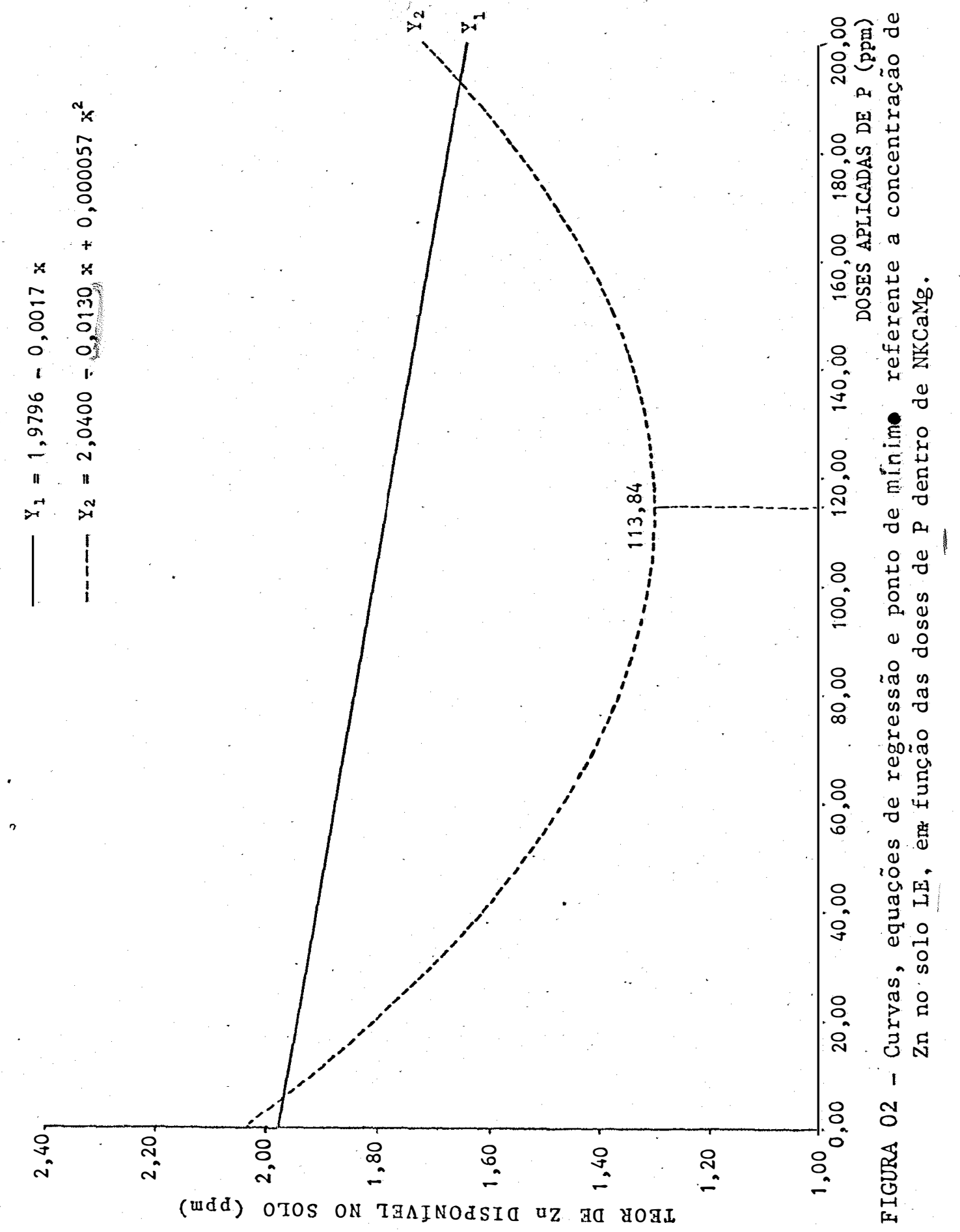


refere à disponibilidade de $\mathrm{Zn}$ no solo, sendo que a dose um de NKCaMg diminuiu significativamente o parâmetro analisado, quan do se compara com as doses zero e dois (Tabela 16). Isto já era esperado uma vez que a dose um inclui material corretivo de acidez, o mesmo não ocorrendo nas doses zero e dois, tanto é,que essa disponibilidade foi função do pH do solo, com o qual se correlacionou $\left(-0,91^{* *}\right)$, conforme a Tabela 14 .

Com relação aos dois solos, observa-se um compor tamento diferente das doses de $P$ em relação à disponibilidade de Zn. Verifica-se que no solo LE houve diferença significativa entre as doses de P dentro de NKCaMg nas doses zero e dois, o mesmo não ocorrendo para doses de $P$ dentro de NKCaMg na dose um; ao passo que para o solo PV, não houve diferença significativa entre as doses testadas de P. Isto mostra respostas distintas com a aplicação de doses de $P$, em relaçãó à concentração de $Z n$ nos dois solos ou, quando se varia outros elementos; podendo as doses de P, diminuir, aumentar, ou mesmo não afetar a disponibilidade de $\mathrm{Zn}$.

Como diminuição na disponibilidade de $\mathrm{Zn}$ no so1o LE, quando se aplicou doses de P dentro de.NKCaMg na dose zero, tal fato foi devido ao efeito das doses de P, uma vez que o pH não se correlacionou com o $\mathrm{Zn}$ disponível do solo $(r=0,22)$, como consta na Tabela 14. Para doses de P dentro de NKCaMg na do se dois, a mesma explicação pode ser dada, pois o pH também não se corre1 acionou com o $\mathrm{Zn}$ disponíve1 do solo $(\mathrm{r}=0,36)$. Esses resul- 
Tabela 15. Desdobramento da ànälise de variância em regressão linear e quadrática, para a concentração de $\mathrm{Zn}$ no solo PV, referente a doses de P dentro de NKCaMg nas doses zero, um e dois.

\begin{tabular}{lcl}
\hline Causas de variação & G.L. & Q.M. \\
\hline Regressão linear & 1 & 0,01417 \\
Regressão quadrätica & 1 & 0,0093 \\
Tratamento & $(2)$ & 0,0071 \\
Resíduo & 9 & 0,0125 \\
\hline
\end{tabular}

Tabela 16. Efeito das doses de NKCaMg na concentra ção de $\mathrm{Zn}$ disponível (ppm) no solo PV.

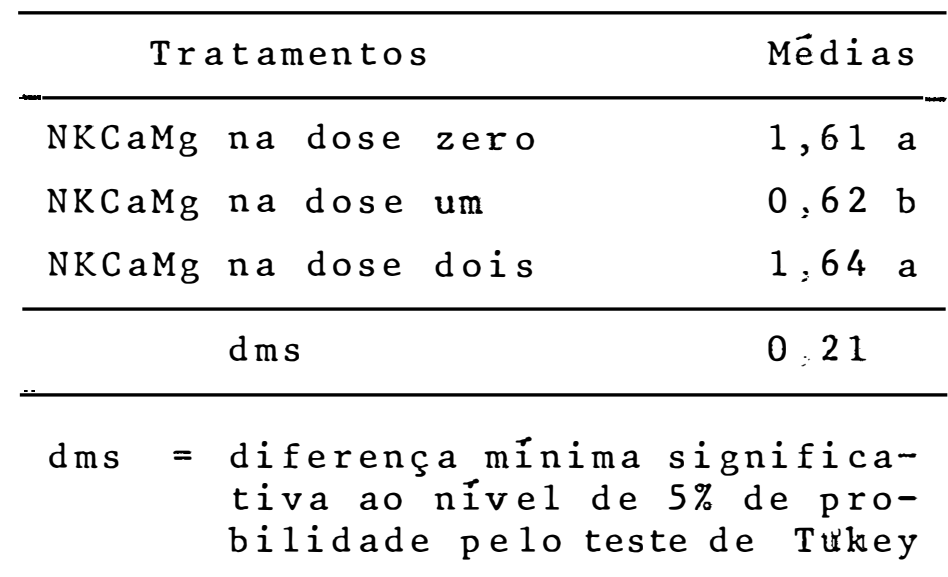


tados em que hä diminuiçãó na disponibilidade de $Z$ n no solo, com apl icação de $P$, concordam com os obtidos por BINGHAN (1963), que trabaIhando com a cultura do milho concluiu que o fösforo diminuía a disponibilidade de Zn no solo; tambēm Misra \& Misra (1969) e Singh \& Dartigues (1969), citados por KALYANASUNDARAM e MEHTA (1970) relatam que a aplicação de $P$ tem um efeito depressivo na dispo nibilidade de $Z$ n no solo; KEEFER et alii (1967) relatam que a reação do $P$ com o solo torna o $Z n$ menos disponível; MANDAL \& HALDAR (1980), estudando o efeito da aplicação de três níveis de $\mathrm{P}(0,50$ e $100 \mathrm{ppm})$ em três tipos de solos incubados em laboratório, verificaram que havia diminuição na disponibilidą de de Zn no solo com a aplicação de $P$, e que o efeito depressivo do. $P$ na extração do $Z n$ foi mais proeminente no $Z n$ nativo do solo do que o aplicado; PRAZAD et alii (1968), HULAGUR et $a Z_{i} i(1975)$, ELLIS et $a Z_{i} i$ (1964), KALYANASUNDARAM \& MEHTA (1979) e BADANUR \& VENKATA RAO (1980), relatam que a aplicação de altas doses de $P$ reduz a disponibilidade de $Z n$ no solo. SEATZ \& JURINAK (1957) concluem que a diminuição na disponibili dade de $\mathrm{Zn}$ deve ser devido a formação de $\mathrm{Zn}_{3}\left(\mathrm{PO}_{4}\right)_{2} \cdot 4 \mathrm{H}_{2} \mathrm{O}$.

SINGH \& SINGH (1980) relatam apenas que o P e Zn se comportam antagonicamente tanto em solos saturados como em solos não saturados. HALDAR \& MANDAL (1981) estudando em casa de vegeta ção o efeito da aplicaçäo de $P$ e $Z n$, concluiram que a aplicação de $P$ diminuía a concentração de $Z n$ nas raízes e parte aérea do arroz, e que esta diminuição era devida à menor disponibilidade do Zn no solo. KHAN (1969), estudando em casa de 
vegetação a resposta do milho doce e arroz à aplicação de P, $\mathrm{Zn}$ e $\mathrm{CaCO}_{3}$, verificou que em condiçöes de solo inundado tanto - $\mathrm{P}$ como o $\mathrm{CaCO}_{3}$ reduziu o conte üdo de $\mathrm{Zn}$ extraído dos so1os. Spencer (1960), citado por PAULI et alii (1968), verificou que o superfosfato imobilizava o $\mathrm{Zn}$ no solo, diminuindo a concentração de $Z n$ das raízes e das folhas. LANGIN et alii (1962) citam que o problema de deficiência de Zn se agrava mediante a aplicação de $\mathrm{P}$, ou em $\mathrm{pH}$ alto onde a disponibilidade de Zn è diminuída.

Doses de P podem também aumentar a disponibilidade de Zn, como se verifica pela Figura $02\left(Y_{2}\right)$, a partir da aplicação de $113,84 \mathrm{ppm}$ de P. Tal fato não è devido ao pH do solo, com o qual não se correlacionou (Tabela 14). Esse resul tado concorda com os obtidos por BINGHAN \& GARBER (1960) onde é citado que o excesso de $P$ resultou em um aumento da solubilida de de $Z n$, citam ainda a não precipitação do Zn pelo fosfato. ELSOKKARY et alii (1981), estudando a aplicação de altas doses de $P(100-200-400$ ppm) e 12,5 e 25 ppm de Zn, concluiram que a aplicação de $P$ aumentou o conteúdo de $Z$ n extraído $\operatorname{com}\left(\mathrm{NH}_{4}\right)_{2} \mathrm{CO}_{3}-\mathrm{EDTA}$. MARINHO \& IGUE (1972), trabalhando em três solos considerados deficientes em $\mathrm{Zn}$, verificaram um aumento na quantidade de $Z n$ extraído pelo método do EDTA, pela aplicação de $P$, embora não houvesse nenhuma tendência definiti va no caso do método do HCl. 
Por outro 1 ado, doses de $P$ podem não afetar a disponibilidade de $Z$ n no solo. Tal fato se verifica na Tabe 1a 12 , quando se testou doses de $P$ dentro de NKCaMg na dose um, ou mesmo na Tabela 10 , onde doses de $P$ não influenciaram a disponibilidade de $Z n$, tanto quando as doses de $P$ foram iso ladas, como em interação com NKCaMg. Esses resultados concor dam com os obtidos por BOAWN et alii (1954): JAMISON (1943); OLSEN (1965); STUKENHOLTZ (1966) e BINGHAN (1963), os quais citam que a aplicação de $P$ năo tem efeito na disponibilidade de $\mathrm{Zn}$ no solo.

4.1.3. Efeito de doses de $K$ e NPCaMg na disponibilidade de $Z$ n no solo

As anāises de variância e coeficientes de varia ção, referentes à concentração de $Z n$ disponível nos solos LE e PV, estão inseridas na Tabela 17 . Na Tabela 18 encontra-se o desdobramento da anälise de variäcia em regressão 1 inear e quadrätica e na Tabela 19 o efeito das doses de NPCaMg na concentração de Zn disponível; para o solo LE. Os coefici cientes de correlação para os dois solos, entre o pH e a concen tração de Zn disponível, encontram-se na Tabela 20 , e nas Tabe 1as 21,22 e 23 estão apresentados os desdobramentos da anā1 ise de variância referente à concentração de $\mathrm{Zn}$ disponível no solo PV, em relação às doses de K x NPCaMg, nas doses zero, 
Tabela 17. Anälises de variância e coeficientes de variação para doses de K e NPCaMg, referente a concentração de Zn disponível (ppm), nos solos LE e PV.

\begin{tabular}{cccc}
\hline Causas de variação & G.L & LE & PV \\
\hline K & 2 & 0,0017 & $0,3463^{* *}$ \\
NPCaMg & 2 & $0,8727 * *$ & $6,3117^{* *}$ \\
K x NPCaMg & 4 & 0,0322 & $0,2654^{* *}$ \\
Tratamento & $(8)$ & $0,2347 *$ & $1,7972^{* *}$ \\
Resíduo & 27 & 0,0266 & 0,0218 \\
\hline Coeficiente de variação & & 9,98 & 10,32 \\
\hline
\end{tabular}

** - Significativo ao nível de $1 \%$ de probabilidade

Tabela 18. Desdobramento da análise de variância em regressão linear e quadrätica., para a concentração de $\mathrm{Zn}$ no solo LE, referente a doses de K dentro de NPCaMg nas doses zero, um e dois.

\begin{tabular}{lcc}
\hline Causas de variação & G.L. & Q.M. \\
\hline Regressão linear & 1 & 0,0004 \\
Regressão quadrática & 1 & 0,0029 \\
Tratamento & $(2)$ & 0,0017 \\
Resíduo & 9 & 0,0266 \\
\hline
\end{tabular}


Tabela 19. Efeito das doses de NPCaMg na concentração de $Z$ n disponível ( $\mathrm{ppm}$ ) no solo LE.

\begin{tabular}{cc}
\hline \multicolumn{1}{c}{ Tratamentos } & Médias \\
\hline NPCaMg na dose zero & 1,88 a \\
NPCaMg na dose um & 1,35 b \\
NPCaMg na dose dois & 1,66 a \\
\hline dms & 0,24 \\
\hline \multirow{2}{*}{$=$} & \\
& $\begin{array}{l}\text { diferença mínima significa } \\
\text { tiva a nivel de } 5 \% \text { de pró } \\
\text { babilidade pelo teste de } \\
\text { Tukey, }\end{array}$
\end{tabular}


Tabela 20. Coeficientes de correlação entre a concen tração de Zn disponível nos solos LE e PV, $x$ pH do solo.

\begin{tabular}{|c|c|c|}
\hline \multirow[b]{2}{*}{ Tratamentos } & \multicolumn{2}{|c|}{$\mathrm{Zn} \quad \mathrm{x}$} \\
\hline & LE & PV \\
\hline Doses de $K$ dentro de & & \\
\hline NPCaMg na dose zero & & $-0,15$ \\
\hline Doses de $K$ dentro de & 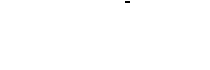 & \\
\hline NPCaMg na dose um. & & 0,08 \\
\hline Doses de $K$ dentro de & & \\
\hline NPCaMg na dose dois & & $-0,27$ \\
\hline Doses de K dentro de & & \\
\hline NPCaMg nas doses zero, um e dois & $-0,61 * *$ & \\
\hline
\end{tabular}

** - Significativo ao nível de $1 \%$ de probabilidade 
Tabela 21. Desdobramento da anälise de variância em regressão linear e quadrática; para a concentração de $\mathrm{Zn}$ no solo $\mathrm{PV}$, referente a doses de $K$ dentro de NPCaMg na dose zero.

\begin{tabular}{lcc}
\hline Causas de variação & G.L. & Q.M. \\
\hline Regressao linear & 1 & $0,1512^{*}$ \\
Regressão quadrätica & 1 & 0,0160 \\
Tratamento & $(2)$ & 0,0836 \\
Residuo & 9 & 0,0218 \\
\hline
\end{tabular}

* - Significativo ao nível de $5 \%$ de probabilidade 
Tabela 22. Desdobramento da anāilse de variância em regressão linear e quadrática, para a con centração de $\mathrm{Zn}$ no: solo PV, referente a doses de K dentro de NPCaMg na dose um.

\begin{tabular}{lcc}
\hline Causas de variação & G.L. & Q.M. \\
\hline Regressão linear & 1 & 0,0018 \\
Regressão quadrätica & 1 & 0,0006 \\
Tratamento & $(2)$ & 0,0012 \\
Resíduo & 9 & 0,0218 \\
\hline
\end{tabular}

Tabela 23. Desdobramento da anālise de variância em regressão linear e quadrática, para a con centração de Zn no solo $\mathrm{PV}$, referente a doses de K dentro de NPCaMg na dose dois.

\begin{tabular}{lcc}
\hline Causas de variação & G.L. & Q.M. \\
\hline Regressão linear & 1 & 0,0242 \\
Regressão quadrätica & 1 & $1,5606^{* *}$ \\
Tratamento & $(2)$ & $0,7924^{* *}$ \\
Resíduo & 9 & 0,0218 \\
\hline
\end{tabular}

** - Significativo ao nível de $1 \%$ de probabilidade 
um e dois, respectivamente. A Figura 03 ilustra o efeito das doses de K dentro de NPCaMg na doze zero $\left(Y_{1}\right)$ e na dose dois $\left(\mathrm{Y}_{2}\right)$.

Para o solo LE, conforme a Tabela 17 , verifica se que não houve efeito significativo das doses de $K$ sobre a disponibilidade de $Z n$, quando se isolou as doses de $K$, ou mes mo em interação com a mistura NPCaMg. No desdobramento em efeito linear e quadrätico também não se verificou efeito das doses de K (Tabela 18). As doses de NPCaMg exerceram um efeito significa tivo na concentração de Zn disponível no solo (Tabela 17), com a dose um acarretando diminuição significativa nesta concentração, quando comparada às doses zero e dois (Tabela 19). Essa vạ riação foi devida a mudança do pH, com o qual manteve correlação, como se verifica pela Tabela 20 ( $r=-0,61 * *)$, fato coerente, desde que se utilizou material corretivo de acidez na dose um de NPCaMg .

Para o solo PV, houve efeito significativo das doses de $K$ e NPCaMg, assim como da intenação $K \times$ NPCaMg, ou seja, as doses de $K$ estão influenciando a mistura NPCaMg, c. con forme a Tabela 17. No desdobramento verifica-se que as doses de K dentro de NPCaMg na dose zero foram diferentes estatisticamente, com os dados se ajustando à equação de regressão 1 inear em relação à concentração de $Z n$ disponível (Tabela 21). Na Figura $03\left(\mathrm{Y}_{1}\right)$, é ilustrado tal fenômeno, havendo um aumento de $28.10^{-4}$ ppm de $Z n$ a cada ppm de $K$ aplicado. Tal fato se deve ao $K$ aplicado e não ao $\mathrm{pH}$ do solo, pois o mesmo não 


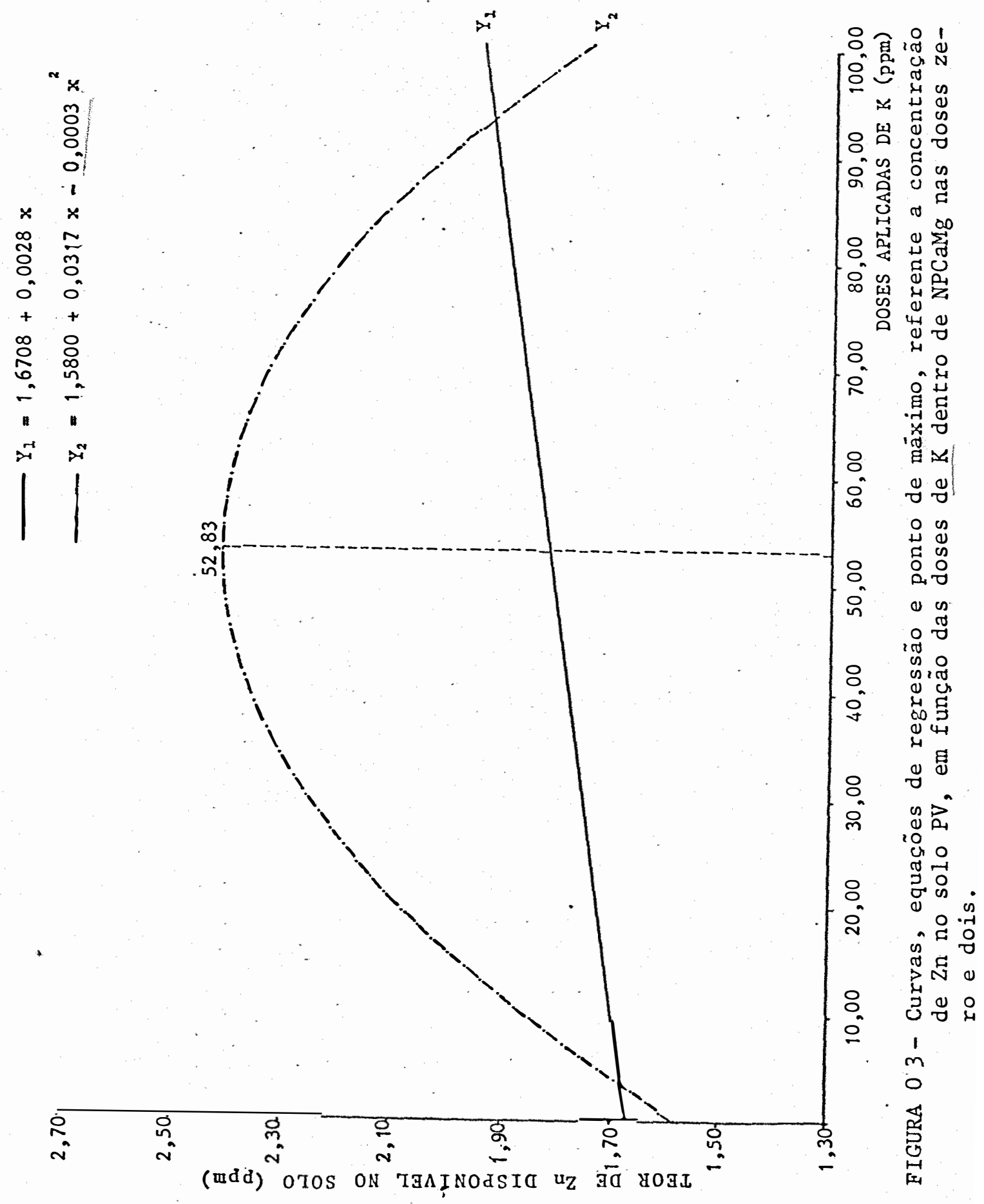


se correlacionou com o Zn disponível do solo, como consta na Tabela $20(\mathrm{r}=-0,15)$. Para as doses de $\mathrm{K}$ dentro de NPCaMg na dose um, não houve efeito na concentração de $Z n$ disponível conforme se verifica na Tabela 22. Na Tabela 23, consta o efeito quadrático das doses de $K$ dentrode NPCấg na dose dois e, na Figura $04\left(\mathrm{Y}_{2}\right)$ e ilustrado tal efeito, onde se verifica uma curva com ponto de mäximo. Esse efeito também não se correlacionou com o $\mathrm{pH}$ do solo $(\mathrm{r}=-0,27)$, como consta na Tabe1a 20 .

$$
\text { Quando se comparam os dois solos, verifica-se um }
$$

comportamento diferente na disponibilidade de $Z n$ em relação às doses aplicadas de $K$. No solo LE as doses de $K$ não influen ciarama disponibilidade de $\mathrm{Zn}$ ao passo que, no solo PV houve diferenças estatísticas entre as doses de $K$ dentro de NPCaMg nas doses zero e dois.

Tais resultados mostram,que as doses de $K$ tem um comportamento diferente não somente em relação ao tipo de solo, como também devido a presença de outros elementos.

No presente trabalho as doses de K näo afetaram a disponibilidade de Zn no solo, quando foram testadas no solo LE, ou quando testadas no solo PV nos tratamentos onde estava incluso corretivos de acidez. Deve-se frisar que o pH do solo não se correlacionou com a disponibilidade de Zn no solo PV e se correlacionou no solo LE. 
Na Figura $03\left(\mathrm{Y}_{2}\right.$ a partir da aplicação de $52,83 \mathrm{ppm}$ de K), observou-se diminuição na concentração de $Z n$, o que cor robora o trabalho de STUKENHOLTz et ali $i$ (1966).

Por outro lado, observa-se na Figura 03 ( $_{1}$ e $\mathrm{Y}_{2}$ até a aplicação de 52,83 ppm de K), que houve aumento na dispo nibilidade de $\mathrm{Zn}$, concordando com os resultados obtidos por WEAR e PATTERSON (1965).

4.2. Faţores que afetam a concentração de $\mathrm{Zn}$ na planta

4.2.1. Efeito de doses de $N$ e PKCaMg na concentração de Zn na planta

Na Tabela 24 encontram-se as anälises de variância e coeficientes de variação, sobre os dados da cóncentração de $Z$ n na planta, em relação aos tratamentos testados. Nas Tabelas 25, 26 e 27 , constam os desdobramentos da anälise de variância, em regressão linear e quadrātica, para doses de $N$ dentro de PKCaMg na dose zero, na dose um e na dose dois, res pectivamente. Os efeitos diretos (P) entre a concentração de Zn na planta e as doses aplicadas de $N$, os efeitos indiretos nesta relação ( $P x r)$, via porcentagem na planta de $N, P, K$, $\mathrm{Ca}, \mathrm{Mg}$, conteúdo de matéria seca da parte aérea, teor disponí 
Tabela 24: Anālises de variância e coeficientes de variação, referente aos dados da concentração de $Z n$ na plan ta (ppm) em relação a doses de $N$ e $\mathrm{PKCaMg}$, em um LE e PV.

\begin{tabular}{ccrr}
\hline & & \multicolumn{2}{c}{$Q$ M } \\
\cline { 3 - 4 } Causas de variação & G.L & LE & PV \\
\hline N & 2 & $43,3611^{*}$ & $744,36^{* *}$ \\
P KCaíg & 2 & $1.085,7778^{* *}$ & $9281,445^{* *}$ \\
N x PKCaMg & 4 & $77,2778^{* *}$ & $353,9425^{* *}$ \\
Tratamento & $(8)$ & $320,9236^{* *}$ & $2683,4225^{* *}$ \\
Residuo & 27 & 13,6389 & 14,8244 \\
\hline Coeficiente de variação & & 7,58 & 5,90 \\
\hline
\end{tabular}

* - Significativo ao nível de $5 \%$ de probabilidade ** - Significativo ao nível de $1 \%$ de probabilidade

Tabela 25. Desdobramento das anālises de variância, pa ra doses de $\mathrm{N}$ dentro de $\mathrm{PkCaMg}$ na dose zero, em regressão 1 inear e quadrática.

\begin{tabular}{lcrr}
\hline & & \multicolumn{2}{c}{$Q$ M } \\
\cline { 3 - 4 } Causas de variação & G.L & LE & \multicolumn{1}{c}{ PV } \\
\hline Regressão linear & 1 & $171,1250^{*}$ & $2628,125^{* *}$ \\
Regressão quadrätica & 1 & 40,0420 & $77,0417^{*}$ \\
Tratamento & $(2)$ & 105,5835 & 1352,5833 \\
Resíduo & 9 & 23,7500 & 33,7503 \\
\hline
\end{tabular}

* - Significativo ao nível de $5 \%$ de probabilidade ** - Significativo ao nível de $1 \%$ de probabilidade 
Tabela 26. Desdobramento das anälises de variância, para doses de $N$ dentro de PKCaMg na dose um em regressão 1 inear e quadrätica.

\begin{tabular}{lccc} 
& & \multicolumn{2}{c}{ Q M } \\
\cline { 3 - 4 } Causas de variação & G.L & LE & PV \\
\hline Regressão 1inear & 1 & 6,1250 & $66,1250^{*}$ \\
Regressão quadrätica & 1 & $70,0417^{* *}$ & 1,0417 \\
Tratamento & $(2)$ & 38,0834 & 37,5834 \\
Resíduo & 9 & 13,6389 & 14,8244 \\
\hline
\end{tabular}

* - Significativo ao nível de $5 \%$ de probabilidade ** - Significativo ao nível de $1 \%$ de probabilidade 
Tabela 27. Desdobramento das anālises de variância, para do* ses de $N$ dentro de PKCaMg na dose dois em regressão linear e quadrätica.

\begin{tabular}{lccc} 
& & \multicolumn{2}{c}{$Q$ M } \\
\cline { 3 - 4 } Causas de variação & G.L. & LE & PV \\
\hline Regressão 1inear & & 0,1250 & 55,1250 \\
Regressão quadrätica & 1 & $108,3750 * *$ & $77,0416^{*}$ \\
Tratamento & $(2)$ & 54,2500 & 66,0833 \\
Resíduo & 9 & 13,6389 & 14,8244 \\
\hline
\end{tabular}

* - Significativo ao nível de $5 \%$ de probabilidade ** - Significativo ao nível de $1 \%$ de probabilidade 
vel de Zn no solo e pH do solo, além dos coeficientes de correlação simples $(r)$, coeficiente de determinação $\left(R^{2}\right)$ e variâncias residuais (w), encontram-se nas Tabelas 28,29 e 30 . Na Figura 04 encontram-se as equações de regressão, pontos de mäximo e mỉnimo e as respectivas curvas, referente à variação na concentração de $Z$ n na planta em relação às doses de $N$ dentro de PKCaMg nas doses zero, um e dois.

Com relação ao solo LE (Tabela 24), verifica-se o efeito significativo das doses de $N$ e PKCaMg, além da interação $N$ PKCaMg, o que indica que as doses de $N$ estão influenciando a mistura PKCaMg. Face a isto, foi feito o desdo bramento da anālise de variância para doses de $N$ dentro de cada nível de PKCaMg (Tabelas 25, 26 e 27), detectando-se um efeito linear na concentração de $Z n$ na planta, quando se testou doses de $N$ dentro de PKCaMg na doze zero (Tabela 25), fenômeno este, ilustrado na Figura $04\left(Y_{1}\right)$. Na Tabela 28 , cons ta o efeito direto das doses de $N$ sobre a concentração de $\mathrm{Zn}$ na planta, onde se verifica um efeito negativo $(-0,838)$, o que quer dizer, que se os outros parâmetros interferentes nessa re1 ação, permanecessem constantes, à medida que se aumentasse as doses aplicadas de $N$, haveria uma diminuição na concentração de Zn na planta. Como efeito indireto, evidenciou-se a porcenta gem na planta de $\mathrm{N}, \mathrm{K}, \mathrm{Ca}$ e o teor disponível de Zn no solo. A concentração de $N$ e $K$ exerceram um efeito negativo na relação concentração de $Z n$ na plantax doses de $N(-0,673$ e $-0,682$ 
Tabela 28. Desdobramento das correlações simples, em componentes de efeitos diretos e indiretos, para a concentração de. Zn na planta $x$ doses de $N$ dentro da dose zero de PKCaMg, coeficientes de determinação e variâncias residuais, nos solos LE e PV.

\begin{tabular}{|c|c|c|c|c|c|c|}
\hline \multirow[b]{2}{*}{ Modo de ação } & \multicolumn{2}{|c|}{$\begin{array}{l}\text { Efeito direto } \\
\text { (P) }\end{array}$} & \multicolumn{2}{|c|}{$\begin{array}{l}\text { Efeito indireto } \\
(\mathrm{P} \times \mathrm{r})\end{array}$} & \multicolumn{2}{|c|}{$\begin{array}{l}\text { Correlação } \\
\quad(r)\end{array}$} \\
\hline & $\mathrm{LE}$ & $\mathrm{PV}$ & $\mathrm{LE}$ & $\mathrm{PV}$ & LE & $\mathrm{PV}$ \\
\hline \multicolumn{7}{|l|}{ Zn na planta $\mathrm{x}$ doses de $\mathrm{N}$} \\
\hline Efeito direto & $-0,838$ & 0,174 & & & & \\
\hline Efeito indireto via $\% \mathrm{~N}$ & & & $-0,673$ & $-0,056$ & & \\
\hline Efeito indireto via \% $\mathrm{P}$ & & & 0,063 & $-0,001$ & & \\
\hline Efeito indireto via $\% \mathrm{~K}$ & & & $-0,682$ & $-0,180$ & & \\
\hline Efeito indireto via \% Ca & & & 1,160 & 0,099 & & \\
\hline Efeito indireto via \% $\mathrm{Mg}$ & & & 0,016 & $-0,033$ & & \\
\hline Efeito indireto via teor $\mathrm{d}$ & $\mathrm{m} \cdot \mathrm{s}$ & & $-0,034$ & $-0,015$ & & \\
\hline Efeito indireto via $\mathrm{Zn}$ dis & onível & & 0,826 & 0,018 & & \\
\hline Efeito indireto via $\mathrm{pH}$ & & & $-0,044$ & $-0,294$ & & \\
\hline \multicolumn{5}{|c|}{ Total ( $r$, Zn na planta $x$ doses de $N$ ) } & $-0,206$ & $-0,284$ \\
\hline $\mathrm{R}_{10}^{2}(1,2, \ldots, 9)=\mathrm{R}^{2}$ & & & 0,913 & 0,971 & & \\
\hline$R_{10 W}^{2}=W$ & & & 0,087 & 0,029 & & \\
\hline
\end{tabular}


Tabela 29. Desdobramento das correlações simples, em componentes de efeitos diretos e indiretos, para a concentra ção de $Z n$ na planta e doses aplicadas de $N$ dentro da dose um de PKCaMg, coeficientes de determinação e variāncias residuais, nos solos LE e PV.

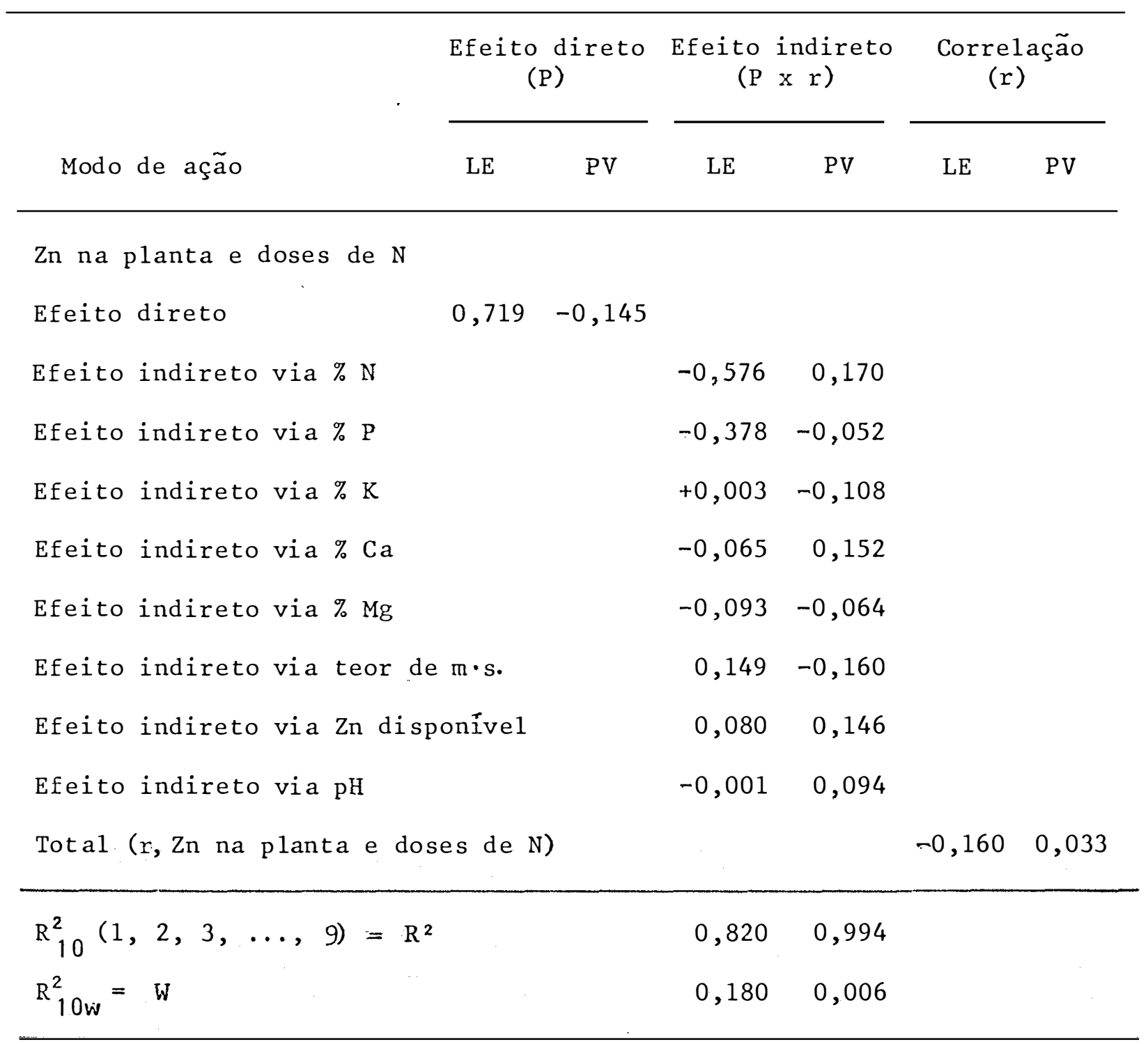


Tabela 30. Desdobramento das correlações simples, em componentés de efeitos diretos e indiretos, para a concentração de Zn na planta $x$ doses aplicadas de $N$ den-tro da dose dois de PKCaMg, coeficientes de determinação e variâncias residuais, nos solos LE e PV.

\begin{tabular}{|c|c|c|c|c|c|c|}
\hline \multirow[b]{2}{*}{ Modo de ação } & \multicolumn{2}{|c|}{$\begin{array}{c}\text { Efeito direto } \\
\text { (P) }\end{array}$} & \multicolumn{2}{|c|}{$\begin{array}{l}\text { Efeito indireto } \\
\left(\begin{array}{l}(\mathrm{P} \times \mathrm{r})\end{array}\right.\end{array}$} & \multicolumn{2}{|c|}{$\begin{array}{l}\text { Corrèlação } \\
\text { (r) }\end{array}$} \\
\hline & $\mathrm{LE}$ & $\mathrm{PV}$ & $\mathrm{LE}$ & $\mathrm{PV}$ & $\mathrm{LE}$ & $\mathrm{PV}$ \\
\hline \multicolumn{7}{|l|}{ Zn na planta $x$ doses de $N$} \\
\hline Efeito direto & 0,352 & 0,179 & & & & \\
\hline Efeito indireto via \% $\mathrm{N}$ & & & $-0,418$ & 0,372 & & \\
\hline Efeito indireto via \% P & & & 0,063 & $-0,649$ & & \\
\hline Efeito indireto via $\% \mathrm{~K}$ & & & $-0,673$ & $-0,003$ & & \\
\hline Efeito indireto via \% Ca & & & 0,486 & $-0,049$ & & \\
\hline Efeito indireto via \% $\mathrm{Mg}$ & & & $-0,360$ & 0,110 & & \\
\hline Efeito indireto via teor de & $\mathrm{m} \cdot \mathrm{s}$ & & $-0,511$ & $-0,207$ & & \\
\hline Efeito indireto via $\mathrm{Zn}$ disp & onível & & 0,503 & 0,081 & & \\
\hline Efeito indireto via $\mathrm{pH}$ & & & 0,346 & 0,00 & & . \\
\hline Total ( $r$, Zn na planta $x$ do & ses de & N) & & & $-0,248$ & $-0,166$ \\
\hline $\mathrm{R}_{10}^{2}(1,2, \ldots, 9)=\mathrm{R}^{2}$ & & & 0,948 & 0,938 & & \\
\hline $\mathrm{R}_{10 \mathrm{~W}}^{2}=\mathrm{W}$ & & & 0,052 & . 0,062 & & \\
\hline
\end{tabular}




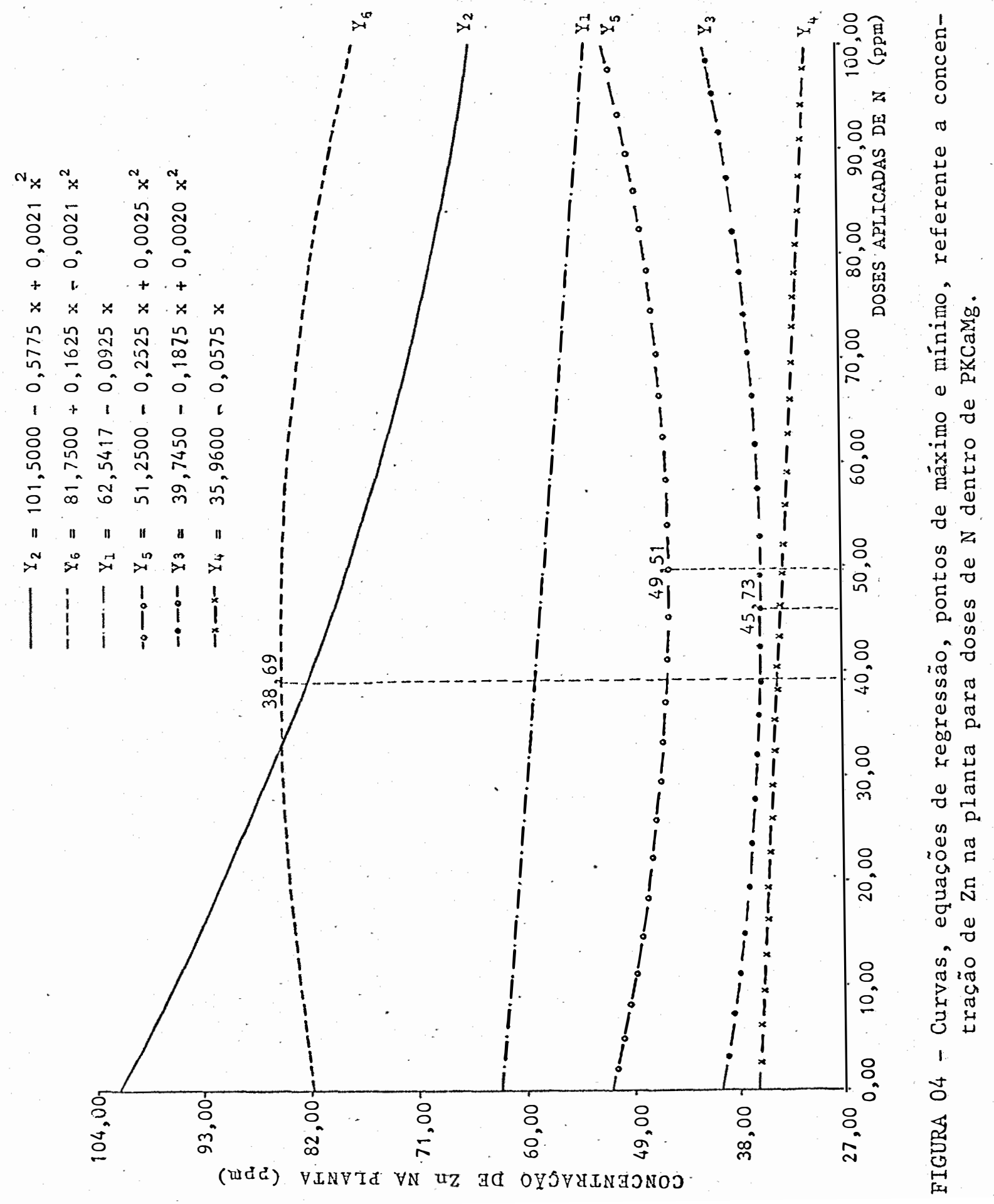


respectivamente), ou seja; a medida que hä um aumento na concentração de $N$ e $K$ na planta, há uma diminuição nesta relação. Pa ra a concentração de Ca na planta e $Z n$ disponível no solo, o efeito na relação foi positivo $(1,160$ e 0,826 respectivamente), o que quer dizer que a medida que hâ um aumento na concentração de Ca na planta ou no teor de $\mathrm{Zn}$ disponível no solo, hả um aumento na relação concentração de $Z n$ na planta $x$ doses de $N$; desde que os outros parâmetros permaneçam constantes. Com relação aos outros parâmetros analisados, os efeitos foram de menor magnitude e quando se verifica a somatória de todos os efei tos estudados, nota-se que prevaleceu o efeito negativo, ou seja, à medida que se aumentou a dose de $N$ aplicada, houve diminuição na concentração de $Z n$ na planta $(r=-0,206)$, conforme ilustrado na Figura $04\left(Y_{1}\right)$.

Para o cultivo no solo PV, verifica-se pela Tabela 24 , o efeito significativo das doses de $N$, PKCaMg, assim como da interação $N$ PKCaMg. Na Tabela 25 , consta o efeito quadrático das doses de $N$ dentro de PKCaMg na doze zero, em relação à concentração de $Z n$ na planta e na Tabela 28 , verifi ca-se que o efeito direto das doses de $N$ sobre a concentração de $Z n$ na planta foi positivo $(0,174)$. Como efeito indireto, os parâmetros de maior magnitude foram a concentração na planta de $K(0,180)$, Ca $(0,099)$ e. pH do solo $(-0,294)$. Os outros parâmetros analisados tiveram um efeito ainda menor, preva lecendo entretanto o efeito negativo, ou seja, a medida que se 
aumentou as doses de $N$ aplicadas, houve uma diminuição na concentração de $Z$ n na planta $(r=-0,284)$, como se verifica pela Figura $04\left(\mathrm{Y}_{2}\right)$.

Com relação aos coeficientes de determinação $(0,913$ e 0,971 , respectivamente para o solo LE e PV), isto indica que $91,3 \%$ e $97,1 \%$ da variação na concentração de Zn na planta foi explicada pelas variáveis consideradas e apenas $8,7 \%$ e $2,9 \%$, pela variäve 1 residua 1 .

Para doses de $N$ dentro de PKCaMg na dose um, o desdobramento da anälise de variāncia se encontra na Tabe1 a 26 , onde se verifica o efeito quadrätico no solo LE e efeito linear no solo PV, para a concentração de $\mathrm{Zn}$ na planta. Na Tabela 29 consta os efeitos diretos e indiretos das doses de N dentro de PKCaMg na dose um, onde se verifica que para o solo LE, o efeito direto das doses de $N$ sobre a concentração de $\mathrm{Zn}$. na planta, foi positivo $(0,719)$, mas totalmente neutralizado pe, los efeitos indiretos via porcentagem na planta de $N(-0,576)$ e $\mathrm{P}(-0,378)$; os outros parâmetros exerceram efeitos de menor magnitude, de tal modo que a correlação simples entre a concentração de $Z n$ na planta $x$ doses aplicadas de $N$, foi nega tiva e não significativa $(r=-0,160)$. Na Figura $04 \quad\left(Y_{3}\right)$ é ilustrado o pequeno efeito das doses aplicadas de $N$ sobre a concentração de $Z n$ na planta. Para o solo PV, o efeito dire to das doses aplicadas de $N$ sobre a concentração de $Z n$ na plan ta foi negativo $(-0,145)$ e de uma magnitude bem menor quando com 
parado ao efeito direto no solo LE. Os efeitos indiretos positivos de maior evidência, se referem a concentração na planta de $N(0,170), C a(0,152)$ e teor disponível de $Z$ n no solo, e como efeito indireto negativo, o teor de matëria seca da parte aérea $(-0,160)$, o que sugere um efeito diluição. Como o efeito direto e o teor de matéria seca foram contrabalançados pe la concentração de $N$ e Ca na pianta e o teor disponível de Zn no solo, o coeficiente de correlação simples foi não significativo $(r=0,033)$. Na Figura $04\left(\mathrm{Y}_{4}\right)$ consta a pequena variação na concentração de $Z n$ na planta, quando se confronta com as doses ap 1 icadas de N.

Os coeficientes de determinação 0,820 e 0,994 , respectivamente para o solo LE e PV, indicam que para o so1o LE outros parâmetros podem ter atuação significativa na con centração de $Z n$ na planta, o mesmo não ocorrendo para o PV.

Para as doses de $N$ dentro de PKCaMg na dose dois, o desdobramento da anālise de variância ençontra-se na Ta bela 27 , tendo a concentração de $Z n$ na planta um comportamen to quadrático, tanto no solo LE como no PV. Na Tabela 30 cons ta o efeito direto positivo das doses aplicadas de $N$ na concen tração de Zn na planta, para o cultivo no solo LE $(0,352)$, ao passo que o coeficiente de correlação simples foi negativo $(\cdot-0,248)$, isto devido aos efeitos indiretos, negativos de maior magnitude que o efeito direto, como os efeitos indiretos via porcentagem na planta de $N(-0,418), K(-0,673), \operatorname{Mg}(-0,360)$ e o teor de 
matéria seca $(-0,551)$. Por outro lado, houve efeitos indiretos positivos como a porcentagem na planta de $P(0,063)$, Ca $(0,486)$, o teor disponível de $\mathrm{Zn}$ no solo $(0,503)$ e o $\mathrm{pH}(0,346)$, mas todos eles neutralizados pelos efeitos indiretos negativos, conferindo assim, pequena variação na concentração de $Z n$ na planta (Figura $04, \mathrm{Y}_{5}$ ). Para o solo PV, houve a mesma tendên cia, com efeito direto positivo $(0,179)$ e o coeficiente de correlação simples negativo $(-0,166)$. Isto devido principalmenaos efeitos indiretos via porcentagem de $P$ na planta $(-0,649)$ e o teor de matéria seca $(-0,207)$, embora efeitos indiretos po sitivos também tenham ocorrido, como a concentração de $\mathrm{N}$ e $\mathrm{Mg}$ na planta $(0,372$ e 0,110 , respectivamente) , alêm do teor dis.ponível de $2 n$ no solo $(0,081)$, resultando numa pequena variação na concentração de $Z n$ na planta, conforme ilustrado na Figura $04\left(\mathrm{Y}_{6}\right)$.

$$
\text { Os coeficientes de determinação }(0,948 \text { e } 0,938 \text {, }
$$

respectivamente no solo LE e PV) indicam que $94,8 \%$ e $93,8 \%$ da variação na concentração de $Z n$ na planta, foi explicada pelos pàrâmetros analisados .

Esses resultados, em que aumentando-se as doses aplicadas de $N$ diminui-se a concentração de $Z n$ na planta, como se observa pela Figura $04\left(\mathrm{Y}_{1}, \mathrm{Y}_{2}, \mathrm{Y}_{3}\right.$ até $45,73 \mathrm{ppm}$ de $\mathrm{N}, \mathrm{Y}_{4}, \mathrm{Y}_{5}$ até $49,51 \mathrm{ppm}$ de $\mathrm{N}$ e $\mathrm{Y}_{6}$ a partir da aplicação de 38,69 ppm de $N$ ), encontram respaldos nos trabalhos de REUTHER e SMITH (1950), BOAWN e CRAWFORD (1957), CHAUDHRY e LONERAGAN 
(1972), concordando que essa diminuição foi devido ao maior desenvolvimento das plantas, apenas quando se testou doses de N dentro de PKCaMg na dose um, no solo PV e, doses de $N$ dentro de PKCaMg na dose dois, nos dois solos. OZANNE (1955) cita que o Zn absorvido pode ficar retido nas raízes como complexo Zn- proteína, embora isto possa ter ocorrido, tal fato se torna inconsistente uma vez que neste trabalho o sistema radicular não foi analis ado.

Como explicação para o trabalho em estudo, no que tange à diminuição na concentração de $Z n$ na pḷanta, ela de pende do tipo de solo e não somente das doses de $N$, assim como da mistura PKCaMg. Para doses de $N$ dentro de PKCaMg na dose zero no solo LE, os efeitos negativos de maior evidência se deve às doses aplicadas de $N$ e a concentração de $N$ e $K$ na plan ta, e no PV, à concentração de $K$ na planta e ao pH do solo. Para doses de $N$ dentro de PKCaMg na dose um, no LE, foram as concentrações de $\mathrm{N}$ e $\mathrm{P}$, na planta e, no solo, $\mathrm{PV}$, as doses doses aplicadas de $N$, K na planta e ao teor de matéria seca (efeito diluição). Para doses de $N$ dentro de PKCaMg na dose dois, no LE houve mais fatores interagindo, ou seja, $N$, K e Mg na planta e teor de matéria seca e no pV, principalmente a concentração de $P$ na planta e o teor de matēria seca.

$$
\text { Com relação ao aumento na concentração de } Z \text { n na }
$$
planta, ilustrado na Figura $04\left(_{3}\right.$ a partir de 45,73 ppm de $N$, $\mathrm{Y}_{5}$ a partir de 49,51 ppm de $\mathrm{N}$ e $\mathrm{Y}_{6}$ até a aplicaçãode 38,69 ppm 
de $N$ ), esses resultados concordam com os obtidos por SINGH ,e SINGH (1981) quando trabalharam com doses de ate 80 ppm de $N$, THOMPSON (1962) verificou tambēm um aumento na concentração de Zn em plantas de milho, o mesmo ocorrendo com TERMAN e ALLEN (1974), SINGH e FRANKLIN (1974), PARKER (1962), PUMPREY et ali (1963). STANTON e BURGER (1970) verificaram o mesmo em painço; SOLTANPOUR (1969) com a cultura da batata: CHAUDHRY et alii (1977) com plantas de arroz cultivada em dois solos calcārios inundados e MURAOKA (1981) em experimento de vasos com a cultura do feijoeiro. No presente trabalho, o efeito positivo de maior destaque na concentração de $Z n$ na planta, para os tratamentos doses de $N$ dentro do PKCaMg na dose um, no solo LE, foi o efeito direto das doses de N. Para os tratamentos doses de $N$ dentro de PKCaMg na dose dois, no solo LE foi mais proeminente o efeito direto das doses de $\mathrm{N}$, porcentagem de Ca na planta, teor de Zn disponível e pH do solo e, para o so1o PV, o efeito direto das doses de $N$ e a porcentagem na plan ta de $\mathrm{N}$ e $\mathrm{Mg}$.

4.2.2. Efeito de doses de P e NKCaMg na concentraçäo de $\mathrm{Zn}$ na planta

As anälises de variância dos dados da concentraçăo de Zn na planta, estão apresentadas na Tabela 31 . Os desdobramentos das anālises de variância encontram-se nas Tabe- 
las 32,33 e 34 e nas Tabelas 35,36 e 37 estão apresentados os efeitos diretos, indiretos, coeficientes de correlação simples, coeficientes de determinação e variâncias residuais, para os cultivos nos solos LE e PV. Na Figura 05, en contram-se as equações de regressão, pontos de máximo e mínimo, e as respectivas curvas, referente à variação na concentração de Zn na planta, quando se confronta doses de P dentro da dose zero, um e dois de NKCaMg.

Para o solo LE, verifica-se que houve efeito sig nificativo das doses de $\mathrm{P}$, NKCaMg e da interação ' $\mathrm{P} x$ NKCaMg (Tabela 31), no que se refere à concentração de Zn na planta. Como a interação foi significativa, fez-se os desdobramentos com os dados da concentração de $Z n$ tendo um comportamento quadráti co, quando se desdobrou doses de P dentro de NKCaMg na dose zero (Tabela 32). Com relação ao desdobramento da correlação simples (Tabela 35), verifica-se que o efeito direto das doses de $P$ sobre a concentração de $Z n$ na planta, foi positivo $(0,326)$, . ou seja, a medida que fosse aumentada as doses de $P$ haveria um aumento na concentração de $Z n$ na planta, desde que outros fato res não estivessem interferindo. Como existem värios outros fa tores atuantes, isto não ocorreu e a medida que. houve aumento nas doses aplicadas de $P$, diminui-se a concentração de Zn na plan ta, até a aplicação de 161,46 ppm de P, aumentando-se com a aplicação de doses mais elevadas, como está ilustrado na Figura $05\left(\mathrm{Y}_{1}\right)$. Os fatores que fizeram com que o coeficiente de correlação simples fosse negativo, foram principalmente a concentração na planta de $P$ e K 
Tabela 31. Anālises de variância e coeficientes de variação, referente aos dados da concentração de $\mathrm{Zn}$ na plan ta (ppm) em relação a doses de $P$ e NKCaMg, em um LE e PV.

\begin{tabular}{ccrr}
\hline & & \multicolumn{3}{c}{$Q$ M } \\
\cline { 3 - 4 } Causas de variação & G.L & LE & PV \\
\hline P & 2 & $332,1115^{* *}$ & $1581,3333^{* *}$ \\
NKCaMg & 2 & $1317,3615^{* *}$ & $20012,5817^{* *}$ \\
P x NKCaMg & 4 & $45,9442^{* *}$ & $1342,2950^{* *}$ \\
Tratamento & $(8)$ & $435,3404^{* *}$ & $606,6250^{* *}$ \\
Residuo & 27 & 7,8333 & 67,3704 \\
\hline Coeficiente de variação & & 5,86 & 10,43 \\
\hline
\end{tabular}

** - Significativo ao níve1 de $1 \%$ de probabilidade.

Tabela 32. Desdobramento das anālises de variância, para doses de $P$ dentro de NKCaMg na dose zero, em regressão linear e quadrätica.

\section{Q $M$}

\begin{tabular}{lccc} 
Causas de variação & G.L. & LE & PV \\
\hline Regressão 1inear & 1 & $406,1250^{* *}$ & $6105,1250^{* *}$ \\
Regressão quadrätica & 1 & $100,0416^{* *}$ & $1488,3750^{* *}$ \\
Tratamentio & $(2)$ & 253,0833 & 3796,7500 \\
Resíduo & 9 & 7,8333 & 67,3704 \\
\hline
\end{tabular}

** - Significativo ao níve1 de $1 \%$ de probabilidade. 
Tabela 33. Desdobramento das anālises de variância para doses de $P$ dentro de NKCaMg na dose um, em regressão 1 inear e quadrätica.

\begin{tabular}{lcrc}
\hline & & \multicolumn{2}{c}{ Q M } \\
\cline { 3 - 4 } Causas de variação & G.L & LE & PV \\
\hline Regressão linear & 1 & 18,0000 & 12,500 \\
Regressão quadrätica & 1 & 0,6666 & 240,6666 \\
Tratamento & $(2)$ & 9,3333 & 126,5833 \\
Resíduo & 9 & 7,8333 & 67,3704 \\
\hline
\end{tabular}

Tabela 34. Desdobramentos das anälises de variância, para do ses de $P$ dentro de NKCaMg na dose dois, em regres são linear e quadrātica.

\begin{tabular}{lcrcc}
\hline & & \multicolumn{2}{c}{$Q$ M } \\
\cline { 3 - 4 } Causas de variação & G.L. & LE & PV \\
\hline Regressão 1inear & 1 & $253,1250^{* *}$ & 253,1250 \\
Regressão quadrätica & 1 & $70,0426^{* *}$ & $392,0426^{* *}$ \\
Tratamento & $(2)$ & $161,5833^{* *}$ & $322,5833^{*}$ \\
Resíduo & 9 & 7,8333 & 67,3704 \\
\hline
\end{tabular}

* - Significativo ao nível de 5\% de probabilidade ** - Significativo ao nível de $1 \%$ de probabilidade 
Tabela 35. Desdobramento das correlações simples em componentes de efeitos. diretos e indiretos, para a concentração de $\mathrm{Zn}$ na planta $\mathrm{x}$ doses de $P$ dentro da dose zero de NKCaMg, coeficientes de determinação e variâncias residuais, nos solos LE e PV.

\begin{tabular}{|c|c|c|c|c|c|}
\hline \multirow[b]{2}{*}{ Modo de ação } & $\begin{array}{l}\text { Efeito direto } \\
\text { (P) }\end{array}$ & \multicolumn{2}{|c|}{$\begin{array}{l}\text { Efeito indireto } \\
\qquad(\mathrm{P} \times \mathrm{r})\end{array}$} & \multicolumn{2}{|c|}{$\begin{array}{l}\text { Correl ação } \\
\quad(r)\end{array}$} \\
\hline & $\mathrm{PV}$ & LE & $\mathrm{PV}$ & LE & $\mathrm{PV}$ \\
\hline Zn na planta $x$ doses de $P$ & & & & & \\
\hline Efeito direto & $-0,028$ & & & & \\
\hline Efeito indireto via $\% \mathrm{~N}$ & & $-0,024$ & 0,004 & & \\
\hline Efeito indireto via $\% \mathrm{P}$ & & $-0,689$ & $-0,290$ & & \\
\hline Efeito indireto via \% $\mathrm{K}$ & & $-0,522$ & 0,438 & & \\
\hline Efeito indireto via \% Ca & & 0,018 & 0,000 & & \\
\hline Efeito indireto via \% $\mathrm{Mg}$ & & $-0,020$ & 0,068 & & \\
\hline Efeito indireto via teor de $\mathrm{m} \cdot \mathrm{s}$ : & & 0,483 & 0,167 & . & \\
\hline Efeito indireto via $\mathrm{Zn}$ disponível & & 0,220 & 0,007 & & \\
\hline Efeito indireto via $\mathrm{pH}$ & & 0,018 & $-0,022$ & & \\
\hline Total ( $r, Z n$ na planta $x$ doses de $P$ & & & & $-0,190$ & 0,346 \\
\hline $\mathrm{R}_{10}^{2}(1,2, \ldots, 9)=\mathrm{R}^{2}$ & & 0,942 & 0,996 & & \\
\hline $\mathrm{R}_{10 \mathrm{w}}^{2}=\mathrm{W}$ & & 0,058 & 0,004 & & \\
\hline
\end{tabular}


Tabela 36. Désdobramento das correlações simples em componentes de efeitos diretos e indiretos para a concentração de Zn na planta $x$ doses de $P$ dentro da dose um de NKCaMg, coefićientes de determinação e variâncias residuais, nos solos LE e PV.

\begin{tabular}{|c|c|c|c|c|c|c|}
\hline \multirow[b]{2}{*}{ Modo de ação } & \multicolumn{2}{|c|}{$\begin{array}{l}\text { Efeito direto } \\
(\mathrm{r})\end{array}$} & \multicolumn{2}{|c|}{$\begin{array}{l}\text { Efeito indireto } \\
(\mathrm{P} \times \mathrm{x}) \\
\end{array}$} & \multicolumn{2}{|c|}{$\begin{array}{l}\text { Correlação } \\
(\mathrm{r})\end{array}$} \\
\hline & LE & $\mathrm{PV}$ & LE & $\mathrm{PV}$ & LE & PV \\
\hline
\end{tabular}

Zn na planta $\mathrm{x}$ doses de $\mathrm{P}$

Efeito direto $+0,092-0,118$

Efeito indireto via \% $\mathrm{N}$ $-0,033-0,358$

Efeito indireto via \% $\mathrm{P}$

$-0,095 \quad 0,529$

Efeito indireto via \% $\mathrm{K}$

$-0,154 \quad 0,106$

Efeito indireto via \% Ca

$0,6720,048$

Efeito indireto via \% $\mathrm{Mg}$

$-0,430 \quad 0,010$

Efeito indireto via teor de $\mathrm{m} \cdot \mathrm{s}$

$-0,148-0,527$

Efeito indireto via $\mathrm{Zn}$ disponível

$-0,063 \quad 0,208$

Efeito indireto via $\mathrm{pH}$

$-0,023-0,262$

Total ( $r$, Zn na planta $x$ doses de $P$ ) $-0,186-0,340$

$\begin{array}{lll}\mathrm{R}_{10}^{2}(1,2, \ldots, 9)=\mathrm{R}^{2} & 0,831 & 0,986 \\ \mathrm{R}_{10 \mathrm{~W}}^{2}=W & 0,169 & 0,014\end{array}$


Tabela 37. Desdobramento das correlações simples em componentes de efeitos diretos e indiretos, para a concentração de Zn na planta $x$ doses de $P$ dentro da dose dois de NKCaMg, coeficientes de determinação e variâncias residuais, nos solos LE e PV.

\begin{tabular}{|c|c|c|c|c|c|c|}
\hline \multirow[b]{2}{*}{ Modo de ação } & \multicolumn{2}{|c|}{$\begin{array}{l}\text { Efeito direto } \\
\text { (P) }\end{array}$} & \multicolumn{2}{|c|}{$\begin{array}{l}\text { Efeito indireto } \\
\qquad(\mathrm{P} \times \mathrm{r})\end{array}$} & \multicolumn{2}{|c|}{$\begin{array}{l}\text { Correlação } \\
\quad(\mathrm{r})\end{array}$} \\
\hline & LE & $\mathrm{PV}$ & LE & PV & LE & $\mathrm{PV}$ \\
\hline \multicolumn{7}{|l|}{ Zn na planta $x$ doses de $P$} \\
\hline Efeito direto & $-0,110$ & 0,180 & & & & \\
\hline Efeito indireto via $\% \mathrm{~N}$ & & & 0,015 & $+0,024$ & & \\
\hline Efeito indireto via $\% \mathrm{P}$ & & & $-0,036$ & $-0,016$ & & \\
\hline Efeito indireto via \% $\mathrm{K}$ & & & $-0,022$ & $-0: 193$ & & \\
\hline Efeito indireto via \% Ca & & & $-0,007$ & $-0,155$ & & \\
\hline Efeito indireto via \% $\mathrm{Mg}$ & & & 0,056 & $-0,008$ & & \\
\hline Efeito indireto via teor de & $\mathrm{m} \cdot \mathrm{s}$ & & 0,003 & 0,553 & & \\
\hline Efeito indireto via $\mathrm{Zn}$ dis & ponivel & & $-0,058$ & 0,000 & & \\
\hline Efeito indireto $\mathrm{pH}$ & & & $-0,007$ & $-0,036$ & & \\
\hline Total ( $r$, Zn na planta $x$ do & ses de $\mathrm{P}$ & & & & $-0,166$ & 0,343 \\
\hline $\mathrm{R}_{10}^{2}(1,2, \ldots, 9)=\mathrm{R}^{2}$ & & & 0,978 & 0,972 & & \\
\hline $\mathrm{R}_{10 \mathrm{~W}}^{2}=\mathrm{W}$ & & & 0,022 & 0,028 & & \\
\hline
\end{tabular}




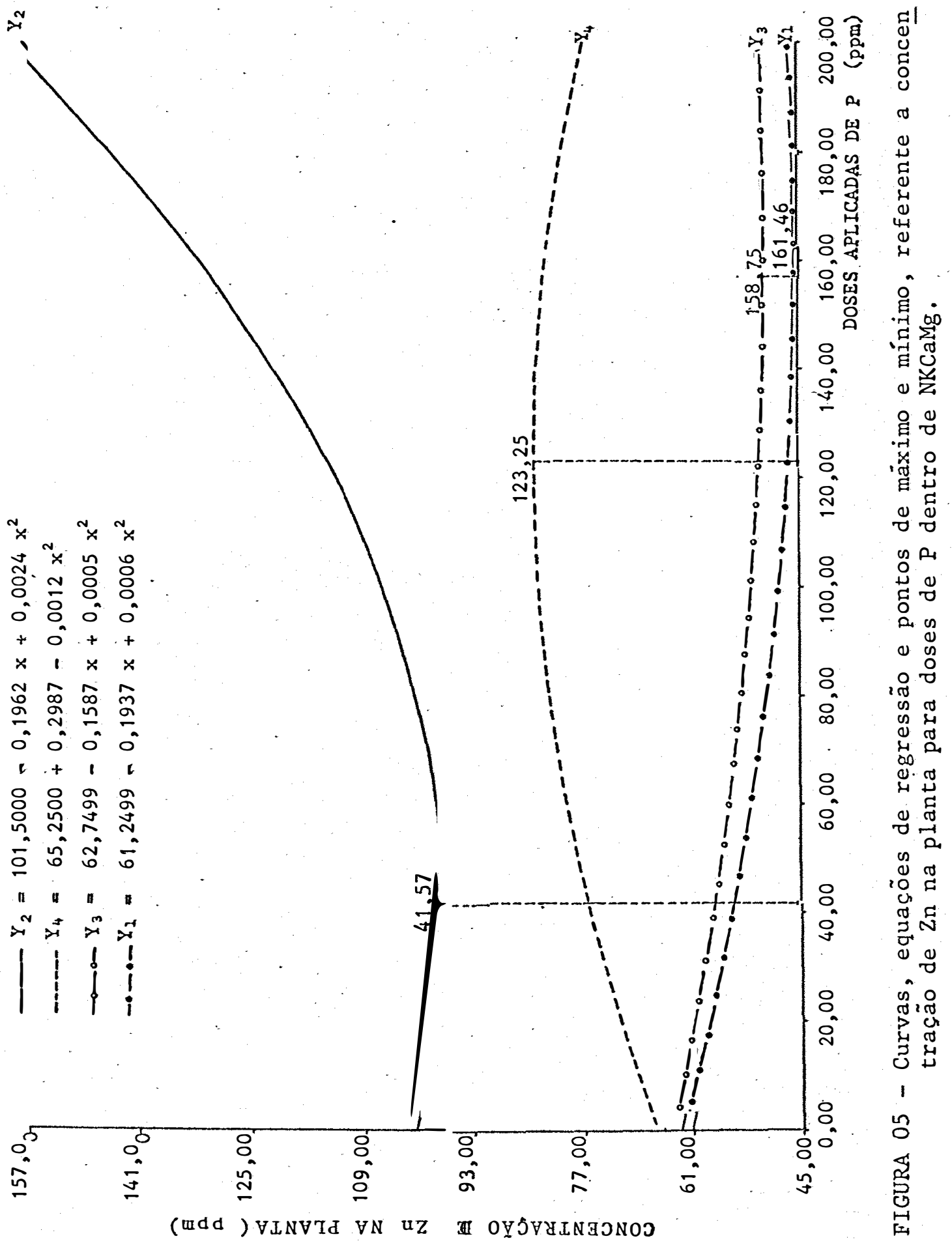


$(-0,689$ e $-0,522$, respectivamente $)$, au seja, a medida que se aumenta a concentração de $P$ e $K$ na planta, há uma diminuição na relação concentração de $Z n$ e doses de P. Por outro lado,, o teor de matéria seca e o $\mathrm{Zn}$ disponível no solo, mantiveram um efeito positivo nesta relação $(0,483$ e 0,220 , respectivamente), mas foram neutralizados pelo efeito das concentrações de $P$ e K. Os outros parâmetros analisados tiveram efeitos insignificantes. Quando o cultivo se deu no solo PV, houve também um efeito significativo das doses de $P$, NKCaMg e da intera ção, sobre a concentraçãode $\mathrm{Zn}$ na planta (Tabela 31). Feito o desdobramento, verificou-se um comportamento quadrätico das doses de $P$ dentro de NKCaMg na dose zero, na concentração de $Z n$ na planta (Tabela 32), fenômeno este ilustrado na Figura 05 ( $\mathrm{Y}_{2}$ ). No desdobramento do coeficiente de correlação simples (Tabela 35), verifica-se que o efeito direto das doses de $P$ sobre a concen-. traçãó de $Z n$ na planta foi negativo $(-0,028)$, mas o coefi .. ciente de correlação simples foi positivo $(0,346)$, isto devido principalmente aos efeitos indiretos da concentração de $K$ na planta $(0,438)$ e ao teor de matéria seca $(0,167)$. A concentração de $P$ teve um efeito indireto negativo $(-0,290)$, como ocorreu com o cultivo no solo LE, evidenciando desta maneira, a relação inversa entre as concentrações de $\mathrm{P}$ e a relação $\mathrm{Zn} n \mathrm{a}$ planta $x$ doses de P.

Os coeficientes de determinação foram respectiva mente 0,942 e 0,996 para o solo LE e PV, indicando que aper 
nas $5,8 \%$ e $0,4 \%$ da variação na concentração de $Z n$ na planta, não foi explicada pelas variāveis estudadas.

Com relação ao des dobramento das doses de $\mathrm{P}$ den tro de NKCaMg na dose um, não se verificou efeitos significativos dessa interação no solo LE (Tabela 33), o que quer dizer que neste caso as doses de $P$ não estão influenciando a concentração de $Z n$ na planta. Mesmo assim foi feito o desdobramen to da correlação simples (Tabela 36), verificando-se um efeito direto das doses de $P$, de pequena magnitude no solo LE $(0,092)$ e um coeficiente de correlação simples negativo $(-0,186)$. Como efeito indireto positivo, verificoumse apenas o da concentração de Ca $(0.672)$, sendo todos os outros parâmetros negati vos, ressaltando a concentração de $\operatorname{Mg}(-0,430)$, os quais neutra lizaram totalmente o efeito direto e, o indireto via porcentagem de Ca.

Para o solo PV, tambëm não houve efeito signifi cativo das doses de $P$ dentro de NKCaMg na dose um, para a concentração de $Z n$ na planta (Tabela 33). 0 desdobramento do coe ficiente de correlação simples encontra-se na Tabela 36, onde se verifica o efeito direto negativo $(-0,118)$ das doses de P sobre a concentração de Zn na planta, e um coeficiente de correlação simples também negativo $(-0,340)$. Para os efeitos indiretos positivos, os de maior magnitude foram a porcentagem de $P$ na planta $(0,529)$ e o Zn disponível no solo $(0,208)$ e como efeitos indiretos negativos a porcentagem de $N(\cdots 0,358)$, o 
teor de matériạ seca $(-0,527)$ e o pH do solo $(-0,262)$, explican do desta forma o coeficiente de correlação simples negativo. Os coeficientes de determinação $(0,831$ e 0,986$)$ respectivamente para o LE e PV, indicamo quanto a variação de $Z n$ na planta é explicada pelos parâmetros analisados. .

Para o solo LE, houve efeito significativo qua drātico, quando se desdobrou os tratamentos doses de $P$ dentro de NKCaMg na dose dois (Tabela 34), como se verifica na Figura $05\left(\mathrm{Y}_{3}\right)$. Na Tabela 37 constata-se o . efeito direto negativo das doses de $P$ sobre a concentração de $Z n(-0,110)$, o mesmo ocorrendo com o coeficiente de correlação simples $(-0,166)$, uma vez que os efeitos indiretos foram de pequena magnitude e se anularam.

Para o solo PV, os dados sobre a concentração de $Z n$ na planta tiveram um efeito quadrático, quando se variou doses de $P$ dentro de nKCaMg dose dois (Tabe 1 a 34), conforme ilustrado na Figura $05\left(\mathrm{Y}_{4}\right)$. Quando se desdo brou o coeficiente de correlação simples (Tabela 37) verificou-se um efeito direto positivo nas doses de $P$ sobre a concentração de Zn $(0,180)$, o mesmo ocorrendo com o coeficịente de correlação simples $(0,343)$. Dos efeitos indiretos positivos, apenas o teor de matéria seca se sobressaiu $(0,553)$, e como negativo a porcentagem de $\mathrm{K}(-0,193)$ e $\mathrm{Ca}(-0,153)$; os outros efeitos in diretos foram inexpressivos. Para o coeficiente de determinação, 0,978 no solo LE e 0,972 para o PV, isto indica que a 
quase totalidade da variação na concentração de $Z n$ na planta, foi explicada pelas variảveis estudadas.

Os resultados em que aumentando-se as doses ap $1 \underline{i}$ cadas de $P$, diminui-se a concentração de $Z n$ na planta, como se observa na Figura 05 ( $\mathrm{Y}_{1}$ até a aplicação de 161,46 ppm de P, $Y_{2}$ até a ap1icação de 41,57 ppm de $\mathrm{P}, \mathrm{Y}_{3}$ até a aplicação de 158,75 ppm de $\mathrm{P}$ e $\mathrm{Y}_{4}$ a partir da aplicação de 123,25 ppm de P) corroboram os resultados obtidos por BURLESON e PAGE (1967); STUKENHOLTZ et alii.(1966); WARNOCK (1970); SHARMA et alii(1968 a, b) ; PAULSEN e ROTIMI (1968), os quais sugerem o problema de mobilidade do Zn para a parte aérea. KHAN (1969); MARINHO e IGUE (1972) ; LOPEZ GOROSTIAGA e MALAVOLTA (1974); rer latam o efeito diluição. BAHIA e BRAGA (1974); BOAWN e LEGGET (1964) e MILLIKAN (1963) citam que o desequilïbrio nas plantas entre o $P$ e $Z n$ ê devido a distürbios metabölicos nas células da planta, através da interferência do $P$ na função metabólica do Zn. Outros autores citam a precipitação do Zn pe 1o P na superfície das raízes, como STUKEnHoltz et alii (1966), ELLIS et alii (1964) e MOTSARA (1974). Tambëm BROWN et alii (1970); BROWN $\quad$ e TIFFIN (1962), BURLESON et ali $i$ (1961), CHAUDHRY e SHARIF (1974), CHRISTENSEN e JACKSON (1982), ELLIS et a $i$ i (1964), FAGERIA e ZIMMERMANN (1979), JACKSON et alii (1967), LANGIN et a $i$ i (1962), LO e REISENAUER (1968), PATIL e SOMAWANSHI (1982), RUDGERS et a $i$ i (1970), SHARMA et a $i$ i (1968a), TERMAN e ALLEN (1974), THOMPSON (1962) e 
GANIRON et alii (1968), citam o P causando diminuição na concentração de $Z n$ nos tecidos das plantas; dando como explicação desse efeito, a atuação do $P$ no sítio de absorção, limitaçãona translocação e efeito diluição. Citam ainda, alguns deles, que essa diminuição depende de vários fatores como tipo de planta, efeito da temperatura, umidade e outros.

No presente ensaio não foi estudado o efeito da umidade, temperatura, diferentes tipos de plantas, sistema radi cular e outros, mas pode-se verificar que a diminuição da con centração de $\mathrm{Zn}$ na planta, variou com o tipo de solo e com a aplicação de $P$ e outros nutrientes. Com relação à aplicação de P dentro de NKCaMg na dose zero, a concentração de $P$ e K na planta (no solo LE) e apenas a concentração de P (no solo PV), exerceram efeitos negativos consideráveis na relaçäo $\mathrm{Zn} n$ a planta $x$ doses de P.

Para a aplicação de doses de P dentro de NKCaMg na dose dois, as concentrações de $\mathrm{P}, \mathrm{K}$ e $\mathrm{Ca}$ na planta, o teor de Zn disponível e o pH do solo (LE) e as concentrações de $P$, $K$, Ca e Mg na planta e pH do solo (PV), mantiveram um efeito negativo na relação $Z n$ na planta $x$ doses de $P$.

Para o aumento na concentração de $Z n$ na planta, conforme se verifica na Figura 05 ( $Y_{1}$ a partir de 161,46 ppm de $\mathrm{P}, \mathrm{Y}_{2}$ a partir da aplicação de 41,57 ppm de $\mathrm{P}=\mathrm{Y}_{3}$ a partir de $158,75 \mathrm{ppm}$ de $\mathrm{P}$ e $\mathrm{Y}_{4}$ atẻ a aplicação de 123,25 ppm de P), es se incremento encontra respaldos no trabalho de WALLACE et ali $i$ 
(1974), em que é citado que em altas doses de P, quando o so10 não era deficiente em $\mathrm{Zn}$, a planta absorvia mais zinco. Tam bẻm ORABI et alii (1981) obtiveram aumentos na absorção e conteüdo de $Z n$ em plantas de milho, com a aplicação de P, BASAK et alii (1982) com a cultura do arroz, WALLACE e ALEXAN DER (1978) com cinco cultivares de soja, em solução nutritiva, quando o pH era baixo e LONERAGAN et alii (1979) em solo podzó lico com a cultura do trevo. No presente trabalho, o efeito direto das doses de $K$ sobre a concentração de $Z$ n na planta, o teor de matéria seca e o teor de Zn disponível, quando o cultivo se deu no solo LE e a concentração de K na planta no solo PV, exerceram efeitos positivos, nos tratamentos doses de $P$ dentro de NKCaMg na dose zero. Para doses de P dentro de NKCaMg na dose dois, os parâmetros que exerceram efeitos positivos foram a concentração de $N$ e Mg na planta, para o solo LE e principalmente o teor de matéria seca para o solo PV.

4.2.3. Efeito de doses de $K$ e NPCaMg na concentração de Zn na planta.

As anālises de variância sobre os dados da concentração de $Z n$ na planta, se encontram na Tabela $38 . \quad$ Nas Tabelas 39,40 e 41 encontram-se os desdobramentos das anāli ses de variância e nas Tabelas.42, 43 e 44 constam os efeitos diretos, indiretos, coeficientes de correlação simples, coefi - 
Tabela 33. Anảitses de variância e coeficientes de variação, referente aos dados da concentração de 2 n na plan ta (ppm) em relação a doses de K e NPCaMg, em um LE e P.V.

\begin{tabular}{cccc}
\hline & & \multicolumn{2}{c}{$Q$ M } \\
\cline { 3 - 4 } Causas de variação & G.L & LE & PV \\
\hline K & 2 & 20,3300 & $598,6950 * *$ \\
NPCaMg & 2 & $1770,5800 * *$ & $3652,0300^{* *}$ \\
K x NPCaMg & 4 & $187,1700^{* *}$ & $936,8200^{* *}$ \\
Tratamento & $(8)$ & $541,3125 * *$ & $1531,0911^{* *}$ \\
Resíduo & 27 & 7,9352 & 51,7593 \\
\hline Coeficiente de variação & & 5,28 & $9,32$. \\
\hline
\end{tabular}

** Significativo ao níve1 de $1 \%$ de probabilidade.

Tabela 39. Desdobramento das anāilises de variância, para doses de K dentro de NPCaMg na dose zero, em regres são linear e quadrática.

\begin{tabular}{lccc}
\hline & & \multicolumn{2}{c}{$Q$ M } \\
\cline { 3 - 4 } Causas de variação & G.L. & LE & PV \\
\hline Regressão 1inear & 1 & $200,0000^{* *}$ & $391,1250^{*}$ \\
Regressão quadrätica & 1 & $140,1667^{* *}$ & 51,04166 \\
Tratamento & $(2)$ & $170,0934^{*}$ & 201,0831 \\
Resíduo & 9 & 7,9352 & 51,7593 \\
\hline
\end{tabular}

\footnotetext{
* - Significativo ao nível de $5 \%$ de probabilidade ** - Significativo ao níve1 de $1 \%$ de probabilidade
} 
Tabela 40, Desdobramento das anälises de variāncia, para doses de K dentro de NPCaMg na dose um, em regressäo linear e quadrätica.

\begin{tabular}{lcccc}
\hline & & \multicolumn{2}{c}{ Q M } \\
\cline { 3 - 4 } Causas de variação & G.L. & LE & PV \\
\hline Regressão linear & I & 0,0000 & $325,1250^{*}$ \\
Regressão quadrätica & 1 & $130,6667 * *$ & $3825,3750^{* *}$ \\
Tratamento & $(2)$ & 653334 & 2075,2500 \\
Resíduo & 9 & 7,9352 & 51,7593 \\
\hline
\end{tabular}

* - Significativo ao nível de $5 \%$ de probabilidade. $* *$ - Significativo ao nível de $1 \%$ de probabilidade.

Tabela 41 , Desdobramento das anälises de variância, para doses de K dentro de NPCaMg na dose dois, em regres são linear e quadrätica.

\begin{tabular}{lcrcc}
\hline & & \multicolumn{2}{c}{ Q M } \\
\cline { 3 - 4 } Causas de variação & G.L & LE & P V \\
\hline Regressão 1inear & 1 & 24,5000 & 8,0000 \\
Regressão quadrätica & 1 & $294,0000^{*}$ & $384,0000^{* *}$ \\
Tratamento & $(2)$ & 159,2500 & 196,0000 \\
Resíduo & 9 & 7,9352 & 51,7593 \\
\hline
\end{tabular}

** - Significativo ao nível de $1 \%$ de probabilidade. 
Tabela 42. Desdobramentos das correlações simples em componentes de efeitos diretos e indiretos para a concentração de Zn ña planta $x$ doses de $K$ dentro da dose zerode NPCaMg, coeficientes de determinação e variancias residuais, nos solos LE e PV.

\begin{tabular}{|c|c|c|c|c|c|c|}
\hline \multirow[b]{2}{*}{ Modo de ação } & \multicolumn{2}{|c|}{$\begin{array}{l}\text { Efeito direto } \\
\text { (P) }\end{array}$} & \multicolumn{2}{|c|}{$\begin{array}{l}\text { Efeito indireto } \\
((\mathrm{P} \times \mathrm{r})\end{array}$} & \multicolumn{2}{|c|}{$\begin{array}{l}\text { Correlação } \\
\quad(r)\end{array}$} \\
\hline & $\mathrm{LE}$ & $\mathrm{PV}$ & $\mathrm{LE}$ & $\mathrm{PV}$ & $\mathrm{LE}$ & PV \\
\hline \multicolumn{7}{|l|}{ Zn na planta $x$ doses de $K$} \\
\hline Efeito direto & 0,300 & $-0,295$ & & & & \\
\hline Efeito indireto via $\% \mathrm{~N}$ & & & $-0,037$ & $-0,030$ & & \\
\hline Efeito indireto via \% $\mathrm{P}$ & & & 0,008 & 0,000 & & \\
\hline Efeito indireto via \% $\mathrm{K}$ & & & $-0,228$ & $-0,292$ & & \\
\hline Efeito indireto via \% Ca & & & 0,005 & 0,120 & & \\
\hline Efeito indireto via \% Mg & & & 0,023 & 0,013 & & \\
\hline Efeito indireto yia teor de m.s & & & $-0,034$ & 0,002 & & \\
\hline Efeito indireto via Zn disponíve & & & 0,024 & $-0,085$ & & \\
\hline Efeito indireto via $\mathrm{pH}$ & & & 0,000 & 0,172 & & \\
\hline Total ( $r$, Zn na planta $x$ doses & de $K$ ) & & & & 0,032 & $-0,397$ \\
\hline $\mathrm{R}_{10}^{2}(1,2, \ldots, 9)=\mathrm{R}^{2}$ & & & 0,949 & 0,926 & & \\
\hline $\mathrm{R}_{10 \mathrm{~W}}^{2}=\mathrm{W}$ & & & 0,051 & 0,074 & & \\
\hline
\end{tabular}


Tabela 43 Desdobramento das correlações simples em componentes de efeitos diretos e indiretos, para a concentração de Zn na planta $x$ doses de $K$ dentro da dose um de NPCaMg, coeficientes de determinação e variân ciasresiduais, nos solos LE e PV.

\begin{tabular}{|c|c|c|c|c|c|c|}
\hline \multirow[b]{2}{*}{ Modo de ação } & \multicolumn{2}{|c|}{$\begin{array}{c}\text { Efeito direto } \\
\text { (P) }\end{array}$} & \multicolumn{2}{|c|}{$\begin{array}{l}\text { Efeito indireto } \\
\left(\begin{array}{l}(\mathrm{P} \times \mathrm{r})\end{array}\right.\end{array}$} & \multicolumn{2}{|c|}{$\begin{array}{l}\text { Correlação } \\
(\mathrm{r})\end{array}$} \\
\hline & LE & PV & LE & PV & LE & PV \\
\hline \multicolumn{7}{|l|}{ Zn na planta $x$ doses de $K$} \\
\hline Efeito direto & $-0,128$ & $0,32: 3$ & & & & \\
\hline Efeito indireto via $\% \mathrm{~N}$ & & & $-0,056$ & $-0,311$ & & \\
\hline Efeito indireto via \% $\mathrm{P}$ & & & 0,154 & 0,285 & & \\
\hline Efeito indireto via $\% \mathrm{~K}$ & & & $-0,015$ & $-0,396$ & & \\
\hline Efeito indireto via \% Ca & & & $-0,123$ & $-0,243$ & & \\
\hline Efeito indireto via \% $\mathrm{Mg}$ & & & 0,010 & 0,107 & & \\
\hline Efeito indireto $v i a$ teor de & $\mathrm{m} \cdot \mathrm{s}$. & & $-0,016$ & 0,381 & & \\
\hline Efeito indireto via $\mathrm{Zn}$ dispon & ível & & $-0,010$ & 0,097 & & \\
\hline Efeito indireto $v i a p H$ & $\cdot$ & & $-0,060$ & $-0,087$ & & \\
\hline Total ( $r$, Zn na planta $x$ dado & s de $\mathrm{K}$ ) & & & & $-0,244$ & 0,164 \\
\hline $\mathrm{R}_{10}^{2}(1,2, \ldots, 9)=\mathrm{R}^{2}$ & & & 0,836 & 0,304 & & \\
\hline$R_{10 W}^{2}=W$ & & & 0,164 & 0,196 & & \\
\hline
\end{tabular}


Tabela 44. Desdobramento das correlaçöes simples em componentes de efeitos diretos e indiretos, para a concentração de $Z$ n na planta $x$ doses de $K$ dentro da dose dois de NPCaMg, coeficientes de determinação e variâncias residuais, nos solos LE e PV.

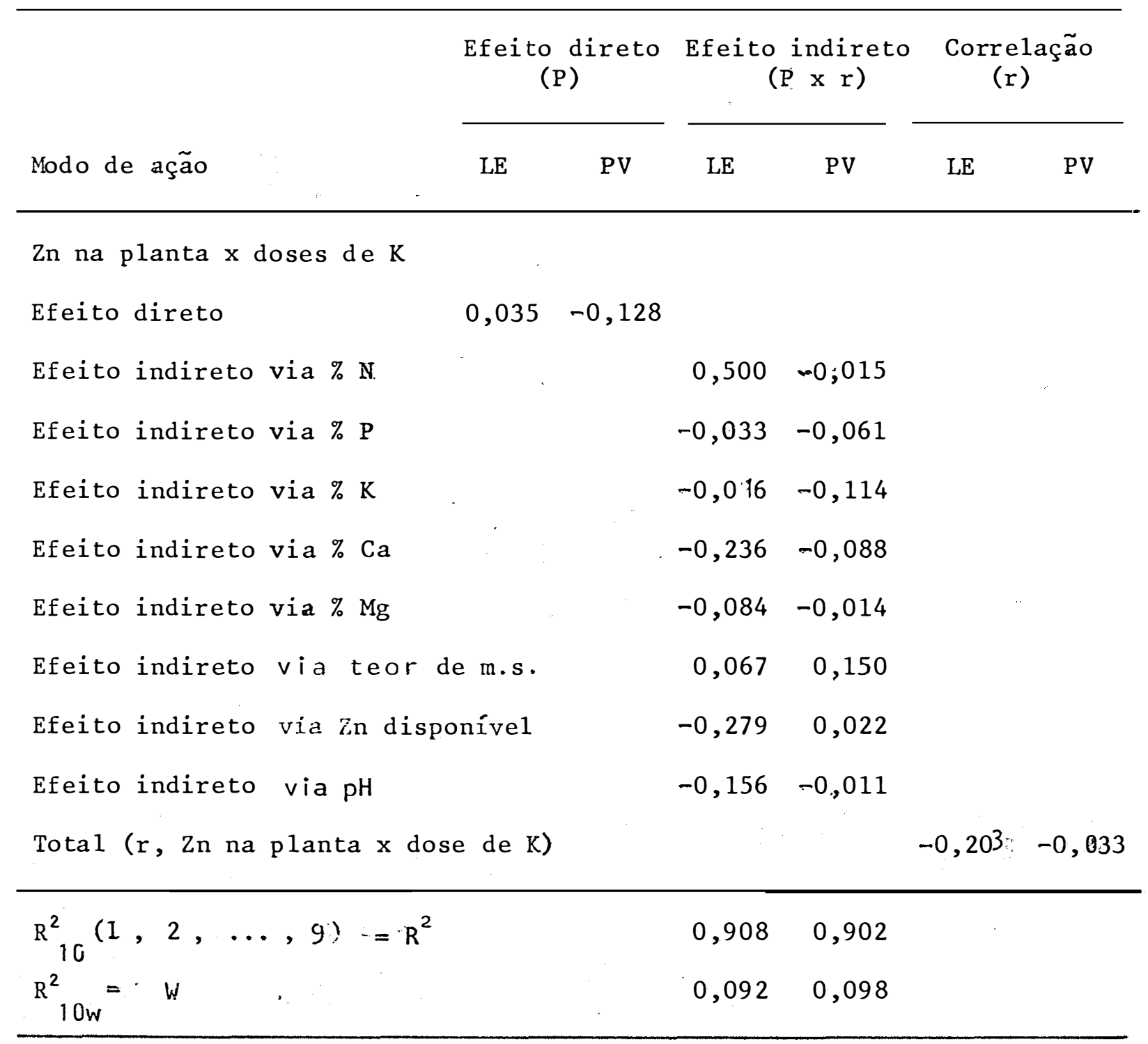


cientes de determinação e viariâncias residuais, nos cultivos rea lizados nos solos LE e PV. As equaçöes de regressäo, pontos de mäximo e mínimo, e as respectivas curvas referentes a concen tração de $Z n$ na planta estão inseridas na Figura 06.

Com relação ao solo LE, constata-se o eféito significativo da mistura NPCaMg e da interação $\mathrm{K} x \mathrm{NPCaMg}$, au seja, embora as doses de $K$ isoladamente nãotenham sido signifi cativas no que concerne a concentração de $Z n$ na planta, elas exerceram influência na mistura NPCaMg (Tabela 38). Feito o desdobramento (Tabela 39), verifica-se que os dados da concentração de Zn na planta, tiveram um comportamento quadrático em relação a doses de $K$ dentro de NPCaMg na dose zero; tal fato pode ser observado na Figura $06\left(Y_{1}\right)$. No desdobramento da cor relação simples (Tabela 42) verifica-se para o solo LE, um efei to direto positivo $(0,300)$ das doses de $K$ em relação ao $Z n$ na planta, e um coeficiente de correlação simples também positivo, mas de menor magnitude $(0,032)$, isto devido principalmente ao efeito indireto via concentração de $\mathrm{K}(-0,228)$; os outros parâmetros foram insignificantes. Para o solo PV, também houve efeito significativo da interação $K \times$ NPCaMg (Tabela 38). 0 desdobramento em regressão para doses de $K$ dentro de NPCaMg na dose zero, se encontra na Tabela 39 , onde pode se observar que a concentração de $Z n$ na planta teve um comportamento 1 inear em relação a esses tratamentos, conforme ilustrado na Figu ra $06\left(\mathrm{Y}_{2}\right)$. No desdobramento da correlação simples entre a 


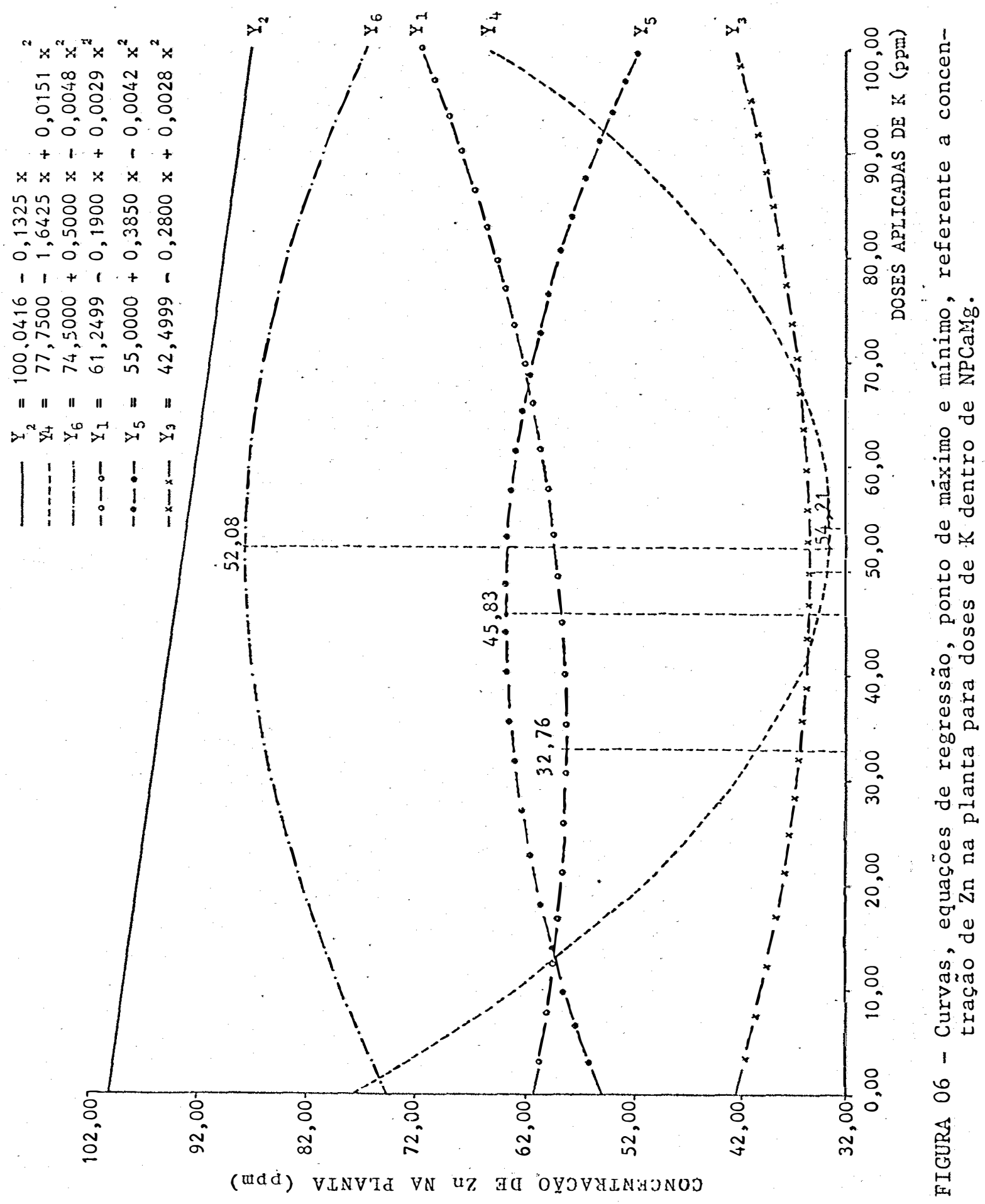


concentração de $\mathrm{Zn}$ na planta $x$ doses de $K$ (Tabela 42), verifica se um efeito direto negativo $(-0,295)$, o mesmo ocorrendo para o coeficiente de correlação simples $(-0,397)$, devido princi .. palmente ao efeito indireto negativo via concentração de K $(-0,292)$. O coeficiente de determinação foi alto $(0,949$ e 0,9 26) respectivamente para o solo LE e PV, o que indica que a variação na concentração de $Z$ n na planta é explicado em, $94,9 \%$ e 92,6 pelas variäveis consideradas.

Para doses de $K$ dentro de NPCaMg na dose um, o desdobramento da anâlise de variância se encontra na Tabe 1 a 40 , onde se verifica o efeito quadrätico para a concentração de Zn na planta, nos dois solos em estudo, conforme se observa na Figura 06 ( $Y_{3}$ para o LE e $Y_{4}$ para o PV). Na Tabela 43 consta o desdobramento das correlações simples onde se verifica um efeito direto negativo $(-0,128)$ das doses de $K$ sobre a concentração de $Z n$ na planta, cultivada no solo LE, o mesmo ocorrendo para o coeficiente de correlação simples $(-0,244)$, isto devido ao equilíbrio entre os efeitos indiretos, com realce para a concentração de $\mathrm{P}(0,154)$ e $\mathrm{Ca}(-0,123)$, o que explica o baixo coeficiente de correlação simples. Para o solo PV, o efeito direto foi positivo $(0,323)$, assim como os efeir tos indiretos via porcentagem de $\mathrm{P}(0,285), \mathrm{Mg}(0,107)$, teorde matéria seca $(0,381)$ e o Zn disponível $(0,097)$. Os outros parâmer tros analisados tiveram efeitos indiretos negativos, neutrali zando dessa maneira os efeitos positivos e conferindo um baixo 
coeficiente de correlação simples $(0,164)$. Os coeficientes de determinação $(0,836$ e 0,804$)$ respectivamente para o solo LE e $\mathrm{PV}$, indicam que $83,6 \%$ e $80,4 \%$ na variação da concentração de Zn na planta é explicada pelas variáveis estudadas.

Para doses de $K$ dentro de NPCaMg na dose dois, verifica-se pela Tabela 41, que houve efeito quadrätico para a concentração de $Z n$ na planta, fenômeno ilustrado na Figura 06 , como $Y_{5}$ para o LE e $Y_{6}$ para o PV. Na Tabela 44 encontram "se os desdobramentos das correlações simples, verificandorse um efeito direto positivo $(0,035)$, no solo LE, para doses de K $x$ concentração de $Z n$ na planta, e como efeito indireto positivo, a concentração de $N$ teve uma grande magnitude $(0,500)$, o mesmo não ocorrendo para o teor de matériáseca $(0,067)$; os outros parâmetros tiveram um efeito indireto negativo de pequena magnitude, excetuando-se a concentração de Ca $(-0,236)$ e o teor de Zn disponível $(-0,279)$, o que conferiu um baixo coefi ciente de correlação simples e negativo $(-0,203)$. No solo PV, o efeito direto foi negativo $(-0,128)$, assim como os efeitos indiretos via concentração de $\mathrm{N}(-0,015), \mathrm{P}(-0,061), \mathrm{K}(-0,114)$, $\mathrm{Ca}(-0,088), \mathrm{Mg}(-0,014)$ e $\mathrm{pH}$ do solo $(-0,011) ;$ como efeito indireto positivo o teor de matéria seca $(0,150)$ teve maior participação que o $Z$ n disponível $(0,022)$, conferindo assim um baixo coeficiente de correlação simples $(-0,033)$, para as doses de $K x$ concentração de $Z n$ na planta. Os coeficientes de determinação $(0,908$ e 0,902$)$, respectivamente para o solo 
LE e PV, indicam que $90,8 \%$ e $90,2 \%$ da variação na concentra ção de $Z n$ na planta foi explicada pelas variāveis estudadas.

Com relação à diminuição na concentração de $\mathrm{Zn}$ na planta, mediante a aplicação de $K$, como se obsserva na Figu ra 06 ( $_{1}$ até a aplicação de 32,76 ppm de K, $Y_{3}$ até a aplicação de 50 ppm de $K, Y_{4}$ até a aplicação de 54,21 ppm de K, $\mathrm{Y}_{5}$ a partir da aplicaçäo de 45,83 ppm de K e $\mathrm{Y}_{6}$ a partir da ap 1 icação de $52,08 \mathrm{ppm} \mathrm{de} \mathrm{K);} \mathrm{encontram} \mathrm{respaldos} \mathrm{nos} \mathrm{trabar}$ 1hos de STUKEnHoltz et a $i$ i (1966) onde é citado que altas doses de $K$ diminuiram a absorção de $Z n$ pela cultura do milho. WARD et ali $i$ (1963), TERMAN e ALLEN (1974) e SHUKLA e MUKHI (1979) relatam o mesmo efeito do K diminuindo a concentração de $\mathrm{Zn}$ nas plantas de milho.

Neste trabalho, os efeitos negativos exercidos na relação concentração de zinco $x$ doses de $K$ foram devido aconcen tração de $K$ no solo LE e ao efeito direto das doses de K além da concentração de $K$, no solo PV, quando se testou doses de K dentro de NPCaMg na dose zero. Para doses de K dentro de NPCaMg na dose um, esse efeito negativo foi devido principalmen te ao efeito direto das doses de $K$ e a concentração de Ca na planta, quando cultivada no solo LE e a concentração de N, K e Ca na planta, quando cultivada no PV. Para doses de K den tro de NPCaMg na dose dois, os efeitos negativos foram devido principalmente a concentração de Ca, Zn disponível e pH do solo, no LE e ao efeito direto das doses de $K$, e a concentração de 
K, no solo PV.

Com relação ao aumento na concentração de $Z n$ na planta, como se verifica na Figura $06\left(\mathrm{Y}_{1}\right.$ a partir de 32,76 ppm de $K, Y_{3}$ a partir de 50 ppm de K, $Y_{4}$ a partir de 54,21 ppm de K, $Y_{5}$ até a aplicação de 45,83 ppm de K e $Y_{6}$ até a aplicação de 52,08 ppm de K), concorda com os dados obtidos por WEAR e PATTERSON (1965), os quais atribuiram ao efeito indireto do K na relação P - Zn; de GALLO et alii (1975) que verificaram au mentos na concentração de $Z n$, nas diferentes partes da planta de milho, com a aplicação de $\mathrm{K}$; de TIWARI et alii (1982), que concluiram que com o aumento no suprimento de $k$ em batata, ha* via uma maior absorção e utilização do Zn. THOMPSON (1982) também verificou aumento na concentração de $Z n$ em folhas de mir 1ho mediante a aplicação de doses baixas de $K$, o mesmo não ocor rendo quando se aumentava as doses de $K$.

No presente ensaio, para o solo LE, quando se testou doses de $K$ dentro de NPCaMg na dose zero, as doses de $K$ exerceram um efeito direto positivo na concentraçäo de $Z n$ na planta. A concentração de Mg na planta e o teor de Zn disponível no solo também exerceram efeitos positivos. Para doses de K dentro de NPCaMg na dose um, os efeitos diretos foram der vido a concentração de $P$ e Mg na planta, quando cultivada no LE e, devido principalmente ao efeito direto das doses de $K$ na concentração de $\mathrm{Zn}$ na planta, alëm da concentração de $\mathrm{P}, \mathrm{Mg}$, teor de matëria seca e Zn disponível, no solo PV. 
Para doses de $K$ dentro de NPCaMg na dose dois, os efeitos positivos foram devido principalmente a concentração de N na planta, quando cultivada no solo le e ao teor de mate ria seca e ao Zn disponível, quando a planta foi cultivada no so10 PV . 
5. CONCLUSÕES

Nas condições em que o trabalho foi realizado pode-se concluir:

Experimento I :

- As doses de $N$, na omissão da aplicação de PKCaMg, não influenciaram o teor de $Z n$ disponível e exerceram um efeito linear decrescente na concentração de $Z$ n na planta, quando cultivada no solo LE. Quando o cultivo se deu no solo PV, as doses de $N$ aumentaram o teor de $Z n$ disponível e exerceram um efeito quadrático na concentração deste elemento na planta.

- Na presença da dose um de PKCaMg, as doses de $N$ aumentaram o teor de Zn disponível e exerceram um efeito quadrático na concentração de $Z$ n na planta, para o solo LE e; não influen* 
ciaram o teor de $\mathrm{Zn}$ disponível mas, exerceram um efeito 1inear decrescente na concentração de $Z n$ na planta no cultivo no solo PV.

- Quando as doses de $\mathrm{N}$ foram aplicadas dentro da dose dois de PKCaMg, elas exerceram um efeito quadrático no teor de Zn disponíve1 e na sua concentração na planta, quando cultivada no solo LE; e não influenciaram o teor de $Z n$ disponível mas exerceram um efeito quadrático na concentração do elemento na planta, quando cultivada no solo PV.

Experimento II :

- Na omissão da ap 1 icação de NKCaMg, as doses de P diminuiram o teor de Zn disponível no solo e exerceram um efeito quadráa tico na sua concentração na planta, quando utilizou-se o so 1o LE. Para o solo PV* as doses de $P$ não influenciaramo teor de $Z n$ disponível no solo e exerceram um efeito quadräti co na concentração do micronutriente na planta.

- As doses de P dentro de NKCaMg na dose um, não exerceram efeitos no teor de $\mathrm{Zn}$ disponĩvel e na concentração de $\mathrm{Zn}$ na planta, em ambos os solos estudados.

- Na presença da dose dois de NKCaMg, as doses de P exerceram um efeito quadrātico, tanto no teor de $\mathrm{Zn}$ disponîvel no solo 
quanto na sua concentração na planta, no cultivo do solo LE. No solo PV, as doses de $P$ não afetaram o teor de Zn disponivel e exerceram um efeito quadrático na concentração do elemento na planta.

Experimento III :

- Na ausência da aplicação de NPCaMg, as doses de K não exerce ram efeitos no teor de $Z$ n disponível no solo LE e exerceram um efeito quadrático na concentração de Zn na planta. No so1o PV, as doses de $K$ aumentaram o teor de $\mathrm{Zn}$ disponivel e diminuiram a concentração do elemento na planta.

- As doses de $K$ dentro da dose um de NPCaMg não influenciaram o teor de $Z n$ disponível e exerceram um efeito quadrático na concentração deste elemento na planta, quando cultivada tanto no solo LE, quanto no solo PV.

- Quanto äs doses de K dentro de NPCaMg na dose dois, elas não afetaram o teor de $Z n$ disponível no solo LE e exerceram um efeito quadrático na concentraçäo de Zn na planta. No solo $P V$, as doses de $K$ exerceram um efeito quadrätico tanto no teor de $\mathrm{Zn}$ disponível, quanto na sua concentração na planta. 
6. LITERATURA CITADA

ANUÄRIO ESTATÍISTCO DO BRASIL, 1984. Fundação Instituto Braşi1eiro de Geografia e Estatística - IBGE, Rio de Janeiro, V. 44 , p. $1-918$

BADANUR, V.P. e B.V. VENKATA RAO, 1980. Influence of phosphorus building on availability on micronutrients red soil of Banga1ore. Soil Sci., Baltimore, 130(5):251-257.

BAHIA, F.G.F.T.C. e J.M. BRAGA, 1974. Influência da adubação fosfatada e calagem sobre a absorção do zinco em dois solos de Minas Gerais. Revista Ceres. Viçosa, 21(115):167-192.

BASAK, A.; L.H. MANDAL e M. HALDAR, 1982. Interaction of phosphorus and molybdenium in relation to uptake and utilization of molybdenium, phosphorus, zinc, copper and manganese by rice. Plant and Soil, The Hague , 68(2):261-269. 
BINGHAN, F.T., 1963. Relation between phosphorus and micronutrients in plants. Soil sci. Soc. Amer. Proc.: Madison, $27: 389-391$.

BINGHAN, F.T. e M.J. GARBER, 1960. Solubility and availability of micronutrients in relation to phosphorus fertilization. Soi1 Sci. Soc. Amer. Proc. Madison, 24 (3):209-213.

BINGHAN, F.T.; J.P. MARTIN e J.A. CHASTAIN, 1958. Effects of phosphorus fertilization of California soils on minor element nutrition of citrus. Soil Sci., Baltimore: 86 : 24-31.

BOAWN, L.C.; B.A. KRANTZ e J.L. EDDINGS, 1970. Zinc-phosphorus fertilization in the zinc nutrition of several irrigated crops. Soil Sci. Soc. Am. Proc., Madison, 34:365-368.

BOAWN, L.C. e G.E. LEGGET, 1964. Phosphorus and zinc concentrations in russet burbank potato tissue in relation to development of zinc deficiency symtoms. Soil sci. Soc. Amer. Proc., Madison, 28: $229 \cdots 232$.

BOAWN, L.C.; F.G. VIETS e C.L. CRAWFORD, 1954. Effect of phosphate fertilizers on zinc nutrition of field beans. Soil Sci., Ba1timore 78:1-7. 
BOAWN, L.C.; F.G. VIETS JR.; C.L. CRAWFORD e J.L. NELSON, 1960 . Effect of nitrogen carrier, nitrogen rate, zinc rate, and soil pH on zinc uptake by sorghum, potatoes: and sugar betts. Soil sci., Ba1timore, 90:329-337.

BROWN, A.L.; B.A. KRANTZ e J.L. EDDINGS, 1970. Zinc-Phosphorus interactions as measured by plant response and soil analysis. Soilsci., Baltimore, $110(6): 415-420$.

BROWN, J.C. e L.O. TIFFIN, 1962. Zinc deficiency and iron chlorosis dependent on the plant species and nutrient element balance in Tulare clay. Agron., J., Madison, 54: $356-358$.

BURLESON, C.A.; A.D. DACUS e C.J. GERARD, 1961. The effect of phosphorus fertilization, on the zinc nutrition. of several irrigated crops. Soil Sci. Soc. Amer. Proc., Madison, $25:$ $365-368$.

BURLESON, C.A. e H.R. PAGE, 1967. Phosphorus and zinc interactions in flax. Soil Sci. Soc. Amer. Proc., Madison, $\underline{31}: 510-513$.

CATANI, R.A. e A.0. JACINTho, 1974. Avaliação da fertilidade do solo. Métodos de anälise. Piracicaba, Livroceres Ltda. 57 p.

CHAUDHRY, F.M.; M.A. KAUSAR; A. BASHIR e R.A.H. MATULLAH; 1977 . Mechanism of $N$ effect on Zn nutrition of flooded rice. Plant and Soil, The Hague, $46: 649-654$. 
CHAUDHRY, F.M. e J.F. LONERAGAN, 1970. Effects of nitrogen, copper and zinc fertilizers on the copper and zinc nutrition of wheat plants. Aust. J. Agric. Res., Melbourne, 21 (6): $865-879$.

CHAUDHRY, F.M. e J.F. LONERAGAN, 1972. Zinc absorption by wheat seediings: I. Inhibition by macronutrient ions in short.term experiments and its relevance to long term zinc nutrition. Soil Sci. Soc. Amer. Proc., Michigan, 36(2):323327.

CHAUDHRY, F.M. e M. SHARIF, 1974. Micronutrient problems of crops in Pakistan, with special reference to zinc and copper deficiency in sice production. Isotope aided micronutrient studies in rice production with special reference to zinc deficiency. FAO / IAEA, Viena, p. $1 \cdots 24$.

CHRISTENSEN, N.W. e T.L. JACKSON, 1982. Potential for phosphorus toxicity in zinc - stressed corn and potato. Soi1 Sci. Soc. Amer.: J., Madison, $45(5): 904 \cdots 909$.

ELLIS Jr., R.; J.F. DAVIS e D.L. THURLOW, 1964. Zinc availability in calcareous Michigan soils as influenced by phosphorus leve 1 and temperature. Soil Sci. Soc. Amer. Proc., Madison, $\underline{28}: 83-86$. 
ELSOKKARY, I.H.; H.A. EL“ATTAR e M.A. AMER, 1981. Influence of phosphorus and zinc fertilizers on the uptake of $P$ and $Z n$ by corn plants grown in highly calcareous soils. Plant and Soil, The Hagues, $\underline{59: 227-236 .}$

FAGERIA, H.K. e F.J.P. ZIMERMANN, 1979. Interação entre fósforo, zinco e calcärio em arroz de sequeiro. Rev. Bras. Ci. do Solo, Campinas; $\underline{3}(2): 88 \cdots 92$.

GALLO, J.R.; K. IGUE; O.C. BATAGLIA; A.M. FURLANI e L.E.C. MI RANDA, 1975. Influência do uso continuo de fertilizantes na nutrição mineral do milho híbrido IAC Hmd/6999 B. Anais do XV Congresso Brasileiro de Ciência do Solo, Campinas, SP. p. 245-254.

GANIRON : R.B.; D.C. ADRIANO: G.M. PAULSEN e L.S . MORPHY : 1969 . Effect of phosphorus "-zinc interaction in corn. Soil sci. Soc. Amer. Proc. Madison, 33(2):306-309.

GIORDANO, P.M.; J.J. MORTVEDT e R.J. PAPENDICK, 1966. Responses of corn (Zea mays L.) to zinc, as affected by placement and nitrogen source. Soil Sci. Amer. Proc., Madison, 30:767-778.

HULAGUR; B.F.: R.T. DANGARWALA e B.V. MENTA, 1975. Interrelationship among available zinc, copper and phosphorus in soil. J. Indian Soc. Soil Sci., 23 (2):231-235. 
JACKSON: T.L.: J. HAY e D.P. MOORE, 1967. The effect of zinc on yield and chemical composition of sweet corn in the willamette valley. Amer. Soc. Hort. Sci. Proc., Madison, 91: 462-471.

KALYANASUNDARAN, N.K. e B.V. MEHTA, 1970. Availability of zinc, phosphorus and calcium in soils treated with varying levels of zinc and phosphate - A soil incubation study. Plant and Soil, The Hague, 33(3):699-706.

KEEFER, R.F. e R.N. SINGH, 1968. The mecanism of P and Zn interaction in soils as revealed by corn growth and composition. Int. Congr. Soil Sci., Adelaide, Trans. 9th, II:367-374.

KHAN, D.H., 1969. Response of sweet corn and rice to phosphorus, zinc and calcium carbonate on acid Glenniew soil of California. Soil Sci., Baltimore, 108:424-428.

LAKER, M.C., 1967. Uptake of zinc and phosphorus by plants from a sandy soil. J. Afr. J. Agr. Sci., 10:323-330.

LANGIN, E.J.; R.C. WARD; R.A. OLSON e H.F. RHOADES, 1962 . Factors responsible for poor response of corn and grain sorghum to phosphorus fertilization: II. Lime and P placement effects on P-Zn relations. Soil Sci. Soc. Amer. Proc., Madison, 26:574-578. 
LINDSAY, W.L., 1972. Inorganic phase equilibria of micronutrients in soils. MORTVEDT: J.J.; P.M. GIORDANO e W.L. LINDSAY, ed. Micronutrientes in Agriculture. Soil Sci. Soc. Amer. Inc., Madison, USA, p. $41-57$.

LINDSAY, W.L. e W.A. NORVELL, 1969. Development of a DTPA micronutrient soil test. Agron. Abstr., Madison, p. 84 .

LO, S.Y. e H.M. REISENAUER, 1968. Zinc nutrition of alfafa. Agr. J., Madison, $60: 464-466$.

LONERAGAN, J.F.; D.L. GRUNES; R.M. WELCH； E.A. ADUAYI; A TENGAH; V.A. LAZAR e E.E. CARY, 1979. Phosphorus accumulation and toxicity in leaves in relation to zinc supply. Soil. Sci. Soc. Amer. J., Madison, 43:966-972.

LOPEZ GOROSTIAGA, O.E; e E. MALAVOLTA, 1974. Estudos sobre as relações entre zinco e fösforo na nutrição de plantas. Anais da E.S.A. Luiz de Queiroz, Piracicaba, 31:467-483.

MALAVolta, E., 1980. Elementos de Nutrição Mineral de Plantas. Ed. Agronômica Ceres Ltda., SP. 251 p.

MANDAL, L.N. e M. HALDAR, 1980. Influence of phosphorus and zinc application on the availability of zinc, copper, iron, manganese and phosphorus in waterlogged rice soils. Soil Sci., Baltimore, 130(5): 251-257. 
MARINHO, M.L. e L. IGUE, 1972. Factors affecting zinc absorption by corn from volcanic and soils. Agron. J., Madison, 64:3-8.

MILLIKAN, C.K., 1963. Effects of different levels of zinc and phosphorus on the growth of subterraneum clover (TrifoZium subterraneum L.). Aust. J. Agric. Res., Membourne, 14: $180-205$

MOTSARA, M.R., 1974. Micronutrient research in India - The identification and understanding of the problem with particular reference to zinc deficiency. Isotope - aided micronutrient studies in rice production with special reference to zinc deficiency - FAO/IASA, Vienna, p. 51-74.

MURAOKA, T., 1981. Solubilidade do zinco e do manganês em diversos extratores e disponibilidade desses dois micronutrien tes para o feijoeiro (Phaseolus vulgaris L.) cv. Carioca. Tese apresentada à Escola Superior de Agricultura "Luiz de Queiroz", da Universidade de São Paulo, para obtenção do título de Doutor em Agronomia. Area de Concentração: Solos e Nutrição de Plantas. Piracicaba, 141 p.

OLSEN, S.R., 1972. Micronutrient interactions. In: MORTVEDT, J.J.; P.M. GIORDANO: e W.L. LINDSAY (eds.). Micronutrients in Agriculture. Soil Sci. Soc. Amer. Inc., Madison, 1a. edição, $243-264 \mathrm{P}$ 
OLSON, R.A.; D.D. STUKENHOLTZ e C.A. HOOVER, 1965. Phosphoruszinc relations in corn and sorghum production. Bether crops. P1 ant Food, $44(1): 19-24$.

ORABI, A.A.; A. ABDALLAH; H. MASHADI e H. BARAKAT, 1981. Zincphosphorus relationship in the nutrition of corn plants (Zea mays L.) grown on some calcareous soils. Plant and Soil, The Hague, $59(1): 51-59$.

ORABI, A.A.; A.S. ISMAIL e H. MASHADI, 1982. Zin - phosphorus relationship in the nutrition of tomato plants as affected both by the soil and by the rate of applied zinc. plant and Soil, The Hague, 69(1):67-72.

OZANNE, P.G., 1955. The effect of nitrogen on zinc deficiency in subterraneum clover. Aust. J. biol. Sci., Melbourne, 8 : $47-55$

PARKER, D.T., 1962. Influence of mulching on the manganese of corn plant tissue. Agron. J., Madison, 54:303-305.

PATIL, D.S. e R.B. SOMAWANSHI, 1982. Beneficial effects of combination of $\mathrm{P}$ and $\mathrm{Zn}$ for green gran (Phaseolus aureus L.). Plant and Soil, The Hague, 165(1):125-128. 
PAULI, A.W.; R. ELLIS Jr. e H.C. MOSER, 1968. Zinc uptake and translocation as influenced by phosphorus and calcium carbonate. Agron. J., Madison, 60:394-396.

PAULSEN, G.M. e D.A. ROTINI, 1968. Phosphorus-zinc interaction in two soybean varieties differing in sensibility to phosphorus nutrition. Soil Sci. Soc. Amer. Proc., Madison, $32: 73-76$.

PIMENTEL GOMES F., 1982. Curso de Estatistica Experimental, 10a. edição. Livraria Probel, São Paulo.

PRASAD, K.G.; H. SINHA e N.C. DAS, 1968. Phosphorus-zinc relation as affected by soil application of phosphorus and zinc at various moisture levels. J. Proc. Inst. Chem., India, 40 : $118-122$.

PUMPHREY, F.V.; F.E. KUHLER; R.R. ALLMARAS e S . ROBERTS , 1963. Method and rate of applying zinc sulphate for corn on zinc deficient soil in western Nebraska. Agron. J., Madison, 55: $235-238$.

RAMOS; M. 1973. Efeitos do nitrogēnio e fósforo sobre caracteristicas agronómicas da variedade de trigo IAS 54 e suas relações com a produção. Pesquisa agronómica brasileira, série. agronómica, Brasilia, 8:213-216.

REDDY, G.D.; V. VENKATASUBRIAH e J VENKATESHWORALU, 1973 . Zinc-phosphorus interactions in maize. J. Indian Soc. Soil Sci., New De1hi, $11: 433$. 
REHM, G.W.; R.A. WIESE e G.W. HERGERT, 1980. Response of corn to zinc source and rate of $z$ inc band applied with either orthophosphate or polyphosphate. Soil Sci., Baltimore, 129 (1) $: 36-44$.

REUTHER, R. e P.F. SMITH, 1950. A preliminary report on the relation of nitrogen, phosphorus and magnesium fertilization to yield, leaf composition and the incidence of zinc deficiency in oranges. Proc. Am. Soc. Hort. Sci. Baltimore, $\underline{56: 27-33}$

RUDGERS, L.A.; J.L. DEMETRIO e R. ELLIS, 1970. Interaction among atrazine, temperature and phosphorus-induced zinc deficiency in corn (Zea mays L.). Soil Sci. Soc. Amer. Proc., Madison, 34: $240-244$

SAFAYA, N.M. e B. SINGH, 1977. Differential susceptibility of two varieties of cowfea (Vigna unginiculata(L.) Walp) to phosphorus - induced zinc deficiency. Plant and soil, The Hague, $48: 279-290$.

SANTOS, H.L., 1971. Efeitos do zinco, boro, molibdënio e calagem na soja perene (Glycine max L.) em solos sob vegetação de cerrado, em condições de estufa. U.F.V., Viçosa, Curso de Fitotecnia. (Dissertação de Mestrado).

SARRUGE, J.R. e H.P. HAAG, 1974. Anälises químicas em plantas. Piracicaba, Livroceres Ltda. $57 \mathrm{p}$. 
SEATZ, L.F. e J.J. JURINAK, 1957. Zinc and soil fertility. Yearbook of Agriculture, Washington D.C., p. 115-121.

SEATZ, L.F.; A.T. STEGES e J.C. KRAMER, 1959. Crop response to zinc fertilization as influenced by line and phosphorus. applications. Agron. J., Madison, 51 (8):457-459.

SHARMA, K.C.; B.A. KRANTZ e A.L. BROWN, 1968a. Interaction of $\mathrm{P}$ and $\mathrm{Zn}$ on two dwarf wheats. Agron. J., Madison, 60(3): $329-330$.

SHARMA, K.C.; B.A. KRANTZ; A.L. BROWN e J. QUICK, 1968 b. Interactions of $\mathrm{Zn}$ and $\mathrm{P}$ with soil temperatures in rice. Agron. J., Madison, 60(6):652-655.

SHUKLA, V.C., 1971. Plant growth, Zn concentration and uptake in corn (Zea mays) under different zin rates, zincsources, lime and phosphorus conditions. Indian. J. Agric. Chem., New De 1 hi, $\underline{5}: 19-24$.

SHUKLA, V.C. e A.K. MUKHI, 1979. Sodium, potassium and zinc relationship in corn. Agron. J., Madison, 71(2):235-237.

SINGH, M. e R:E. FRANKLIN, 1974. Availability of native and applied zinc $\left({ }^{65} \mathrm{Zn}\right)$ as affected by nitrogen carriers in normal and saline soils. Plant and Soil, The Hague, 40:699-702. 
SINGH, M. e S.P. SINGH, 1980. Yield of submergil paddy and uptake of $\mathrm{Zn}, \mathrm{P}$ and $\mathrm{N}$ as affected by $\mathrm{liming}$. and $\mathrm{Zn}$ fertilizers. P1ant and Soi1, Hissar, 56(1):81-92.

SINGH, M. e S.P. SINGH, 1981. Effect of nitrogen and zinc on the yield of submerged rice and uptake of $N$ and $\mathrm{Zn}$ on unlimed and limed soils. P1ant and Soil: The Hague, 62(2): $183-192$

SOLTANPOUR, P.N., 1969. Effect of nitrogen, phosphorus and zinc placement on yield and composition, of potatoes. Agr.. J., Madison, $\underline{6}(2): 288-289$.

SPENCER, W.F., 1960. Effects of heavy applications of phosphate and 1 ime on nutrient uptake, growth, freeze injury and root distribution. of grapefruit trees. Soil Sci., Ba1timore. $89: 311-318$.

STANTON, D.A. e R.DU T. BURGER, 1970. Studies on zinc in selected orange free state soils - IV. Factors affecting the availability of zinc. Agrochemophysica. Pretoria, 2 : $33-40$.

STUKENHOLTZ, D.D.; R.J. OLSEN; G. GOGAN e R.A. OLSON, 1966 . On the mechanism of phosphorus-zinc interaction in corn nutrition. Soil Sci. Soc. Amer. Proc., Madison, 30:759-763. 
TANAKA, A: e Y. ISHIZUKA, 1969. Zinc deficiency as the case of 'Akagare' in the rice plant. J. Sci. Soil Manure, Japan, 40:415-419.

TERMAN, G.L. e S.E. ALLEN, 1974. Accretion and dilution of nutrients in young corn, as affected by yield response to nitrogen, phosphorus and potassim. Soil sci. Soc. Amer. Proc., Madison, $38: 455-460$.

THOMPSON, J.W., 1962. Effects of fertilizers and soil amendments on the mineral constituints of maize. Soil Sci., Baltimore, $\underline{94}(1): 323-330$.

THORNE, W., 1957. Zinc deficiency and its control. In: A.G. NORMAN (Ed:). Advances in agronomy. Academic Press Inc. New York, $9: 31-65$.

TIWARI, K.N.; V. NIGAM e A.N. PATHAK, 1982. Effect of potassium and zinc applications on dry-matter production and nutrient uptake by potato variety 'Kufri chandramukhi' (Solanum tuberosum L.) in an alluvial soil of Uttar Pradesh. Plant. and Soil, The Hague, $65(1): 141-147$.

VIETS, F.G. Jr.; L.C. BOAWN e C.L. CRAWFORD, 1957. The effect of nitrogen and type of nitrogen carrier on plant uptake of indigenous and applied zinc. Soil sci. Soc. Amer.Proc., Madison, 21:197-201. 
WALLACE, A.; A.A. ELGAZZAR; J.W. CHA e G.V. ALEXANDER，1974 • Phosphorus levels versus concentrations of zinc and other elements in bush bean plants. Soil Sci., Baltimore, 117(6): $347-351$.

WALLACE, A.; R.T. MUELLER e G.V. ALEXANDER, 1978. Influence of phosphorus on zinc, iron, manganese and copper uptake by plants. Soil Sci., Baltimore, 126(6):336-341.

WARD, R.C.; E.J. LANGIN; R.A. OLSON e D.D. STUKENHOLTZ, 1963 . Factors responsible for poor response of corn and grain soghum to phosphorus fertilization. III. Effects of soil compaction, moisture level and other properties on $\mathrm{P}-\mathrm{Zn}_{\mathrm{n}}$ relations. Soil Sci. Soc. Amer. Proc. Madison, 27:326-330.

WARNOCK, R.E., 1970. Micronutrient uptake and mobility within corn plants (Zea mays L.) in relation to phosphorus induced zinc deficiency. Soil sci. Soc. Amer. Proc., Madison, 34: $765-769$

WEAR, J.I. e R.M. PATTERSON, 1965. Potassium and phosphorus zinc relationships. Crops and Soils, Madison, 18:11.

WRIGHT, S., I921. Correlation and Causation. J. Agric. Res., Washington D.C., 20 (7):557-585. 
YADAV, O.P. e V.C. SHUKLA, 1982. Effect of applied phosphorus and zinc on their absorption and distribution in chickpea plant. Soil Sci., Baltimore, 134(4):239-243. 